\title{
Metric Transition Plans and Activities of Federal Government Agencies
}

\section{Gary P. Carver}

U.S. DEPARTMENT OF COMMERCE

Technology Administration

National Institute of Standards

and Technology

Metric Program

Gaithersburg, MD 20899

Raymond A. O'Brien, Jr.

Metrication Project Office

Internal Revenue Service

Washington, DC 20224

\section{Byron Nupp}

Office of Economics in the Office of the Secretary, and

Metric Coordinator

Department of Transportation

Washington, DC 20509 



\section{Metric Transition Plans and Activities of Federal Government Agencies}

\section{Gary P. Carver}

U.S. DEPARTMENT OF COMMERCE Technology Administration National Institute of Standards and Technology Metric Program Gaithersburg, MD 20899

Raymond A. O'Brien, Jr.

Metrication Project Office Internal Revenue Service Washington, DC 20224

\section{Byron Nupp}

Office of Economics in the Office of the Secretary, and Metric Coordinator

Department of Transportation Washington, DC 20509

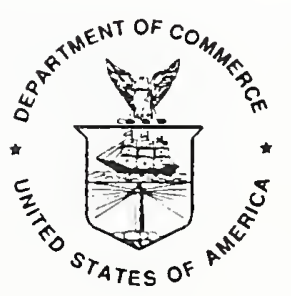

U.S. DEPARTMENT OF COMMERCE Barbara Hackman Franklin, Secretary

TECHNOLOGY ADMINISTRATION

Robert M. White, Under Secretary for Technology

NATIONAL INSTITUTE OF STANDARDS

AND TECHNOLOGY

John W. Lyons, Director 


\title{
METRIC TRANSITION PLANS AND ACTIVITIES OF FEDERAL GOVERNMENT AGENCIES
}

\author{
Gary P. Carver \\ Metric Program \\ Technology Services \\ National Institute of Standards and Technology \\ Gaithersburg, MD 20899
}

Raymond A. O'Brien, Jr.

Manager, Metrication Project Office

Internal Revenue Service

Washington, DC 20224

Byron Nupp

Assistant Director, Office of Economics in the Office of the Secretary, and Metric Coordinator Department of Transportation Washington, DC 20509

\begin{abstract}
This report presents an overview of the metric transition planning efforts of federal agencies. It contains summaries of the individual federal agencies' metric transition plans. It includes a set of criteria for evaluating the quality of an agency metric transition plan. Also included is a description of an overall, "aggregate," appraisal that results when the criteria are applied to the entire federal agency planning effort as though it were a single comprehensive plan. This report is intended for use by federal agencies, as well as by any organizations and individuals whose business-related activities are affected by federal agency programs.
\end{abstract}

\section{KEY WORDS}

Metric; metrication; metric policy; metric system; metric transition. 


\section{TABLE OF CONTENTS}

EXECUTIVE SUMMARY $\ldots \ldots \ldots \ldots \ldots \ldots \ldots \ldots \ldots \ldots \ldots \ldots$

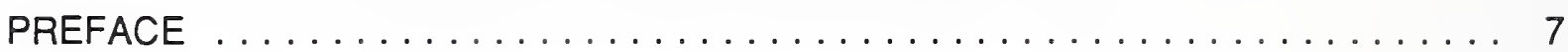

INTRODUCTION .............................. 9

The Federal Government's Metric Transition . . . . . . . . . . . . . . . . 9

Coordination of the Federal Government's Metric Transition $\ldots \ldots \ldots \ldots \ldots \ldots$

Interagency Cooperation . . . . . . . . . . . . . . . . . . . 10

1992: A Special Year . . . . . . . . . . . . . . . . . . . . . 11

PREVIOUS EVALUATIONS $\ldots \ldots \ldots \ldots \ldots \ldots \ldots \ldots \ldots \ldots \ldots \ldots$



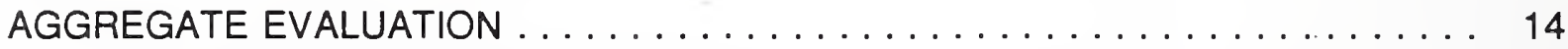

Some Preliminary Qualifications . . . . . . . . . . . . . . . . . . 14

Estimates of Quality and Completeness . . . . . . . . . . . . . . . 15

Other Considerations ............................ 18

IN CONCLUSION ................................ 18

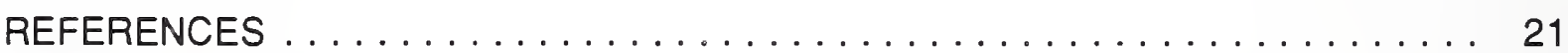

APPENDIX 1. SUMMARIES OF AGENCY PLANS AND ACTIVITIES . . . . . . . 22

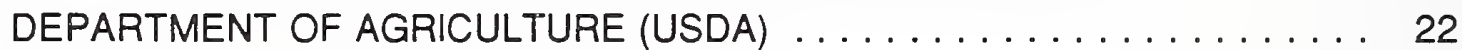

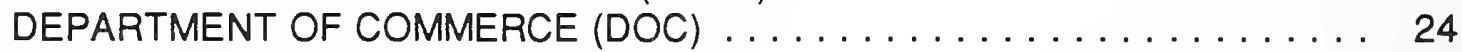

DEPARTMENT OF DEFENSE (DOD) $\ldots \ldots \ldots \ldots \ldots \ldots \ldots \ldots \ldots$

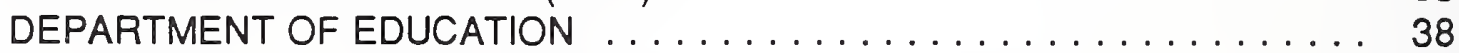

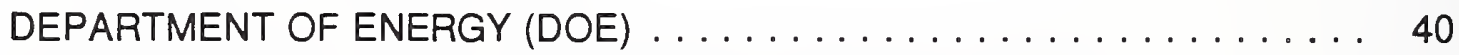

DEPARTMENT OF HEALTH AND HUMAN SERVICES (DHHS) . . . . . . . 44

DEPARTMENT OF HOUSING AND URBAN DEVELOPMENT (HUD) . . . . . 47

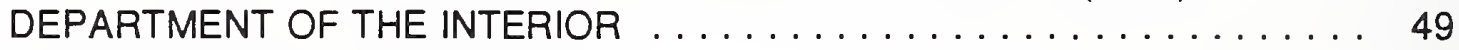

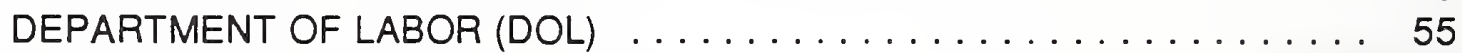

DEPARTMENT OF STATE .................... 56

DEPARTMENT OF TRANSPORTATION (DOT) . . . . . . . . . . . 59

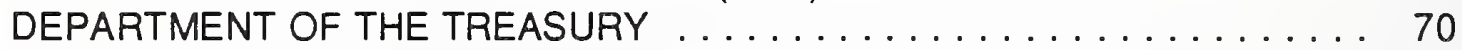

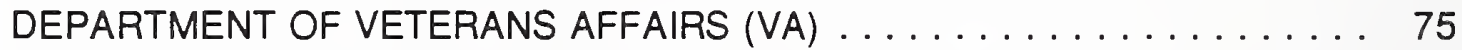

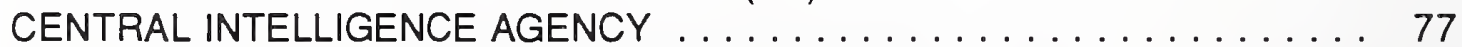

FEDERAL COMMUNICATIONS COMMISSION (FCC) . . . . . . . . . 80

FEDERAL EMERGENCY MANAGEMENT AGENCY (FEMA) . . . . . . . . 80

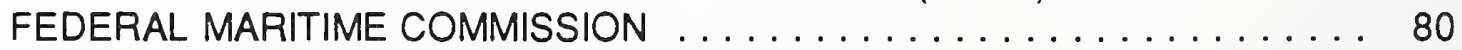

FEDERAL TRADE COMMISSION (FTC) $\ldots \ldots \ldots \ldots \ldots \ldots \ldots \ldots \ldots \ldots$

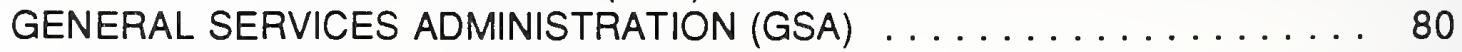

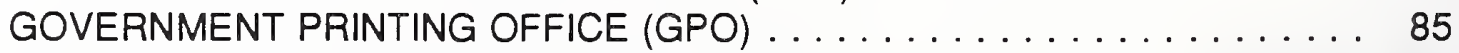

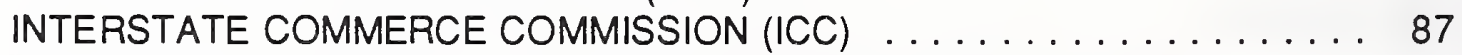

NATIONAL AERONAUTICS AND SPACE ADMINISTRATION (NASA) . . . . 87

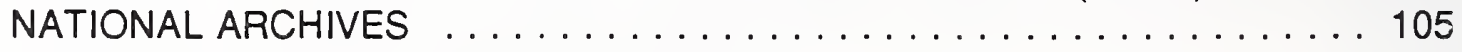

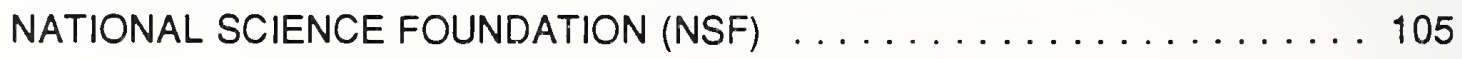


NUCLEAR REGULATORY COMMISSION (NRC)

OFFICE OF PERSONNEL MANAGEMENT (OPM)

OFFICE OF THE U.S. TRADE REPRESENTATIVE

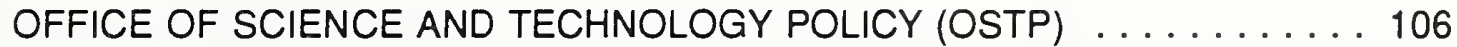

SMALL BUSINESS ADMINISTRATION (SBA) ............... 106

SMITHSONIAN INSTITUTION ....................... 108

TENNESSEE VALLEY AUTHORITY (TVA) ................ 109

U.S. CONSUMER PRODUCT SAFETY COMMISSION ............ 109

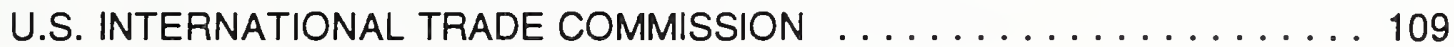

U.S. POSTAL SERVICE . . . . . . . . . . . . . . . . . . . . 110 


\section{EXECUTIVE SUMMARY}

The modern metric system 'is now the international standard of measurement. To be competitive in international markets, products must be designed, manufactured, and specified in metric units of measurement.

Certain industries in the United States have not yet converted the quantitative specifications of their products and services to metric units. Except in a few cases where non-metric units are accepted worldwide, this delay imposes a trade barrier to U.S. products, and thus an impediment to increased competitiveness.

\section{The Challenge}

The Federal Government is required to begin using the metric system in its businessrelated activities, except when it is not economically feasible or it is likely to cause U.S. firms significant inefficiencies or loss of world markets. The purpose of this requirement is to help lead the Nation into a more competitive position in global markets. The amended Metric Conversion Act and Executive Order 12770 require the Federal Government to provide leadership by setting an example and by using its leverage and buying power as the largest customer in the United States to catalyze a transition to the metric system by U.S. industry.

The Secretary of Commerce is required to coordinate the Federal Government's transition to the use of metric units. Working through the Interagency Council on Metric Policy, the interagency Metrication Operating Committee, and a number of functional subcommittees, the Secretary must provide the leadership, policy guidance, and evaluation of overall progress necessary to energize the metric transition by Federal Agencies. This report is in support of the Secretary's responsibilities for leadership and coordination of the federal transition to metric usage. On October 1, 1992, as part of her annual assessment of federal metric transition progress for the President, the Secretary will include recommendations for additional measures, including proposed legislation, that will help to achieve the full economic benefits of metric usage.

\section{The Current Evaluation Methodology}

Previous evaluations of the metric transition efforts of federal agencies by the General Accounting Office and the Congressional Research Service found limited evidence of progress in planning for use of the metric system and a low level of compliance with the requirements. However, now more than ever before, the evidence is increasingly pointing to significant progress by federal agencies in fulfilling the requirements. This assessment is based upon the current Metric Transition Plans of the federal agencies and upon up-todate information about the implementation of the plans.

Planning information from the federal agencies was evaluated using a set of criteria organized into three categories: organizational factors, such as authorities and reporting

The modern metric system is known as the International System of Units, which is abbreviated SI and which is interpreted or modified for use in the United States by the Secretary of Commerce (55 FR 52242, December 20, 1990, "Metric System of Measurement; Interpretation of the International System of Units for the United States"). 
responsibilities; content factors, such as programmatic tasks, transition mechanisms, timetables, interactions, and supporting activities; and maturity factors.

\section{The Current Evaluation Results}

The current evaluation reveals new and encouraging information about the Federal Government's metric transition. The transition effort is both more complicated and more advanced than may have been apparent. All executive departments have draft, partial, or final Metric Transition Plans. Most major independent agencies have completed their plans.

Overall the plans demonstrate good planning methods, comprehensive scope, acceptance at high levels, participation by all levels, private-sector involvement, and a recognition of the need to incorporate metric usage into regular operations. The plans reflect significant progress in adoption of the metric system of units by federal agencies.

Nevertheless, some plans elicit a number of concerns. Most importantly, a few agencies do not yet have comprehensive Metric Transition Plans. Their plans are only general outlines or they are limited to a few operating units, which do not constitute agency-wide plans. Three deficiencies are common to many of the plans: a lack of a consistent basis for review and revision, a tendency to mix program and support elements in task designations, and a lack of proactive and cooperative involvement with industry and the public.

\section{The Recommendations}

It will be beneficial for agencies to review and update their plans as needed and to perform another iteration of their plans in 1993. In addition, as part of this process and since agencies have already scrutinized the measurement sensitivity of their operations and developed initial plans, an interagency review of plans and a greater coordination among agencies can extend the benefits of a shared experience. For example, extraction of a common set of business-related support elements such as procurements, regulations, and grants; interagency review of plans and progress; and coordinated policies for selected actions such as outreach programs, legislative programs, state government coordination, and timing of implementation could help smooth the transition process.

A number of interagency need-driven cooperative activities are ongoing. These include measuring the degree of metrication in U.S. industry, coordinating federal metric construction practices, developing a policy in cooperation with industry on metric size standards for government correspondence and publications, and evaluating metric training materials for use by federal employees. Other need-driven interagency efforts should be encouraged.

\section{The Conclusions}

The Federal Government's metric transition program is proceeding in a practical, orderly, and evolutionary way toward the use of metric units in all business-related activities.

There is no deadline when some instantaneous and dramatic change to metric usage will occur. Federal agencies are developing and implementing transition plans and cooperating on mutual concerns, and they are working with industry and user groups to establish a realistic schedule for change. 
It is evident that the large majority of federal agencies are committed to the metric transition process and have made significant progress. Yet, the range of agency-toagency variations in the rate of progress is broad. Some of the variations in visible progress result from agency programmatic factors. For example, some agencies are much more involved than others in procurements, grants, regulations, and other business-related activities. Also, some agencies have greater impact on U.S. industry, including the regulation of industry, than others. Furthermore, there is a large variation in the size of agencies. Therefore, it is important in assessing the viability of the federal leadership role in the metric transition to inspect the plans of the major industry-influencing agencies and to avoid simple averages or generalizations about all agencies.

The progress that federal agencies are making to implement metric usage will require some time to reach the point where metric units are used routinely. For example, agencies that have implemented a policy to use metric units on all new projects will not make predominant use of the metric system until such new metric usage becomes a significantly large part of the agency's activity. Budgetary restraint which limits new project initiatives, safety considerations, transition costs, and external factors will all affect the pace of the change.

In addition to needing time for metric policies and plans to be implemented in the federal government, continuing visible top-management commitment to the metric transition and leadership is essential for success. This is also true in state and local governments and in the business community. Leadership is especially needed in critical areas that involve long lead times, such as education, including work-force training.

Clearly the completion of federal metric efforts will take time. In addition, to assure the most beneficial result, it will take the continuing support of Congress and the cooperation and active participation of industry and state and local governments.

Although there are competing national priorities, the U.S. moves further every day along the path to joining the global community in measurement standards. The efforts of federal agencies are moving us more rapidly along that path. 


\section{PREFACE}

Change--the resistance to it, the fear associated with it, and the challenge represented by it--is a popular sociological and psychological subject. There is no doubt that change is usually difficult. Clearly this has been true of the U.S. change to the use of the metric system of units.

However, there is another aspect to change that is often overlooked: Whatever the need for change, it is when the success of a change is demonstrated that the demand for the change increases.

In the case of changing to use of the metric system, success has been demonstrated in the United States by many individual companies and by certain industries. As a result, there is a demand in other industries for change. This is consistent with the rationale for the change, the need to remove a trade barrier to U.S. products.

Although the need is also present in the domestic consumer sector, the success related to using the metric system has not yet been visibly demonstrated in that sector.

Consequently, the public is not yet demanding the change.

The Federal Government's role is to provide leadership and encouragement to help U.S. industry make the transition. To succeed in that role, federal departments and agencies are making the transition themselves. Not surprisingly, they are finding that, in some areas, what may seem like a simple and direct change is, in fact, complex and not so straightforward.

For example, the government's primary focus, as required by the Metric Transition Act, is on procurements, grants, and business related activities. Procurements are especially complex because there are a number of requirements that affect the procurement process, including cost, country of origin, small and minority business considerations, and functional specifications. Meeting these requirements can sometimes conflict with achieving the goal of procuring products and services to metric specifications.

In addition, even with a good plan to implement the use of metric units for procurements, the implementation depends on the initiative of many individuals at all levels of the government, as well as the cooperation of their non-federal-agency customers. It may also require coordination, guidance, and possibly federal and business employee training.

Since the planning and implementation are the responsibility of the individual agencies, each agency must deal with these details in its unique environment.

In previous years, there seemed to be a reluctance among agencies to be first to convert to using metric units. At one meeting, someone said they would like to be a settler in the new metric territory, but not a pioneer. Apparently, settlers peacefully build homes and plant crops; while pioneers are viewed as transgressors, and may be treated accordingly. Pioneering is more difficult than participating in a communal environment. This would also hold true in industry, since it is easier for individual companies to participate in an industrywide transition than in a pioneering effort.

Whether the avoidance of being first is due to a fear of taking risks or to a desire to stick with the majority, there is a benefit from this phenomenon. We are seeing the benefit now. In many agencies the desire not to be first is changing into a desire not to be last. Now 
that the momentum is accelerating, the same forces that fostered an aversion to being first are resurfacing and are causing agencies to avoid being last.

Another phenomenon that will soon help to accelerate the metric transition in government and industry is the production in some industries of metric products that are identified by nominal inch-pound units. One example is computer industry hardware, including floppy disks. They are produced to metric specifications, even though the common dimensions cited in this country for the same products are inches. When industry perceives that the metric transition has become more acceptable to the public, these and other products will be more accurately identified by their correct units of measure. Consequently, it will appear that the metric transition is accelerating.

Many companies have policies in place to produce metric products on demand. In some cases these metric products are not truly metric because they may be only non-metric products cut to dimensions that approximate their metric-sized counterparts. However, in most cases companies are aware of international standards and are poised to design and manufacture products completely in round, or rational, metric units. As the demand for and willingness to accept metric products increases, partly due to the encouragement of the Federal Government, this phenomenon will also help accelerate the metric transition in this country.

The information in this report demonstrates that change is occurring--and that it is accelerating.

Gary P. Carver

Raymond A. O'Brien, Jr.

Byron Nupp 


\section{INTRODUCTION}

The leadership and coordination responsibilities of the Department of Commerce in the federal agency metric transition include assessing the progress made by other federal agencies in implementing the use of metric units in their programs. The purpose of such an assessment is to provide feedback and guidance to the agencies that will be beneficial and will help improve their rate of metric transition progress. The primary purpose of this report is to disseminate an overview of the status of the federal agency metric transition that was developed from the assessments.

The second purpose of this report is to provide information to federal departments and agencies that will help them to evaluate, compare, and coordinate their metric transition planning activities.

State and local government agencies, U.S. companies, and the public can benefit also from information on the federal government's metric transition effort. Organizations and individuals in each of these environments will, if they have not already, be making decisions relating to the use of metric units in their business-related activities. The rate at which the federal government implements the use of metric units in its procurements, grants, and other business-related activities directly affects activities in these other sectors of our Nation. Therefore, providing useful information to non-federal agency organizations and individuals is a third purpose of this report.

This report presents an overview of the metric transition planning efforts of federal agencies. It contains summaries of the federal agencies' metric transition plans. It includes an set of criteria for evaluating the quality of an agency metric transition plan. Also included is a description of an overall, "aggregate," appraisal that results when the criteria are applied to the entire federal agency planning effort as though it were a single comprehensive plan. This report is intended for use by federal agencies, as well as by any organizations and individuals whose business-related activities are affected by federal agency programs.

\section{The Federal Government's Metric Transition}

A Public Law [1] and an Executive Order [2] provide both the rationale and the mandate for a transition to the use of metric units. The rationale is the need to remove a trade barrier to U.S. products, as well as to improve our competitive edge, since the modern metric system is now the international standard of measurement. The metric system, for purposes of international trade, is more than just the International System of Units (SI). In international trade, "metric system" refers to the use of product standards and preferred sizes that are accepted by industries and governments throughout the world. Accordingly, it is essential that "world class products" be built to metric specifications to be competitive in the international marketplace.

The mandate in the Law and Executive Order calls for the Federal Government to use the metric system in its business-related activities, unless it is not economically feasible or is likely to cause significant inefficiencies or loss of world markets to U.S. firms. It is intended that the Federal Government help lead the Nation into a position where it can more competitively participate in global markets. The Federal Government can do this by setting an example and by using its leverage and buying power to catalyze a transition to the metric system by U.S. industry. The Federal Government is the largest customer of 
U.S. industry. By offering to buy metric products and services, government can help industry make the transition to the use of metric units of measurement. In addition, by requesting metric products, the government can demonstrate its commitment to the metric system of measurement for the Nation's businesses.

\section{Coordination of the Federal Government's Metric Transition}

The Executive Order designates the Secretary of Commerce as the coordinator of the government transition to the use of metric units. The Department of Commerce has long been concerned with the technical aspects of metric usage through NIST's role as the Nation's science and engineering laboratory for measurement technology and research on standards. Since its founding in 1901, NIST has played a major role in the evolution of a national measurement system policy by providing the measurements, calibrations, data, and quality assurance that are vital to U.S. commerce and industry. NIST also provides technical support to the National Conference on Weights and Measures, an organization of state, county, and city weights and measures enforcement officials and associated business and consumer representatives.

The Executive Order authorizes the creation of an interagency council and advisory committees, as well as the dissemination of policy guidance for agencies. Therefore, the Interagency Council on Metric Policy (ICMP) was chartered by the Secretary of Commerce. It is chaired by the Under Secretary for Technology and is composed of policy-level officials (assistant secretary or equivalent). They represent the federal departments and agencies in the development and coordination of metric usage policies and programs.

The Metric Program of the National Institute of Standards and Technology is the key element of the Department of Commerce metric transition leadership and coordination effort. The Metric Program helps implement national metric policy through a federal agency metric transition by developing and providing policy, guidance, support, and evaluation of progress to federal agencies. The Metric Program chief chairs the interagency Metrication Operating Committee and its Steering Group. Also, the Metric Program provides information and guidance on metric issues to federal agencies, state and local governments, trade associations, business firms, and the general public.

\section{Interagency Cooperation}

A growing number of agencies are cooperating to address common issues and to deal with shared problems. This is especially apparent among agencies whose activities focus on procurement, regulation, and small-business activities.

The Metrication Operating Committee (MOC) is composed of senior-level metric coordinators from the federal agencies. The subcommittees of the MOC address specific topics of interest to several different agencies. These areas include, for example, construction, education, procurement, grants, standards, and federal employee training. Many agencies participate in the activities of the subcommittees and benefit from the combined efforts.

The Construction Subcommittee is one of the most active and successful groups. It has attracted participants from private industry and has published a metric-usage guide for commercial construction. The subcommittee's work is funded by participating federal agencies, and its members have visited Canada to explore the Canadian experience. 
Recently, the National Institute of Building Sciences, which served as secretariat for the subcommittee, created a Construction Metrication Council to build on the work of the subcommittee and to enable even greater participation by private industry. MOC agencies have accepted the Construction Subcommittee's goal to design all new federal facilities in metric units by January 1, 1994.

Another example of the growing cooperation among federal agencies to meet the mandate to use the metric system is the leadership of the Government Printing Office (GPO) and the Internal Revenue Service (IRS) in exploring a change to metric-sized paper, printed forms, and documents. To examine and discuss the issues, GPO invited other agencies to meet with the staff of the Joint Committee on Printing. The approximately 60

representatives considered the advantages and disadvantages of adopting standard metric paper and binding sizes, compared to continuing use of the current sizes described in metric units. They appointed an ad hoc committee to develop surveys of industry and the federal agencies, as well as a timetable for reporting the results. The federal agency survey has been completed. The possible impacts on the paper and printing industries are being examined; they include transition costs and long-term benefits, document handling, storage, reproduction, information management, and other related activities. The consensus of the participants at the meeting was that potential problems should be identified and a progressive policy and practical timetable be developed with industry's cooperation for the Federal Government's transition to the use of metric-sized paper, forms, and documents. The effort is underway.

In both examples, an important outcome will be that U.S. manufacturers (of construction and building products and of paper products) will be in a better position to export their products.

\section{2: A Special Year}

This year, 1992, is a special year in the implementation of the mandate. The law requires that "each federal agency, by a date certain and to the extent economically feasible by the end of fiscal year 1992, use the metric system of measurement in its procurements, grants, and other business-related activities..." The Executive Order requires that agencies provide to the Secretary of Commerce, by June 30,1992, "an assessment of agency progress and problems, together with recommendations for steps to assure successful implementation of the Metric Conversion Act." The Executive Order also requires in 1992, as part of the annual report to the President by the Secretary of Commerce,

"recommendations which the Secretary may have for additional measures, including proposed legislation, that will help to achieve the full economic benefits of metric usage."

This year is also special because more significant progress is occurring than has occurred in any previous year. This will be viewed as a watershed year in the federal metrication process.

\section{PREVIOUS EVALUATIONS}

A 1990 report by the General Accounting Office, METRIC CONVERSION: Plans, Progress, and Problems in the Federal Government, was based upon a survey of federal agencies. [3] The General Accounting Office (GAO) found that planning for metric conversion among the federal agencies was limited. The report noted that schedules, specific target dates, and time frames by which to measure progress were absent. In 
addition, the report stated the finding that progress toward implementing plans and other activities to address specific transition issues was also limited. As a result of a limited planning and progress, as well as other evidence of a low level of effort, the report concluded that there was reason to question the federal agencies' commitment to the transition process.

The GAO report singled out the leadership of the Commerce Department as a major concern. At the time, the Under Secretary for Technology, to whom high-level coordination duties were delegated, had not been designated. The GAO recommended that the Secretary of Commerce take steps to respond to the needs by developing guidelines for federal agencies that include specific time frames and a realistic estimate of resources needed for a transition to use of the metric system of units. The Secretary was also advised to fill existing vacancies on the Metrication Operating Committee's functional subcommittees and to make an effort to encourage their effectiveness.

In November of 1991, the Congressional Research Service (CRS) published a report entitled Metric Conversion Activities of Federal Government Agencies in Compliance with P.L. 100-418, Section 5164, Metric Usage. [4] This report included synopses of the 1990 annual metric progress reports and metric transition plans of federal agencies. The findings in this report were that although agencies are demonstrating a greater commitment toward metric usage, many of them are not fully complying with the legislative mandate, and an "across-the-board" transition to the metric system by the end of fiscal year 1992 is not likely.

As did the GAO report, the CRS report referred to the Commerce Department's leadership role and concluded that the Department needed to enhance its effort to meet the requirements of the law.

\section{METHODOLOGY FOR THIS EVALUATION}

The individual department and agency metric transition plans are the central documents that were used for this evaluation. However, other documentation that involves planning activities and implementation of plans was also included. Furthermore, direct conversations were held with agency metric coordinators to ensure currency of the planning documents and information presented.

The package of planning information was evaluated using a set of criteria that included organizational factors and content factors. In addition, a sense of the "maturity" of the plan was developed.

The organizational factors included the existence and completeness in the plan of the following components:

1. Authority and accountability framework for the planning and implementation processes. The approval by the agency head, the assignment of a metric executive, the tasking of operating unit heads, and the scope of the authorizing instrument are described.

2. Operating unit responsibiiity and reporting. Designation of operating unit reporting responsibilities, scheduling of reports, channels of downward and 
upward communication, provision for problem-solving, and relationships to agency-wide reporting practices are adequately defined.

3. Involvement of personnel throughout the agency. The relation of metric assignments to agency-wide organization and flow of responsibility and communication, the ability of key individuals to reach appropriate staff, and the provision for general staff awareness are adequate.

4. Provision for evaluation and revision. The timing and procedures for updating the plan are described.

5. Arrangements for Incorporation of the planned implementations into regular program actlvlties. Metric conversion, when completed in an agency or operating unit of an agency should be a regular part of operations and the work of the staff. Provisions for identifying such a stage, the timing of it, and the authority to implement it are included.

Criteria numbers two and three involve delegation of authority and responsibility throughout the agency. Involvement of all staff, including top officials as well as support staff, is considered an essential ingredient of a successful plan.

The content factors were evaluated on the basis of the inclusion of the following components:

1. Identlfication of affected programs and actlvitles. Programs are identified in relation to the agency's scope of activities and their measurement sensitivity is indicated.

2. Identlflcation of excluded programs. In accordance with Public Law 100418 , programs are identified where metric usage may be impractical or where metric usage is likely to cause significant inefficiencies or loss of markets to U.S. firms.

3. Provislon for excluslon justification. Where an exclusion in accordance with Public Law $100-418$ is claimed, a suitable justification is provided, including the methods of arialysis that were used. The Executive Order requires exclusions to be approved by the agency head.

4. Timetable for program conversion. The timetable for currently planned transitions, the process for establishing future transition dates, and the steps for converting program activities to use of metric units are described. Blanket or overall timing patterns are avoided; timing provisions are related to the program content.

5. Federal-state-local government consultations and agreements. Interactions with other federal agencies and with state and local governments that involve the transition of program activities to metric usage are described. This includes interrelationships with legislative and regulatory activities. Suitable participation of state and local officials through meetings, conferences, and notices should be provided.

6. International standards affected by metrlc converslon. Any impact of national or international standards activities on program metric transition activities, or, conversely, any impact of program metric transition activities on standards activities, are described. The conference report on Public Law 100418 states the intent of Congress not to force metric conversion in areas where worldwide standards usage and practices adhere to non-metric standards.

7. Prlvate sector consultations. The impact of the metric transition of federal programs on private sector organizations and individuals is described. This 
includes those who supply products and services to the government, are subject to regulations, receive grants and assistance, and provide education and training. Where official notices, awareness campaigns or other efforts to minimize the impact are required, they are described in detail.

8. Federal empioyee training. The extent and type of training required are identified.

9. Private sector education. Federal programs that affect the industry and the public, such as regulations that have measurement sensitivity, may require provision of awareness campaigns or training. These needs and solutions are adequately described.

10. Safety impacts. Provision for safety impact studies and assurance of followon action are described.

11. Special pianning studies. Where long term approaches to complex issues are involved, research and consultation may be required. Such issues are anticipated and contingencies are provided for, should new problems arise.

12. Information resource management. The relationships among existing data systems and computer systems are identified and provision is allowed for the inclusion of any new metric demands on the systems.

13. Legislative programs. Legislative, regulatory, or legal barriers to metric implementation are identified. Where practicable, measures for the removal of such obstacles are described.

14. Budgetary impacts. Where metric conversions cannot be accommodated into existing program budgets, or are not incidental to normal operations, these are noted. Provision is made for increased budgetary needs.

15. Review and revision of the pian. The mechanisms and procedures for appropriate reevaluation and modification of the plan are described.

The maturity factors reflect the conditions for metric conversion in the agency. There were five levels of maturity that were used to judge the degree of maturity: (1) no awareness,

(2) beginning awareness, (3) organized preparation, (4) operational implementation, and

(5) program incorporation.

\section{AGGREGATE EVALUATION}

There are thirty-nine member agencies of the Interagency Council on Metric Policy. Of the fourteen cabinet-level departments, nine have Secretary-approved Metric Transition Plans, three others have plans in "draft" form, and one had a notice in the Federal Register that described its proposed plan and requested comments. Among the twenty-five member agencies that are not departments, nineteen have approved plans and one published a Federal Register notice that describes its metric transition intentions. Several other agencies are participating in a variety of ways in the federal metric transition and the ICMP; however, their plans and policies are not included in this evaluation.

\section{Some Preliminary Quaiifications}

In the rest of this section, the word "agency" refers to one of the thirty-nine ICMP members. No distinction is made between cabinet-level departments and independent agencies. 
Certain agencies have more impact on industry and the public than other agencies through their regulatory, procurement, or other business-related activities, or through their size or budgetary resources. However, no measure of agencies' impacts on industry, or of the economic status of affected industries, was attempted, and no mathematical or other weighting was assigned to any agency for evaluative purposes.

Although the plans are important indicators of intents and probable actions, what really counts is what is actually happening as a result of the actions of the agencies. In many cases, progress is occurring through the policies expressed in the plans instead of as a result of the implementation of specific planned activities. (Frequently this occurs in agencies where plans are designed to distribute responsibility and to empower staff at lower levels in the organization.) Some agencies whose plans appear to be merely general administrative regulations have progressed quite far, and are participating actively in interagency efforts. Other agencies are involved in leadership roles in the overall federal metric transition, but these roles are not reflected in their plans. Collectively, the plans are weak in leadership and coordination activities because they were developed individually by the agencies. A number of cooperative efforts among the agencies are currently ongoing; the individual plans do not contain planning information on these efforts.

It can be concluded, therefore, that the actual state of metric transition planning and implementation at some agencies is not apparent from their plans. (This is evident also in the "significant developments" that are described at the end of the summaries of the plans in the Appendix.) As a result, the actual state of metric transition efforts in the Federal Government is not evident from the agencies' plans.

\section{Estimates of Quallty and Completeness}

The criteria are grouped into "organizational" and "content" factors.

Organizational Factors. The overwhelming majority of the plans assign responsibility and coordination of the agency metric transition process to a high-level official and appropriately place responsibility on the constituent organizational elements to provide more detailed plans as well as reports. All plans designate a metric executive, as required by the Executive Order. Some of the plans centralize authority in one top-level official in the agency while others delegate authority to operating units. (In a few of the latter cases, one or more of the operating units have developed outstanding plans.) In the best plans, the top levels of the agencies not only offer authority and policy guidance, but also direct administrative support in critical areas such as procurement and grants management.

Although the designation of reporting responsibilities is often clear, the schedules of reports and channels of communications are not as clear. The lack of clear channels of communication affects the flow of information on metric issues and, as a result, leads to uncertainty about the procedures and consultations necessary to deal with decisions related to metric changes. While this may not matter in the case of a plan where, for example, the policy is that all new measurement-sensitive activities will use metric units whenever possible, undefined communication paths are an impediment to change where carrying out policy involves significant use of judgement.

The lack of well-defined channels of communication is also an impediment to change where decisions are impacted by other priorities, such as cost. When there are competing priorities, not knowing who has the authority or who must be consulted to make the final 
decision may result in avoidance of any new actions. It is interesting to note that the procedures and communications necessary to exempt an activity or program from required metric specifications are typically well defined, while the procedures for evaluating and updating the plan tend to be vague or absent.

In some agencies' plans, the responsibilities and interactions among officials responsible for carrying out the metric transition planning and reporting activities are not directly related to other functional operations at agencies. This inhibits the incorporation of planned changes into regular program activities. Furthermore, unless the plan contains specific efforts and timetables for completing them, the weak relationship among metric transition activities and other functional activities may inhibit the progress of the metric transition. The relative isolation of the metric-related responsibilities and authorities in many agencies is not conducive to incorporating the use of metric measures into ongoing functional operations.

Generally, agencies' plans can be rated "good" in their organizational factors, although a minority are incomplete in some of the required factors, especially the provisions for plan evaluation and revision and for incorporation of the plan into regular program activities. Plans that are most complete in meeting the organizational criteria provide top-level direction yet delegate responsibility of carrying out the policy to lower, more programmatic, levels.

Content Factors. The overall quality of the plans is good. They are well-written, follow good planning practices, and promise some significant achievements. However, the plan contents could be improved by better definition of the programs and activities that are to be addressed and by clearer statements of the desired accomplishments. There is a need for more specific and more detailed descriptions of new or changed functional activities as a result of metrication. The formulation of policy into substantive tasks with well-defined durations and sequences of steps is weak in some plans. Few of the plans contain, or require in the planning process, quantitative information.

The identification of affected programs and activities is good. They are mainly the business-related activities identified in the Executive Order. The most significant defect in many plans is simply the omission of important agency programmatic activities that are measurement-sensitive.

The identification of excluded programs and the provisions for justifying the exclusion of programs are good. Appropriately, excluded programs tend to be large, ongoing programs having existing non-metric hardware, programs where safety factors are paramount, and programs where it is believed that the U.S. industry is non-metric. Few of the plans require suitable analytic procedures for determining practicality, significant inefficiencies, or loss of U.S. markets.

Timetables for converting programs to the use of metric units are usually specific and appropriate to the program content.

Interactions with other federal agencies and with state and local government organizations are seldom mentioned in the plans. For many agencies, such interactions are not normal components of their programs and may not need to be discussed in their plans. However, some agencies' activities have a large impact on state and local government programs. Irı 
a number of cases, such agencies have also neglected to plan for interactions with the states and localities.

It is ironic that the modern metric system of units is an international standard; yet, most agency plans omit mention of international standards. Many agencies design parts, buy equipment, or utilize measurement-sensitive information that is dependent upon international standards. However, those agencies that have operating units that are involved directly in standards-related activities do take appropriate account of the interaction between their activities and the activities of international standards bodies.

The plans are reasonably responsive to the need to cooperate and coordinate transition efforts with customers affected by agency actions. Many agencies have published notices and have participated in activities with representatives from industry and other groups. This especially includes cooperative interactions with suppliers of products and services and, most often, recipients of grants and assistance. Most plans could be improved by the inclusion of conversion methodologies and the consultation with industry on specific metric transition goals. There is a need for more proactive interactions with entire industries, possibly through appropriate industry associations, to evaluate the mutual needs and to plan cooperative approaches for making appropriate changes on an acceptable time scale.

Federal employee training is adequate to good in the plans. Training is easy to do. However, it is not clear whether the training is tutorial, awareness-oriented, technical, or application-specific (such as procurement-specific) in nature. In addition, it is not evident that agencies have analyzed the type of training needed by employees who must make decisions or take specific actions to implement the intent of the plans.

With a few exceptions, private-sector education is not applicable to certain agencies and is not addressed by others. This factor tends to be completely missing from agency plans. Although there is no mandate to educate ordinary citizens about the metric system, there is a requirement in the Executive Order to "increase understanding of the metric system of measurement through educational information and guidance and in Government publications." Several, primarily technology-related agencies, have published documents useful in this regard.

Safety impacts are suitably addressed by the appropriate agencies.

Special planning studies are scarce in the plans. Although complex issues are anticipated, sometimes they are anticipated so well and in so much detail that the discussion may appear to be justifying programs as candidates for exception or implying that exceptions might be the rule at this time. Few contingencies are described where complex issues are concerned. Most often in areas recognized to have complexities, the plans present a gradual approach, such as the use of dual units for a period of time. Rarely are alternatives offered, or criteria and dependencies established to decide among them.

In the aggregate, the plans cover a very wide range in quality in their content factors. Fully half of the larger agencies range from adequate to good. Of the rest, most of them incompletely address the agency's functional areas and responsibilities. More importantly, several of the plans are outstanding examples of high-quality, thoughtful, and complete approaches to meeting complicated challenges. 
Maturity Factors. Not surprisingly, agencies that meet the content criteria completely and with high quality planning methods are further along toward "program incorporation." Other agencies range from beginning awareness to operational implementation. No agency plan could be considered to reflect "no awareness" of the metric transition task.

\section{Other Considerations}

Scrutiny of the federal agency Metric Transition Plans leads to the conclusion that the agencies can do better. Examination of the current actions of the agencies suggests that they will do better.

The strength of the connection between what is in a particular plan and what that agency accomplishes is not always apparent. The provision of authority and responsibility in a plan may or may not translate to active involvement and leadership by responsible officials. A timetable with specific tasks and dates may or may not lead to any efforts or accomplishments. Because some agency activities are easier to convert to metric specifications than others, some plans may not adequately anticipate the difficulty of implementing the planned accomplishments. In many cases, agencies are constrained by factors they cannot control, such as budgets or the actions of industry and the public. Plans are just that--plans.

As a result of such considerations and of the aggregate evaluation of the current plans, it seems that it would be desirable for each agency to revise its plan periodically. This process would include a comparison of planned actions with what the agency is actually accomplishing. It would also take into account what the agencies are accomplishing cooperatively and the progress of the metric transition occurring in industry. One goal would be to incorporate more specific tasks into the plans; such tasks could be based upon the experiences of the agencies in their current efforts.

It is likely that periodically and iteratively revising the plans will result in greater value to the agencies than they could gain from treating their plans as "one-shot" plans, even if those plans were ideal. In any event, since compliance with the law and the Executive Order has been essentially achieved, agencies are ready for the next steps. In the federal agency metric transition planning process, the next steps are reevaluation and revision of the plans.

\section{IN CONCLUSION}

The Federal government's metric transition program is proceeding in a practical, orderly, and evolutionary way toward the use of metric units in all business-related activities. There is no deadline when some instantaneous and dramatic change to metric usage will occur. Federal agencies are developing and implementing transition plans and cooperating on mutual concerns. They are working with industry and user groups to establish a realistic schedule for change. And they are implementing concrete and practical steps to achieve an orderly transition.

There are some new and encouraging signs that come from this current evaluation of the agency metric transition plans. Among the encouraging signs are: 
1. Federal agency metric transition plans demonstrate appropriate prioritization and reasonable planning approaches;

2. Comprehensive inclusion of agency programs in the plans is evolving;

3. There is acceptance of metric-transition responsibility by high-level agency officials;

4. Within agencies, operating units are participating to a significant degree in the metric transition process;

5. There is provision for appropriate public involvement in agency metric transition plans; the plans clearly show a commitment to cooperation with the general public, state and local government organizations, technical associations, and private sector firms and organizations;

6. The plans contain an implicit recognition of the ultimate incorporation of metric usage into regular agency operations; and, most importantly,

7. The plans reflect significant progress in adoption of the metric system of units by federal agencies.

There are also some concerns. The concerns include the following:

1. A few agencies have not developed comprehensive and detailed agency-wide Metric Transition Plans;

2. There is no consistent requirement for review and revision of plans;

3. There is a tendency to mix programmatic tasks and support tasks in the plans;

4. Some agencies' plans reveal a need for technical assistance; and

5. There is a need for more proactive involvement and cooperation with industry.

It is evident that federal agencies are committed to the metric transition process and have progressed significantly. Yet, the range of agency-to-agency variations in the rate of progress is broad. Agency transition planning activities extend from a demonstratively high degree of maturity and effective involvement of agency staff to a low-visibility, administrative-only implementation that may have little effect in its current form.

Some of the variations in visible progress result from agency programmatic factors. For example, some agencies are much more involved than others in procurements, grants, regulations, and other business-related activities. Also, some agencies have greater impact than others on U.S. industry, including the regulation of industry, than others. Furthermore, there is a large variation in the size and resources of agencies. Therefore, it is important in assessing the viability of the federal leadership role in the metric transition to inspect the plans of industry-influencing agencies that have the most impact and to avoid simple averages or generalizations about all agencies.

It will be beneficial for agencies to review and update their plans as needed and to perform another iteration of their plans in 1993. In addition, as part of this process and since agencies have already scrutinized the measurement sensitivity of their operations and developed initial plans, an interagency review of plans and a greater coordination among agencies can extend the benefits of a shared experience. For example, extraction of a common set of business-related support elements such as procurements, regulations, and grants; inter-agency review of plans and progress; and coordinated policies for selected actions such as outreach programs, legislative programs, state government coordination, and timing of implementations could help smooth the transition process. 
A number of interagency need-driven cooperative activities are ongoing. These include measuring the degree of metrication in U.S. industry, coordinating federal metric construction practices, developing a policy in cooperation with industry to make available to the government paper for publications and correspondence in metric sizes at costs equivalent to non-metric sizes, and evaluating commercially available metric training materials for federal employees. At the same time, other need-driven interagency efforts should be encouraged.

The progress that federal agencies are making to implement metric usage will require some time to reach the point where metric units are used routinely. For example, agencies that have implemented a policy to use metric units on all new projects will not make predominant use of the metric system until the new projects become a significantly large part of the agency's total activity. Budgetary restraint which limits new project initiatives, safety considerations, transition costs, and external factors will all affect the pace of the change.

For example, in construction, until a large fraction of old facilities are replaced with new facilities, or are renovated extensively, almost all government facilities, as well as major equipment, will still be described in non-metric units. The use of metric units to describe existing items, however, may be an option, but there will be situations (for example, for safety) where this is not desirable or acceptable.

In addition to needing time for metric policies and plans to be implemented in the federal government, a continuing, visible, top-management commitment to the metric transition and leadership is essential for success. This is also true in state and local governments and in the business community. Leadership is especially needed in critical areas that involve long lead times, such as education, including work-force training.

Clearly the completion of federal metric conversion will take time. In addition, to assure the most beneficial result, it will take the continuing support of Congress and the cooperation and active participation of industry and state and local governments.

Although there are competing national priorities, every day the U.S. moves further along the path to joining the global community in measurement standards. The efforts of federal agencies are moving us more rapidly along that path. 


\section{REFERENCES}

1. Metric Conversion Act of 1975 (Public Law 94-168, 89 Stat. 1007; 15 U.S.C. 205 et seq. as amended by section 5164 of the Omnibus Trade and Competitiveness Act of 1988, Public Law 100-418).

2. Executive Order 12770 of July 25, 1991, "Metric Usage in Federal Government Programs," (56 FR 35801, July 29, 1991).

3. "METRIC CONVERSION: Plans, Progress, and Problems in the Federal Government," General Accounting Office Report RCED-90-131 (March 1990).

4. "Metric Conversion Activities of Federal Government Agencies in Compliance with P.L. 100-418, Section 5164, Metric Usage," Congressional Research Service (November 1991). (Available from the U.S. Government Printing Office, Superintendent of Documents, Congressional Sales Office, Washington, DC 20402.)

5. McCracken, James B., and Carver, Gary P., Recommended Agency Procedures for Implementing Federal Metric Policy, NIST IR 4855 (May 1992). 


\section{APPENDIX 1. SUMMARIES OF AGENCY PLANS AND ACTIVITIES}

The summaries are organized into the following sections:

1. Directives. A description of agency metric program directives, such as administrative manual additions, administrative orders, notices, memorandums, and guidelines.

2. Responsibilities. Formal designations of the Metric Executive, assignments for operating offices, and duties of metric committees, task forces, or other focussed groups.

3. Reporting Requirements. The coordinating mechanism for the collection and dissemination of metric information to ensure timely and comprehensive oversight and reporting.

4. Exceptions to metric usage. The processes that have been defined and implemented to ensure a high-level review of exceptions, exemptions, or waivers to metric usage.

5. Transition efforts. The organization, tasks, events, and transition schedules.

6. Significant developments. A few examples of current activities to implement the plan.

The significant developments are the accomplishments, documented progress, and upcoming initiatives that could significantly affect the metric transition. Often, information on significant developments was obtained through direct contact with representatives of the agencies.

\section{DEPARTMENT OF AGRICULTURE (USDA)}

The Department of Agriculture has a wide variety of programs that involve farming, domestic and foreign trade, conservation, and research and extension services. The Department's research and education oriented programs are favorable areas for the adoption of the metric system. Potential problems and barriers include the great variety and numbers of activities and the diversity of interests affected by those activities. Two important agencies in the Department, the Soil Conservation Service and the Forest Service, are involved in engineering and mapping to a degree not found in other agricultural programs.

\section{Directive}

The Secretary of Agriculture signed Departmental Regulation 1020, "Department of Agriculture Metric Program" on May 26, 1992.

\section{Responsibilities}

a) Metric Executive. The Regulation stipulates that the Assistant Secretary for Administration (ASA) will be responsible for the overall policy, management and coordination of Agriculture's metrication program. In addition, a Metric Coordinator is to be designated who will serve as the Department's focal point and liaison with the other governmental and non-governmental metric organizations. 
b) Subordinate Offices. The Regulation describes a decentralized approach for Departmental metrication; the heads of the subordinate agencies are responsible for conversion plan development and implementation.

c) Metrication Steering Committee. This committee consists of representatives named by each Under Secretary and Assistant Secretary and is responsible for recommending USDA's metrication policy to the Metric Executive; assisting with the review of metrication program plans; and serving on applicable interagency and private sector organizations.

\section{Reporting}

Agriculture's metric program regulation requires the Departmental heads of agencies to prepare annual metrication progress reports as required by statute. Report consolidation is performed by the Deputy Assistant Secretary for Administration and prepared for the signature of the Secretary.

\section{Exceptions to Metric Usage}

The Regulation provides a procedure for processing requests for exceptions to metric usage. Requests for exception must be approved by the Deputy Secretary.

\section{Transition Efforts}

Agriculture's metric transition plan is currently being reviewed by Departmental policy officials. Nevertheless, many of Agriculture's offices and agencies have begun their transition.

\section{SIgnlficant Deveiopments}

a) The Agricuiture Marketing Service (AMS) switched from pounds to kilograms as the basis for charging for its inspection and grading of imported tobacco. Entries on the bills of lading for imported tobacco are stated in kilograms. Therefore, the change alleviates the burden of converting at the inspection and grading sites. All commodity procurement solicitations and specifications use the dual system with inch-pound measurements followed by SI units in parentheses. AMS continued to include metric conversion tables or similar dual system measurements in new or revised grade standards.

b) The Rural Eiectrification Administration (REA) is actively involved in a metric initiative to revise all technical documents and convert them into REA Bulletins or Informational Publications. The conversion schedule parallels the normal revision process and will use the current staff. The initiative's completion date is estimated to be September 1994.

c) During Fiscal Year 1992, the Economic Research Service (ERS) intends to publish a revision to Statistical Bulletin No. 616, Conversion Factors and Weights and Measures. Included will be new metric conversion tables designed to expedite conversion through education of the agricultural community. ERS will also publish SI/inch-pound conversion factors as educational materials in periodicals and other reports.

d) The World Agrlcultural Outlook Board (WAOB) continues to use SI units for its monthly World Agricultural Supply and Demand Estimates (WASDE) report. WASDE data 
for major bulk commodities appears in metric tons. Furthermore, world summary tables show selected country aggregates and specific country data in SI measurements. As a convenience to the Report's users and to promote public acceptance of metrication, the WASDE contains tables to enable users to convert to acres, bushels, bales, pounds, and hundred weight to metric units. In addition, the WAOB has indicated it is prepared to convert animal products to metric units in line with Departmental policy.

e) The Farmers Home Administration (FmHA) has named a Metrication Advisory Committee and a metrication coordinator in each of its state offices. The Committee will provide direction and guidance to headquarters' staffs and state coordinators for the implementation of metrication in FmHA.

f) The Agricultural Research Service (ARS) is using SI measurements in its reporting and publishing of research results, grant agreements, specifications, and acquisition of scientific equipment. ARS is also incorporating SI units into all of its new construction projects.

g) As a pilot construction project, the Office of Operations (OO) will use SI measurements in design and construction standards for replacing the deteriorated draining system in the USDA South Building.

h) The Office of Pubilc Affairs (OPA) designed metric posters and themes for the initial government-wide public-affairs effort. OPA's poster design was selected and printed by the Government Printing Office and is being distributed to other interested agencies.

i) The Food Safety and Inspection Service (FSIS) proposed regulations for mandatory nutrition labeling on most processed meats and poultry products. The proposal requires the use of SI to display nutrient information. Serving sizes would be in both inch-pound and SI units.

\section{DEPARTMENT OF COMMERCE (DOC)}

As designated lead agency in the Federal Government's transition to use of the metric system of units, the Commerce Department has multiple roles. Through the Interagency Council on Metric Policy, it directs and provides guidance to the federal agencies.

Through the National Council on State Metrication, and in cooperation with the National Conference on Weights and Measures, it coordinates the efforts of state and local governments. Through liaison with trade associations, metric-advocacy organizations, and standards organizations, it encourages and assists business enterprises in their voluntary metric transition activities. Through providing information and publications, it helps the public to understand and use the metric system. However, the Commerce Department's primary focus, as required by the Act, is on procurements, grants, and business-related activities of the federal agencies.

\section{Directive}

The Department of Commerce (DOC) issued its internal directive as Department Administrative Order 201-21, "Commerce Metric Program," on July 7, 1989. 


\section{Responsibilities}

a) Secretary of Commerce. The Secretary of Commerce is responsible for:

Directing and coordinating efforts by Federal departments and agencies to implement Federal Government metric usage;

Chartering an Interagency Council on Metric Policy;

If appropriate, forming metric advisory committees from the business community and state and local governments; and

Issuing guidelines, promulgating rules and regulations as policy guidelines for other agencies, and taking such actions as may be necessary to carry out the purposes of the Executive Order.

b) Metric Executive. The Under Secretary for Technology is designated as the DOC Metric Executive. The Under Secretary also chairs the Interagency Council on Metric Policy.

c) NIST Metric Program. The Metric Program of the National Institute of Standards and Technology develops and carries out the Commerce Department's metric program, especially the coordination and oversight responsibilities of the Department. In addition, the NIST Metric Program:

Provides oversight and coordination for the federal interagency metric transition;

Chairs the Metrication Operating Committee and its Steering Group;

Issues policy implementation guidance developed and coordinated through the MOC, and approved by the ICMP, for use by the federal agencies;

Provides support for progress reporting, problem analysis, and corrective actions by the agencies.

Provides leadership for, or participates in, metric-related activities throughout the Federal Government;

Supports and directs the MOC functional subcommittees;

Works with the Under Secretary in his role as Metric Executive;

Prepares Commerce Department plans and reports relating to metrication;

Disseminates information on the metric system and on the Federal Government's metric transition to government organizations, business firms, educational groups, private organizations, and the general public.

d) Departmental Offices and OperatIng Units. Commerce Department offices and operating units have the responsibility to:

Inventory all programs to systematically assess the impact of conversion to the metric system;

Develop metric transition plans; and

Designate a Metric Coordinator as a representative on the Commerce Metric Committee.

e) Commerce Metric Committee (CMC). The Commerce Metric Committee is responsible for coordinating and monitoring the DOC metrication programs and advising the Under Secretary as appropriate. 


\section{Reporting Requirements}

a) The Secretary of Commerce is required to provide annual reports to the President regarding progress made by federal departments and agencies in using the metric system of measurement in federal procurements, grants, and other business-related activities.

b) Departmental Offices and Operating Units are to submit to the Metric Program Office before November 1 of each year, an annual report for the previous fiscal year that includes

Significant milestones or events;

Significant problems encountered in metric conversion; and

Any recommendations regarding overall DOC metric conversion policy or activities.

\section{Exceptions to Metric Usage}

For identified DOC programs to be excluded from metric conversion, justifications must be provided that are based on quantitative information and contain suitable analytical procedures for determining practicality, significant inefficiencies, or loss of U.S. markets. Exceptions to metric usage must be approved by the DOC Metric Executive.

\section{Transition Efforts}

Since DOC has a unique and varied role with respect to the federal agencies' metric transition activities, its responsibilities and its planning activities are diverse. Among other government agencies, the NIST Metric Program provides coordination for the federal agencies transition efforts. This includes non-executive branch agencies such as the Government Printing Office and the U.S. Postal Service. In addition, the Metric Program provides coordination and support to the planning activities of the ICMP, the MOC, and the MOC functional subcommittees.

The Metric Program supports voluntary metric transition activities at state and local government levels by providing advice and informational materials on metrication issues affecting those areas. It also coordinates metrication planning activities with private sector industries, associations, trade groups, business enterprises, and other involved organizations

The various operating units in the Department develop plans and carry out transition activities within their areas of responsibility and specialization.

a) The NIST Metric Program Plan. DOC Government-wide activities are planned and carried out by the NIST Metric Program. The activities are designed to provide policy guidance, leadership, a focus on tangible results, and an evaluation of federal agencies' progress. The plan's milestones are a part of the DOC Management by Objective (MBO) Program. Accordingly, quarterly progress reports are generated to monitor accomplishments. 
The Metric Program developed the following strategies to implement its milestones:

Develop and distribute specific, useful, and practical guidance, criteria, measures, and deliverables for metric usage;

Work with procurement officials to identify procurements and grants where metric usage is attainable, to measure the amount of progress toward desirable metric procurement, and to increase metric usage in federal agency procurements;

Focus direct and indirect resources on developing and testing of specific models, guides, decision trees and other products to assist Government officials and others in metric usage implementation;

Leverage activities for maximum effectiveness by using the DOC operating units and Secretarial Offices, the ICMP and its committees and subcommittees, the National Council on State Metrication (NCSM), the American National Metric Council (ANMC), the U.S. Metric Association (USMA), and influential trade and professional groups to coordinate a cooperative approach that will accelerate progress;

Develop a direction and rationale for implementing metric usage in measurement-sensitive commercial activity to increase efficiency and help align U.S. manufacturing and trade with global market standards;

Identify effective leaders and those whose actions will make a real difference in the pace of change and gain their active involvement and support; and

Utilize the functional subcommittees of the Metrication Operating Committee to provide coordination and cooperation among federal agencies; where a subcommittee does not exist, form an independent group to address the issues, develop plans, organize the efforts, and assign realistic schedules.

Based upon the MBO system, the following milestones are included for 1992 :

Provide specific guidance to federal agencies (including DOC) on the preparation of metric transition plans;

Work with the Office of Program Planning and Evaluation to prepare and submit the DOC Metric Transition Plan;

Recharter the Interagency Council on Metric Policy to reflect the requirements of Executive Order 12770;

Submit the DOC Annual Metric Report to Congress with the FY '93 budget;

Summarize and Report on federal agency metric transition plans;

Provide guidance to agencies on their June 30, 1992, assessment reports to the Secretary;

Develop a metric information packet for the General Services Administration's Consumer Information Center;

Assess the Department of Commerce metric transition progress

b) Operating Unit Transition Pians. Similar to the Metric Program's Government-wide Metric Transition Plan, the Commerce Department offices and operating units use the MBO program to coordinate and monitor metric transition planning milestones and accomplishments. The following are ongoing or 1992 milestones for the operating units. In some cases, for example NIST and NOAA, operating units have already completed 
significant basic milestones in previous years. Therefore, some expected actions may not appear because they are completed and in place. In addition, since these are Fiscal Year 92 milestones, some of them have been completed.

\section{Bureau of the Census}

To increase the use of metric units of measure in census information collection and publication, study the feasibility of using metric measures by holding discussions with manufacturing trade associations to explore collecting and/or publishing selected information in metric measures;

Develop alternative approaches for integrating metric measures into the 1992 census statistics;

Discuss metric transition approaches with users of census data;

Determine census publication and data product formats related to metric measures;

Perform a metric conversion of tables showing data for domestic manufacturing compared to imports and exports; and

Establish a metric training program for selected employees in the areas of foreign trade, manufacturing, and agriculture.

\section{Economic Development Agency (EDA)}

Participate in Commerce Metric Committee meetings;

Survey EDA activities for metric barriers;

Coordinate EDA's Metrication Activities; and

Disseminate metric training and information, as needed.

\section{Bureau of Export Administration (BXA)}

Complete metric awareness training to meet employee metrication needs; Update the Export Administration Regulations with metric measurements; and Report BXA's progress to the Under Secretary for Technology

\section{International Trade Administratlon (ITA)}

Promote metrication in export products by visiting and examining ten existing exporters and ten potential exporters to determine those elements which have proven to be successful with regard to metrication;

In cooperation with the Metric Program Office, continue efforts to incorporate metric measures into ITA data and publications;

Survey ITA operations for potential metric usage;

With the NIST Metric Program, conduct seminars and discussions of additional methods for fostering ITA metric usage;

Select and examine several ITA programs to determine their effectiveness for implementing metric measures; and

Contact other agencies (e.g., Bureau of Mines, FEMA, GSA) to identify and assess parallel activities. 


\section{Minorlty BusIness Development AdmInIstration (MBDA)}

Include metrication guidelines in FY '93 requests for applications to the Minority Business Development Centers (MBDC) and Indian Business Development Centers (IBDC);

Coordinate $M B D C / I B D C$ program requirements initiative to include metric awareness as a Management and Technical Assistance (M\&TA) capability being offered to Minority Business Enterprises;

Involve regional directors in soliciting status performance reports from MBDCs/IBDCs on progress made in providing metric-related M\&TA services to MBEs; and

Disseminate metric material to Regions, MBDCs and IBDCs, and make public presentations on the metric system at regional and national meetings.

\section{National Instltute of Standards and Technology (NIST)}

Develop NIST guidelines and revise "Guide for the Use of the International System of Units";

Distribute publications about the metric system, the use of metric units, and metric conversion; and

Develop guidelines and instructions for the NIST technical units to ensure that procurement requests generated conform to metric standards and usage.

\section{Nationai Oceanlc and Atmospheric Adminlstration (NOAA)}

Draft a comprehensive metric transition plan, have it approved by line officers, and submit it to the Metric Program Office;

Draft and circulate metric guidelines for the procurement function highlighting several significant issues deserving priority attention;

Develop a two-level metric orientation program targeted for program activities, field activities, and headquarters managers and administrative personnel;

Submit an FY '92 Metric Progress Report to the Metric Program;

Issue a final NOAA Metric Transition Plan;

Convert 75\% of Next Generation Water Level Measurement System (NGWLMS) Tide Gauge and Processing Systems to metric standards; and

Convert six (6) new nautical charts to metric measurements.

\section{Natlonal Technical Information Service (NTIS)}

Promote and distribute (on a cost recovery basis) educational publications designed to increase the understanding and use of the metric system;

Participate in quarterly Commerce Metric Committee meetings; and

When acceptable to GPO, incorporate metric specifications in draft printing contracts. 
Report progress to Under Secretary for Technology;

Participate in Commerce Metrication Committee meetings;

Convert GMF to metric units;

Develop training program; and

Conduct metric training.

\section{Patent and Trademark Office (PTO)}

Submit an accomplishment report on metrication activities;

Determine the feasibility of a rule change requiring metric measurements in patent applications;

Survey members of the patent bar to determine the feasibility of requiring metric measurements in patent applications;

Revise the following publications to encourage metric usage: "Basic Facts About Trademarks," "Basic Facts about Patents," "Disclosure Document Program," and "General Information Concerning Patents;" and

Inform patent and trademark applicants of PTO policy of preferred metric usage by publishing its metric policy in PTO's Official Gazette.

\section{United States Travel and Tourism Administration (USTTA)}

Review USTTA international tourism promotion programs to determine the use of metric measurements;

Review USTTA brochures and publications to determine the need to convert to metric measurements; and

Include metric measurements in USTTA expanded facilitation program efforts by providing metric signs for foreign visitors.

\section{Significant Developments}

a) The Office of Program Planning and Evaluation, in conjunction with the Metric Program, directed a detailed inventory of all DOC metric transition plans and strategies. This monitoring effort is in addition to the DOC MBO program. It is intended to assess systematically the impact of metric transition and to be the foundation for a consolidated and comprehensive DOC transition plan.

The inventory was conducted at the budget sub-activity level for each operating unit. Inventory data elements included: conversion impact, strategy, special emphasis, barriers and impediments, completion dates, and estimated costs. Results of the inventory should provide a measure of the status of DOC metrication activities, and become the basis for future metric planning and implementation initiatives.

b) The NIST Metric Program, with the cooperation of the Internal Revenue Service and other operating units within the Commerce Department, is conducting a public-use survey to determine the degree of metrication in U.S. industry. The survey will also address the impact and relationship of U.S. industry metrication activities on the implementation of federal agencies' metric transition plans. The results of the survey will provide strategiclevel metrication information to support U.S. trade and competitiveness decision-making, as well as to provide industry with metric product information that can be used for planning and marketing purposes. 
Specialists from the Bureau of the Census, the Bureau of Economic Affairs, and the International Trade Administration are assisting with developing and performing the survey. Also, the Chairman of the President's Export Council has offered the Council's assistance with the survey effort and other related initiatives.

c) The NIST Metric Program delivered specific metric implementation guidance through the Interagency Council on Metric Policy (ICMP) and the Metrication Operating Committee (MOC). In addition, written guidance was provided via the NIST interagency report, "Recommended Agency Procedures for Implementing Federal Metric Policy." [5]

d) The NIST Metric Program, in conjunction with the MOC Steering Group, provided detailed guidelines to the agencies for preparing their assessments of metrication progress, problems, and recommendations. They were approved by the ICMP and adopted for the June 30, 1992 reports to the Secretary. The guidelines will be used as a basis for future Agency annual reports by providing a uniform and structured reporting framework and will help to assure measurable and substantive information.

e) Census completed its product clearance for the 1992 Census of Manufacturers and determined very little interest from respondents in converting quantity measures to metric standards. Since Census has had continual difficulty collecting most of its quantity measure, Census believes it unwise to convert to metric measurements. However, it does plan to collect a small number of products using metric measurements. In addition, the results of both the Recordkeeping Practices Survey and the product clearance process were interpreted to indicate that collecting quantity data in metric measurements was generally not feasible. Census will continue to explore with data users the possibility of publishing either conversion factors or metric equivalents for some of the data.

f) Census completed $55 \%$ of the conversion of Current Industrial Reports (CIR) Series' Domestic/Import/Export Data Tables to show metric data for domestic manufacturing compared to imports and exports. Census will be reviewing its $75 \mathrm{CIR}$ series to determine the feasibility and schedules for converting the remaining surveys now published in inchpound measurements.

g) Census has performed a metric conversion and verification of the U.S. tables for the "Joint Statistical Handbook for the U.S. and U.S.S.R." Setting the tables into final form for printing caused difficulty due to the differences in the sizes of each country's tables. The goal is to present the tables in tandem to enable easy comparison.

h) NIST performed a survey of its activities to identify barriers to metric transition. The barriers identified were lack of immediate availability of metric supplies from U.S. manufacturers; a need to continue supporting long-term NIST facilities and equipment that was designed in inch-pound units; and customers' insistence on measurement-related services using non-metric units.

i) NIST is revising its Administrative Manual Chapter 2.03 "Procurement" by including requirements for requisitioners to evaluate each request for metric product availability. In addition, the NIST procurement staff is including the requirement for identifying metric equivalent acceptability in its annual procurement planning data collection system.

j) NIST published a notice in the Commerce Business Daily seeking architectural and engineering services for phased construction of new advanced research and development 
(R\&D) facilities and renovation of its R\&D facilities in Gaithersburg, MD and Boulder, CO. The notice used all metric units and stated: "It is the intent of the Government to utilize the metric system of measurement (SI units) in the project design and construction to the fullest extent possible and economically feasible." The desired contract will have a maximum total value of $\$ 50$ million. One of the criteria for selection of the project team include experience in designing facilities using metric units of measurement.

k) NIST recently published the following eight items on metric topics:

Guide for the Use of the International System of Units, The Modernized Metric System, NIST SP 811.

The International System of Units (SI), NIST SP 330.

Interpretation of the SI for the United States and Metric Conversion policy for Federal Agencies, NIST SP 814.

"The Modernized Metric System Wall Chart," NIST SP 304A.

"Metric Conversion Card," NIST SP 365.

"Metric Ruler," NIST SP 376.

Recommended Agency Procedures for Implementing Federal Metric Policy, NISTIR 4855.

"A Metric America: A Decision Whose Time Has Come"--for Real, NISTIR 4858.

I) NIST is developing a bibliographic database of metrication references compiled from NIST, other government agencies, and private organizations. The structure of each entry will contain the title, source, availability, price, a brief abstract of the contents, and search indices. NIST anticipates making the database available in textual or data (word processing) formats.

m) NOAA's National Marine Fisheries Service (NMFS) scientific data collections, including biological observations and fishery-independent measures from research vessel cruises, use metric system measurements. However, inch-pound units continue to be used in fish landings (pounds), canned fish volumes, and processed fish portions (ounces). Conversion of data to metric units is routinely performed by NMFS analysts for reporting to international organizations such as the United Nation's Food and Agricultural Organization. Data distributed to the public or to the fishing industry is generally re-converted to the same format as the original data.

There is moderate to strong resistance by certain sectors of the fishing industry to use SI units. NMFS is sensitive to this problem since much of the data collection is performed on a voluntary basis. However, an exception to industry's use of inch-pound units in reporting data concerns international trade. Beginning in 1990, import/export transactions supplied to NMFS by the Bureau of Census were in metric units. Consequently, NMFS converted its trade data bases and publications including the "1990 Import and Export Annual Summary" to SI measurements.

(n) NOAA's National Ocean Service (NOS), Coast and Geodetic Survey (C\&GS) plans to convert its suite of nautical charts and related products to metric units. To inform the public of the revised charts, C\&GS published and distributed a color brochure entitled "NOAA Nautical Charts are Going METRIC!" 
(o) NIST sponsored the National Conference on Weights and Measures that with the National Council on State Metrication hosted a forum on the metric amendments to the Federal Fair Packaging and Labeling Act signed into law by the President on February 14, 1992.

\section{DEPARTMENT OF DEFENSE (DOD)}

Department of Defense (DOD) programs for national defense are mobilization planning, maintenance of forces and combat organizations, training and military education, weapons systems development, military planning, and alliance maintenance. These programs provide a favorable basis for metric conversion due to their international significance and the heavy dependence of the services on research and development and training and education. In addition to its responsibilities for national defense, the DOD is involved in non-defense industries through the civil works programs of the Corps of Engineers.

The DOD metric transition program focuses on two areas: (1) the development and operation of new weapons systems, including ancillary materiel, in metric units, and (2) the procurement, in metric units, of numerous items for the supply of a complex military establishment.

\section{Directive}

The Department of Defense (DOD) issued DOD Instruction 5000.2, Part 6, Section M, Use of the Metric System, on February 23, 1991. It requires metric standards to be used in all DOD activities, including all elements of defense systems requiring new designs.

\section{Responsibilities}

a) Metric Executive. The Assistant Secretary of Defense for Production and Logistics is designated the Metric Executive.

b) Milestone Decision Authorities. The Milestone Decision Authority (MDA) is the official responsible for approving any waiver requests not to use the metric system. The MDA is the individual designated in accordance with DOD criteria to approve entry of an acquisition program into the next phase. For major defense acquisition programs, the Under Secretary of Defense (Acquisition) or the DOD Component Head (or, when delegated, the Component Acquisition Executive) is the authority. For major systems, the authority can be delegated no lower than the DOD Component Acquisition Executive. For all other programs, the DOD Component Acquisition Executive may delegate MDA to the lowest level deemed appropriate.

c) Defense Metric Transition Management Group (DMTMG). The DMTMG is the group within the Office of the Assistant Secretary of Defense (Production and Logistics) which serves as the Action Office for managing and coordinating the overall DOD metric transition effort. The DOD Metric Coordinator is in this Office

d) Metrication Steering Group (MSG). The MSG, chaired by the DOD Metric Coordinator, has representatives from the DOD Components. The MSG addresses metrication issues and develops recommendations. 
e) Office of Primary Responsibllity (OPR). The OPR is the designated office responsible for each Task under the DOD Metric Transition Plan. Each OPR prepares and maintains a Task Plan detailing specific efforts, approaches to preparing any required longterm plans, initiation and completion of milestones, and team membership.

h) Office of Collateral Responsibility (OCR). The OCR is from a DOD component other than the one with the OPR having adequate authority and expertise for needed actions to support the OPRs.

\section{Reporting}

The DMTMG develops an annual report of metric activities during the past fiscal year for submission to the Under Secretary of Defense for Acquisition USD(A) by January 15 of each year. The report is based on reports submitted by each of the member DOD components. The component reports describe major accomplishments, recommendations, metric standardization documents prepared, and significant metric systems or equipment initially developed or acquired.

\section{Exceptlons to Metrlc Usage}

The metric system will be used in all DOD activities, including all those elements of defense systems requiring new design. However, MDAs may grant waivers on a case-bycase basis if the use of the metric system is not in the best interest of the DOD.

The measurement units in which a system was originally designed will be retained for the life of the system, unless the procuring activity determines it is more advantageous to convert to the metric system. During the transition phase, use of hybrid metric and inchpound designs may be necessary and are acceptable.

Items of commercial design will be specified in metric units when economically available and technically adequate, or when otherwise determined by the procuring activity to be in the best interest of DOD. Bulk materials will be specified and accepted in metric units, unless being required for use in material designed in inch-pound units.

a) The Army is approaching the decision point as to whether it will be seeking waivers for three systems:

\section{All Terrain Lifter Articulated System (ATLAS) \\ 25-ton All Terrain Crane \\ Advance Aviation Forward Area Fueling}

b) Except for the following, all Navy Pre-Milestone I programs use the metric system of measurement. Waivers have been approved by the cognizant approval authorities for these systems acquisitions programs:

T-AGS 45, Oceanographic Research Ship

AN/BSY-2 Submarine Combat System 
Requests for waivers are currently in process for the following acquisition programs:

Strategic Sealift Ship

Amphibious Warfare Ship

c) Within the Air Force, no Pre-Milestone I waivers have been submitted.

\section{Transition Efforts}

DOD is revising its January 1989 Metric Transition Plan to bring it up to date, add more detail, modify tasks, and incorporate new goals. The revised plan should be approved during fiscal year 1993.

There are three major parts to DOD's Metric Transition Plan strategy:

a) Implementation of Metric Units in New Designs. Since 1987, the DOD policy has required use of the metric system in all elements of new systems requiring new design unless a waiver is obtained. DOD is establishing procedures to systematically include metric in their programs reviews. Metric as well as other policy requirements will be reviewed during Defense Acquisition Board reviews (for major systems) and program reviews (for less-than-major systems).

b) Facilitation of Metric in "Buy Commercial" Areas. The second approach is to buy commercial products where significant industry metric transition is planned. In this area, the DOD role is to facilitate industry transition by removing barriers, and giving appropriate preference to acquisition in metric. Examples include the automotive and construction equipment industries. However, DOD will not attempt to force metrication where it would not be economically feasible to do so. Thus, DOD will continue to operate in the inchpound system in commercial areas where significant industry metric transition is not underway.

c) Implementation of the Task Plans. The third approach is to effect transition in several cross-cutting areas of importance to the DOD that cannot be addressed by the other two approaches. These areas are addressed in seven active task plans and four Task Groups maintained on a monitoring/standby basis.

The following is a description of the active task plan objectives. Included in the revised plan are tasks that are in a standby or monitoring status. They are logistics, food, clothing and textiles, and health.

Operations, Safety, and Interoperability. This task identifies opportunities to use the metric system to enhance capabilities and interoperability, develop the interface with other agencies and the private sector to resolve safety issues, evaluate the use of differing measurement systems in operations and related instructions, and develop and implement a phased-conversion plan. It also establishes a central activity to coordinate and integrate military transition efforts related to military operations, safety, and interoperability.

Education and Training. This task involves the identifying and addressing the need for development and implementation of a common metric education program. It considers minimum education requirements for use during basis training and commissioning programs, the feasibility of the Services jointly developing metric training modules to use 
when instructing operations and support personnel, and guidance for including metric proficiency requirements in job standards.

Specifications and Standards. This task entails the development of a Master List of needed metric and non-measurement sensitive documents, emphasizing documents needed in the development phase. It includes establishment of a joint program with industry and non-government standards organizations to expedite the development and coordination of the documents.

Construction. This task establishes a joint metric transition planning group responsible for developing and implementing plans in coordination with appropriate industry associations (construction, architecture, building materials and supplies, etc.). It also identifies bulk materials that can and should be procured in metric quantities, develops a phased schedule for transition, and determines the feasibility of requiring metric dimensions on all overseas military construction projects awarded to U.S. firms.

Electronics. This task addresses development of new military documentation used in specifying electronic components (general specifications, detail specifications, specification sheets, standard military drawings, commercial item descriptions, etc.) by using the metric system of measurement. The revised plan also applies this procedure for fiber optics. However, the plan applies to only new specifications. Any revisions to existing systems are to be done in the inch-pound system.

Test, Measurement, and Diagnostic Equipment (TMDE). The objective of this task is to establish a joint group of metrology experts and TMDE developers to work with NIST and industry in planning and implementing a metric TMDE and calibration standards program. Included in the plan's task are: inventorying and categorizing existing TMDE by density, metrication rates, and capability; assessing the present status of TMDE and conducting market surveys to determine commercial availability and related costs; and assessing the economic feasibility, determining the type of conversion, and establishing priorities and milestones for conversion of TMDE.

Pubiic Affairs. This task encompasses the development and implementation of a comprehensive public relations program and includes development of news releases, articles, and public service radio and television announcements for DOD personnel.

\section{Significant Deveiopments}

a) Exampies of Metric Weapons Systems in the Production Phase:

Army: $\quad$ M120 - 120-mm MORTAR - Towed

Hellfire Missile System

Multiple Launch Rocket System

Family of Medium Tactical Vehicles

Navy: $\quad$ MHC 51 C1 Minehunter Ships

T-45A Trainer Aircraft

Electromagnetic Catapult Aircraft Launching System

NATO Sea Sparrow Missile System

MK-74 Mod O Versatile Exercise Mine Systems 
Marines: $\quad$ M1A1 Main Battle Tank (outside only)

Mobile Electronic Warfare Support System

Advanced Amphibious Assault Vehicle

Combat Excavator

Air Force: Scope Shield

b) Examples of Metric Weapon Systems in the Research, Deveiopment, Test, and Evaluation Stage:

$\begin{array}{ll}\text { Army: } & \text { Ground-Based Surveillance and Tracking System } \\ & \text { Ground-Based Radar } \\ & \text { Ground-Based Interceptor } \\ & \text { Future Armored Resupply Vehicle } \\ & \text { Fiber Optic Guidance Missile } \\ \text { RAH-66 Comanche Helicopter }\end{array}$

Navy: $\quad$ Advanced Rocket System

AN/SQY-1 Surface Ship ASW Combat Systems

Air Force: Brilliant Eyes

Advanced Short Range Air-to-Air Missile

Space-Based Interceptor

Space Surveillance and Tracking System

Boost Surveillance and Tracking System

c) Basic military operations for combat, combat support, and combat service

support elements in a "wartime " scenario are metric except for aerospace (altitudes) and maritime (depths). Operational plans are in metric units, maneuvers including speed and distance are in metric units, as are consumption factors and fuel rates. Basic loads of fuel and food are also in metric units. Combat engineering operations including mine countermeasure operations, maintaining road networks, bridges, and interplay with allies are all in metric units. Planning for combat service support (anticipated storage space for supplies and transportation planning) and intelligence operations including surveillance and reconnaissance also use metric units. Other metric operations include direct and indirect gunfire support. Metric usage is routine for the serviceman during standard military ground operations. Since all of the services have overseas facilities and are trained and equipped to operate in a combat-like environment, personnel at these facilities contend with metric units daily with no apparent difficulty. Defense mapping is mostly metric now, but the maps and charts that are critical to air or undersea navigation are still in inch-pound units.

d) There were no obvious interoperability problems during the Desert Shleid/Desert Storm operation involving systems of measurement. A scanning of the "Joint Center for Lessons Learned System" showed no problems that could be attributed to the use, or lack of use, of metric units.

e) The Services are providing metric training to personnel who need a working knowledge of the metric system--mostly those operating and maintaining metric-based materiel. Metric training modules are provided in the Program Managers Course at the Defense Systems Management College, and to the specification writers and users at the Specification Management Course. 
f) DOD has developed a database of metric specifications and standards needed to support metric weapon systems and equipment. The lists have been provided to the internal standards-preparing activities and to non-Government standards developing groups. A list of federal specifications and standards identified as in need of metric versions has been provided to the General Services Administration. Two specifications and standards workshops have been held: one with the DOD standards community and the other with non-Government standards bodies. DOD issued "Guidelines for Development of Metric Standards and Specifications" in March, 1990.

9) DOD is actively participating in the MOC Construction Subcommittee. It contributed $\$ 84,000$ during fiscal year 1991 to develop and implement the Construction Metric Implementation Proposal. The Army Corps of Engineers is selecting nine pilot projects to be designed and built to metric standards.

h) Beginning as soon as possible, but not later than October 1, 1992, all new military documentation used in specifying electronic and fiber optic components will use metric units. This includes general specifications, detailed specifications, specification sheets, standard military drawings, and commercial item descriptions.

i) The Defense Industriai Supply Center (DISC) has developed, or will soon complete development of, 125 metric specifications for aerospace components to be adopted as SAE standards. DISC has nearly completed a metric transition plan for fasteners and other commodities under its responsibility. Approximately 1,100 other standards will need a metric counterpart, with 300 already having metric counterparts. DISC also publishes an annual status report on the development of some 800 needed metric standards and specifications.

j) The Services have completed a joint study plan and have identified the number of test, measurement, and diagnostic equipment (TMDE) items, metric transition rates, and associated metric transition costs.

k) The DOD Metric Transition Public Affairs Charter has been approved. The American Forces Information Service has established a FY '92 program of developing metric articles, posters, and radio and television service announcements.

I) Virtually all DOD grants programs are conducted using metric standards due to their scientific and technical nature.

\section{DEPARTMENT OF EDUCATION}

The Department of Education's metric transition plan is in draft form.

\section{Directive}

The Department of Education metric policy directive is awaiting senior officer review and approval for publication in the Federal Register for a public comment period. 


\section{Responsibilities}

a) Metric Executive. The Assistant Secretary for Elementary and Secondary School Education is designated as the Metric Executive. The Assistant Secretary provides management oversight and coordination over the Department's outreach activities, transition plan development, and coordination of the development of a Department-wide management system, grants and contracting requirements, training program, and reporting requirements.

b) Metric Coordinating Committee. The Education Metric Coordinating Committee consists of a representative from each Principal Operating Component. It will be chaired by a representative from the office of the Assistant Secretary for Elementary and Secondary School Education and will provide technical advice concerning metric conversion in the Department. It will also serve to keep other Principal Operating Components informed about other federal metric efforts and initiatives.

c) Assistant Secretary for Management and Budget (CFO). The Assistant Secretary for Management and Budget, as the Chief Financial Officer, shall review transition actions and their resources implications as part of the preparation of the Department's annual budget submissions.

\section{Reporting}

The Education directive does not specifically outline reporting requirements. Within 45 days of the official issuance of the policy, the office of the Assistant Secretary for Elementary and Secondary Education will review all aspects of Departmental activity and develop plans and guidelines for implementing the metric system. These plans and guidelines will be reviewed and revised as necessary by January 15th of each year after issuance of the policy. In coordination with other offices, the Assistant Secretary will also collect information necessary to prepare the Department's annual metric progress report to Congress.

\section{Exceptions to Metric Usage}

When metric conversion plans designate programs and activities where conversion is questionable or creates inefficiencies, an analysis justifying such action shall be included as part of the plan.

\section{Metric Transition Pians}

The Department of Education order does not include plans for specific programs or Principal Operating Components.

\section{Significant Deveiopments}

a) Specific Public Affairs Guidance is included in the policy directive, which when issued will dictate using metric units first with inch-pound in parenthesis not later than 12 months after issuance. Two years after issuance, only metric units will be used in Departmental public affairs communications. 
b) For State Formula Grants the Department will prepare a "common rule" policy applicable to using metric units in procurements under these types of grants and will work with Commerce, $\mathrm{OMB}$ and other grant issuing agencies to get the common rule issued.

c) The Department will join with other national education organizations to celebrate National Metric Week ' 92 with specific emphasis on the metric implications of the Department's AMERICA 2000 goals.

d) The Department will develop a metric regulation applicable to using metric units in its procurement and contracting activities. The regulation will be developed by the Grants and Contracts Service with a planned Federal Register publication date of September 1992.

\section{DEPARTMENT OF ENERGY (DOE)}

The Department of Energy (DOE) is one of the principal research agencies in the federal government, and is heavily involved with nuclear, fossil, and solar energy. Nuclear energy, in its various manifestations, dominates the programs of the Department. Regulation of civil power plants, military weapons development and production, and radioactive waste management are three separate concerns. Fossil fuels and renewable energy involve complex and far-reaching research and development programs, as well as significant attention to environmental regulations. The research interests are international in scope as all developed countries are addressing the difficult unsolved problems, for example, acid rain, radioactive waste storage, use of new fossil materials such as oil shale, and the development of solar and other new sources for commercial power.

Metric conversion in DOE should be assisted by the heavy emphasis on research and development in fossil fuels development and conservation, in the emerging bio-energy fields, and in nuclear energy. Most energy products are shipped in bulk quantities which are readily quantified in metric units. There is also growing international trade and joint development in the energy sector where metric measures prevail. Energy industry managers are mostly trained engineers, scientists, and technicians with previous experience in using the metric system.

A principal problem may be the heavy capital intensity of industries with long-lived facilities in the energy sector. Plans for conversion of existing assets to metric units must account for the long replacement cycles of industrial facilities.

\section{Directive}

The Department of Energy issued its initial internal metrication directive as Order 5900.2 on December 12, 1980. The document is entitled "Use of the Metric System of Measurement." DOE has also drafted a revision to the Order which reflects the policy and plans emanating from the new legislation and the Executive Order. Furthermore, a draft notice has been prepared which establishes DOE metrication policy.

\section{Responsibilities}

a) Metrlc Executive. The Director of Administration and Human Resource Management is designated as the DOE Metric Executive and is responsible for establishing, recommending, and interpreting policy for DOE metric transition matters. 
b) Heads of Headquarters Elements. The Heads of Headquarters elements are responsible for developing and keeping current metrication and related plans in their areas of responsibility. The scope and format of those plans are to conform to the applicable portions of the overall Departmental Metric Transition Plan.

c) Office of Primary Responsibility (OPR). A Secretarial Program Office is designated as the OPR for each task in the plan. Supporting the task OPR are other components, i.e., Offices of Collateral Responsibility (OCR), having adequate authority and expertise for the actions needed.

d) Metrication Transition Committee (MTC). The MTC will, based on its review of the task plans, develop an implementation plan with proposed, measurable DOE-wide objectives and schedules for completion of the tasks. The MTC will also review transition efforts and provide assistance and coordination, as appropriate.

\section{Reporting}

a) Task OPRs will provide quarterly progress reports in letter format to the Metric Executive.

b) The annual report to the Congress will be prepared by the Metric Executive based on input from the MTC, task OPRs, and field offices. The report will be coordinated with the MTC and approved by the Secretary.

\section{Exceptions to Metric Usage}

According to the draft revision to Order 5900.2, DOE will use the metric system in all significant projects (major systems acquisitions, major projects, large-scale capital equipment, etc.) that have not initiated Title I design work by January 1994. Waivers or partial waivers to this requirement shall be obtained from the Head of the cognizant Headquarter Element and reviewed by the Metric Executive. Waivers will be issued only upon the submission of documentation demonstrating the economic or technical infeasibility of metrication. They will be based on evaluation criteria that include initial life cycle costs or loss of markets to U.S. firms, unavailability of industry accepted metric standards, and safety-related factors.

\section{Transition Efforts}

The DOE Metric Transition Plan was approved by the Secretary on December 13, 1991. In addition, a Federal Register Notice was issued for public comment (Volume 55, Number 243, dated December 18, 1990).

The DOE Plan is in fact two separate initiatives. The first part of the plan is a collection of tasks that will facilitate the entire Department's conversion to the metric system of measurement. Each of the thirteen different, but somewhat inter-related tasks, address the Agency-level transition. Efforts concerning Department-wide issues such as standards and specifications, safety and operations, training, procurement, construction, etc., will be undertaken.

To be assured that the plan can be implemented, all of the task plans include an implementation scheme, with a detailed list of actions to be performed, and milestone 
dates to be met. To provide the needed authority, each task has an Assistant Secretary level office designated as its Office of Primary Responsibility (OPR). The task's OPR will initiate the necessary headquarter's level changes to remove the policy barriers to metrication, develop Department-wide programs, and establish forums to coordinate the transition.

Furthermore, for the plan to succeed, the second phase is introduced to guarantee that transition occurs at all levels of the organization. The overall DOE Metric Conversion Plan initiates and provides guidance for the creation of up to thirty separate implementation plans to address the variety of individual program and project changes necessary within the DOE organizational elements. These individual plans are to be developed by the head of each major DOE organization (Program Secretarial Offices) who will refine the details of implementation. Under this second phase of implementation, the Program Secretarial Offices will be provided with the authority and responsibility to tailor their implementations to specific operational needs.

The overall DOE Metric Transition Plan tasks and purposes are as follows:

Task 1. Transition Management. The purpose of this task is to provide a focal point for transition activities and a central source of metric information, to integrate and monitor the various tasks, and to prepare the necessary reports required by Congress and the Executive Order.

Task 2. Operations and Safety. This task covers the actions necessary to identify opportunities to enhance capabilities and simplify operations. It also evaluates the use of differing measurement systems on operations and safety to minimize detrimental effects of conversion.

Task 3. Education and Training. This task involves the development and implementation of a comprehensive metric education program including brochures and briefings for DOE personnel and contractors. It also identifies specific metric education and training requirements for different personnel categories.

Task 4. Specifications and Standards. This task includes the development of a master list of measurement-sensitive documents that require revisions or fundamental changes because of metrication. It also explores the establishment of a joint program involving industrial and non-Government standards organizations to expedite the development and coordination of the documents needing revision.

Task 5. Test Measurement, and Diagnostic Equipment (TMDE). This task provides for the establishment of a joint group of metrology experts and TMDE developers to work with NIST and industry in planning and implementing a metric TMDE and calibration standards program.

Task 6. Construction. This task involves the coordination with appropriate industry associations (construction, architecture, building materials and supplies, etc.) to recommend potential metric projects. It also identifies bulk materials and items such as heating, plumbing, electrical equipment, door and window sizes, floor coverings, etc., which can be procured in metric dimensions. 
Task 7. Electronics. This task involves the determination of the extent and appropriateness of metrication in the electronics industry, both domestic and foreign. Also, in concert with DOD and others, it includes obtaining information on the availability of electronic devices in metric specifications and of existing data bases on the availability of such products.

Task 8. Small Business. This task concentrates on encouraging and assisting small businesses, to voluntarily convert to the metric system.

Task 9. Internal and Public Affairs. This task ensures that consistent and sufficiently detailed information is provided to the public and internal DOE audiences.

Task 10. Interface with Metric Countries. The purpose of this task is to avoid duplication and take advantage of the metric experiences of other countries. This could include the adoption of metric specifications and standards in use in foreign countries, without compromising U.S. technology.

Task 11. Metrication Handbook. This task involves the development or adaptation of a metrication handbook for acquisition offices. This handbook would be based on the experiences of organizations currently acquiring metric supplies and services.

Task 12. Procurement and Assistance. This task is designed to determine whether generic solicitation provisions and contract clauses can be expected to be developed for Government-wide application in the Federal Acquisition Regulation (FAR) and whether they will accommodate DOE's needs. In addition, a necessary outreach program is to be developed to ensure that the management and operating contractor's purchasing activities move in concert with DOE's and other Federal agencies' own purchasing activities.

Task 13. Cost Evaluation Guidelines. This task requires the development and issuance of cost evaluation guidelines to be used throughout DOE in making and evaluating cost estimates for metrication of DOE projects. These guidelines are to focus on the life-cycle costs associated with a project, and will be incorporated into future DOE orders concerning metrication.

\section{Significant Developments}

DOE anticipates that the identification of the barriers to metric transition, the development of training programs, and other key implementation actions will have begun or have been completed before September, 1992. The overall completion date for the transition phase will be determined during Fiscal Year 1993.

TralnIng: The Office of Procurement and Assistance has provided a self-training package to all of its personnel. The office of Administration and Human Resource Management has developed an intensive metric training class for all Departmental employees. Its aim is to help the participant to not just convert dimensions but, to think in metric.

Projects: The Advanced Simplified Boiling Water Reactor Program is using the metric system as its primary measuring unit. The Advanced Neutron Source Reactor, the Modular High Temperature Gas-Cooled Reactor Program, and possibly the Advanced Light Water Reactor Program will utilize the metric system for their designs. Most high energy physics projects are already designed in the metric system. The Department has 
established a Construction Working Group to oversee the development of metric pilot construction projects and to provide a forum for the exchange of metric constructionrelated information.

Operations: While many of the existing DOE facilities were developed under the inchpound system of units, some organizations are reporting that they typically report and perform their analyses in the metric system. Five multi-program energy research laboratories have established a Laboratory Operations Coordinating Committee and will hold a workshop with other interested DOE laboratories on metric transition in the summer of 1992.

Public Awareness Initiatives: The Energy Information Agency will include metric information flyers in all of its 75 different publications. Their total circulation is over one half million copies. These reports are distributed to industries and the public. The Western Area Power Administration (WAPA) and the Bonneville Power Administration (BPA) have begun to include the metric system in all published public and internal information. The DOE newsletter, press releases, and all fact sheets published by the Office of Public Affairs have contained dual listing of units since January 1, 1991. The Office of Administration and Human Resource Management and the Office of Public Affairs are working on the development of a metric awareness campaign for the two Departmental headquarters buildings and all other DOE offices. Oak Ridge National Laboratory plans to use metric units in all public communications press releases and interactions with the public.

Private Industry Initiatives: The Office of Domestic and International Energy Policy will start working with U.S. exporters of energy-related foods and services by helping to identify foreign markets and encouraging advantageous transitions to metric. This office is also working to determine the feasibility of the use of metric units in international research and development agreements.

Surveys have been conducted of the industries involved with the development of permanent and interim storage and transportation of high-level radioactive wastes and spent fuel. The results show a mixture of metric products is available, but sometimes at a premium price. Another survey sent to approximately 3000 past and present contractors at the Savannah River Site in Aiken South Carolina has produced more encouraging results. Based on approximately 1600 responses, about $50 \%$ have worked or currently work in the metric system, and about $70 \%$ could work in the system if required. Seventy percent of the responses were from self-described small businesses.

The Office of Small And Disadvantaged Business Utilization has established two initiatives. The first is a distribution of metric conversion information. The other, the conducting of a "mentor-protege" pilot program matches contractors already using the metric system for information exchange and training with small businesses.

\section{DEPARTMENT OF HEALTH AND HUMAN SERVICES (DHHS)}

The Department of Health and Human Services provides many services not related to metric issues. For example, the vast Social Security, welfare and Medicare programs are cash entitlements and payments not affected by units of measurement, except for some medical standards in the regulation of Medicare and Medicaid payments. Metric 
significance in DHHS is concentrated in the Department's extensive health and medical programs where medical procedures and devices, medical and drug contents and dosages, and food and drug manufacture and labeling are measurement sensitive. These same activities are research related, and have the potential for extensive metric applications.

DHHS awards contracts for medical facilities construction and operation and also constructs and operates some hospital and medical facilities. The Department also contains major research agencies including its world-famous National Institutes of Health. Information and statistics, including the National Centers for Disease Control, represent another measurement-sensitive service to the Nation.

DHHS communicates its metric usage requirements with its numerous grantees and contractors in the health care and research areas. The concentration of programs in the medical and health sectors is of assistance to the Department in the metric conversion of its programs since medical care is a science-based activity. A strong international interest has developed in recent years in medical and biological research aimed at new medicines and instruments. Medicines and instruments are also major items in international trade. The Department's construction activities could benefit from the interest in metric conversion in the commercial construction sector.

\section{Directive}

The Department of Health and Human Services has issued its internal directive as part of the General Administration Manual (GAM). It appears as GAM Chapter 8-25, "HHS Metric Program."

\section{Responsibilities}

a) Metric Executive. GAM Chapter 8-25 designates the Director, Office of Management, U.S. Public Health Service as the Metric Executive.

b) Heads of Operating Divisions (OPDIVs). The Heads of OPDIVS are responsible for:

Ensuring organizational implementation of the Act by September 30, 1992; Designating an individual as the metric coordinator for their OPDIV who will serve on the DHHS Metric Transition Steering Committee;

Identifying Federal legislation, regulations, and procedures that unduly restrict the use of the metric system; and

Where applicable, initiating action to eliminate those restrictions and ease transition to the metric system.

c) Metric Transition Steering Committee (MTSC). Members of the MTSC are responsible for planning and coordinating transition to the metric system, and advising their respective OPDIVs on matters relating to metrication.

\section{Reporting}

Each OPDIV is required to submit a report covering accomplishments, problems, recommendations, and other relevant information to the Assistant Secretary for Budget by December 1 of each year. 


\section{Exceptions to Metric Usage}

DHHS does not permit exceptions to the metric usage policy without the approval of the Assistant Secretary for Management and Budget.

\section{Transition Activities}

DHHS has approved its Departmental plan using the policy document GAM Chapter 8-25 as its cornerstone. Accordingly, the OPDIVs are required to implement that policy and develop individual plans and milestones based on their organizational needs.

While the metric transition is being implemented Department-wide, the predominant types of activities in which the metric system is appropriate for use will be in the health care and medical research areas. SI is and will continue to be used in many of the clinical health care activities, including both inpatient and outpatient units, medical records, rehabilitation, medicine nursing, and pharmacy. Furthermore, most of the medical research supported by HHS through grants and contracts is metric-oriented and will use SI in developing specifications for specialized medical/laboratory equipment and supplies.

\section{Significant Developments.}

a) The Public Health Service (PHS) has established an advisory group of health care professionals and intends to identify specific steps for increasing the use of metric products in its health care activities. Through an update to the PHS Grants Policy Statement, proposals from potential awardees to receive grants, cooperative agreements, and other financial assistance are to be submitted to PHS awarding components using SI units. Measurement values in reports, publications, and other communications regarding grants are to be in metric units.

b) The National Institutes of Health $(\mathrm{NIH})$ is cooperating with industry on metric conversion through participation in workshops and the National Academy of Science's Building Research Board. The Standards and Specifications Branch intends to continue its research of the marketplace to identify metric substitutes when preparing specifications for items requested in inch-pound dimensions.

c) The Food and Drug Administration (FDA) issued a revision to its Food Labeling Guide to recommend the inclusion of metric measurements for net contents statements. Also, FDA intends to issue regulations requiring that food label nutrient and serving size information be displayed in SI measurements. Also, through the Federal Register process, FDA's Center for Devices and Radiological Health is developing a revision to the Performance Standard for Diagnostic X-Ray Equipment to reflect the use of SI units. FDA revised its Acquisition Operating Instruction on developing specifications, standards, and other purchasing descriptions to include metric provisions. In 1991, FDA held a public forum to obtain comments on its proposed nutritional labeling regulations, including metric usage regulations.

To implement the education provisions of the Nutrition Labeling and Education Act of 1990 (NLEA), FDA has assembled an agency working group on education. This group is developing modules for a training program to be used by industry, consumers, health professionals, educators, and state governments to instruct the public on areas related to 
NLEA regulations. As a part of this initiative, FDA will include a discussion of metric units of measurement.

d) $\mathrm{NiH}$, the Indian Heaith Service, and the Centers for Disease Control (CDC) are following the MOC Construction Subcommittee's 5-year plan and are each pursuing pilot metric construction projects.

e) The Social Security Administration (SSA) plans to revise the medical listings in its disability program by referring to body weight and height in kilograms and centimeters. These revisions are to be incorporated into the disability process and distributed to the users (principally, the State agencies involved in the disability determination process).

f) The Health Care Financing Administration (HCFA) is establishing a metric review point as part of its regulation clearing process to assist in establishing requirements standards for the dimensions of hospital and nursing home doors, rooms, hallways, etc.

\section{DEPARTMENT OF HOUSING AND URBAN DEVELOPMENT (HUD)}

The principal concern of the Department of Housing and Urban Development (HUD) with metrication is in the area of metric standards for the residential building trades. To a lesser extent there is concern with engineering construction on large buildings and urban renewal projects. HUD programs in housing and mortgage insurance are conducted in the arena of residential construction standards, along with the complex array of local governments and local trade councils. Because the building trades have been reluctant to change standards, residential construction presents a challenge to metric conversion.

\section{Directive}

The Department of Housing and Urban Development has prepared a draft Federal Register Notice intended to inform the public of the policies and procedures for use of the metric system in all program, procurement, and assistance (i.e., grants and cooperative agreements) activities within HUD. Contained in the draft Notice are HUD's metrication program purpose, responsibilities, and reporting requirements.

\section{Responsibilities}

a) Metric Executive. According to the draft Notice, the Deputy Assistant Secretary for Research is to be the Department's Metric Executive.

b) Metric Policy Committee. The draft Notice establishes a Metric Policy Committee that is to be responsible for reviewing and directing the overall Departmental metric activities, including the formulation of the Metric Transition Plan. This committee is to be chaired by the Assistant Secretary for Policy Development and Research and be comprised of the Assistant Secretaries for Administration, Community Planning and Development, Housing, and Public and Indian Housing, and the General Counsel; or their designees at the level of Deputy Assistant Secretary.

c) Metric Coordinating Committee. A Metric Coordinating Committee will be established to provide day-to-day coordination and communication on metric issues within the Department. 
d) Metric Work Group. A Metric Work Group may be established in any major component of HUD, at the discretion of the Metric Policy Committee representative from that component, to coordinate metric implementation or training programs within the component.

\section{Reporting}

The draft Notice stipulates that the Metric Coordinating Committee shall develop an annual report of metric activities during the preceding Fiscal Year, to be provided to the Deputy Assistant Secretary for Research by January 15 of the ensuing year. This report is to cover the metric activities by each element of HUD, and describe major accomplishments, metric standards developed or adopted, and examples of metric use in significant procurements or program activities. This report will be used as the basis for the annual metric report to be included in the Department's annual budget submission.

\section{Exceptions to Metric Usage}

The draft Notice contains no specific provisions for processing exceptions to metric usage.

\section{Transition Efforts.}

The draft notice does not provide a discernible plan which iterates milestones, tasks, and proposed accomplishment dates. However, it does offer procedures that could be used for planning and implementation purposes. These are:

a) Program Offices shall review their existing Guidelines, Standards, Notices, and other requirements to determine where metric measurements should be added to or substituted for existing measurement requirements, and develop a plan to make these changes.

b) Program Offices, in developing procurement requests, contract/assistance/interagency agreement specifications, and/or work statements, notices of fund availability (NOFAs), and application kits, shall assess each requirement which involves measurement standards in terms of its applicability for metric system use.

c) Contracting officers shall review all procurement requests, contract specifications, grant announcements, and interagency agreements for compliance with Federal Acquisition Regulation measurement system requirements.

d) Each program office is responsible for reviewing the applicability of its assistance programs for metric system implementation and shall prepare its NOFAs and application kits accordingly, i.e., to the extent required by the appropriate OMB grants management circulars.

e) Technical reports, studies, position papers, and other documents shall, where appropriate, provide measurements in both the metric and inch-pound systems. Principal interest shall be given to that system primarily used by the constituent group audience for the document. The use of dual measurement systems in such documents shall be reviewed annually by the Metric Policy Committee to determine whether a change in the policy is appropriate. 
f) The Metric Coordinating Committee shall identify and publish conversion information and standards for uniform use throughout the Department, and recommend to the Metric Policy Committee a process for analyzing future actions to determine the measurement system to be used, and for analyzing when such conversion would be considered costbeneficial.

\section{DEPARTMENT OF THE INTERIOR}

The Department of the Interior (Interior) is the land management and natural resource agency of the Federal Government with interests in land surveys and sales, mineral conservation and leasing management, construction, water resource management, wildlife, wilderness, park operation and management, and geology and earth sciences. Favoring metric conversion in Interior are the presence of scientific staffs supporting its various programs.

\section{Directlve}

The Department of Interior issued its internal administrative directive as Departmental Manual Release Part 758 DM 1, "Metric Transition Program," dated December 6, 1991.

\section{Responsibliltles}

a) Assistant Secretary (Policy, Management, and Budget). Part 758 DM 1 designates the Assistant Secretary (Policy, Management, and Budget) as the Interior Metric Executive who is responsible for implementing the use of the metric system within the Department.

b) Assistant Secretaries are responsible for ensuring metric actions in the Department's metric transition plan, that pertain to their respective bureaus and offices, are completed within established time frames.

c) Heads of Bureaus and Offices are to designate a bureau/office metric coordinator.

d) Departmental Metric Coordinator is responsible for:

Managing the Interior metric transition program;

Developing Interior metric policy and providing program assistance to bureaus and offices in implementing the policy;

Developing the Interior metric transition plan and coordinating its implementation;

Serving as the Interior representative to the Metrication Operating Committee; and

Chairing the Interior Metric Work Group (IMWG).

e) Bureau Metric Coordinators are responsible for:

Serving as the central point of contact on metrication matters and participating in the activities of the IMWG for bureaus and offices;

Coordinating the required actions in the Interior metric transition plan for which the bureau or office is responsible; and

Providing reports to the IMWG on accomplishments and progress. 
f) Interior Metric Work Group (IMWG) is responsible for:

Developing and coordinating Interior metric policies and plans; and

Resolving problems and issues associated with the implementation of the metric system.

\section{Reporting Requirements}

The Interior bureaus and offices are to:

Provide input to the IMWG on annual metric transition accomplishments, activities and future plans for metric transition for inclusion in the Interior's annual metric report to Congress;

Provide regular progress reports on milestone accomplishments defined in the Interior Metric Transition Plan; and

Maintain an awareness of their own metric activities to effectively meet requests for information, coordination, and cooperation.

\section{Exceptions to Metric Usage}

There is no provision for exceptions to the use of metric units.

\section{Transition Efforts}

The Interior Metric Transition Plan describes the Department's overall strategy for metrication, defines general requirements and procedures for transition efforts, and details the tasks to be accomplished by designated bureaus and offices. Each task description contains a goal, background statements, a list of required actions, and scheduled completion dates.

The transition tasks in the plan involve applying the metric system to the conduct of Interior's major programs and business activities and acquiring metric supplies and services. The metric transition strategy recognizes the diverse, primarily domestic, industry and commerce with which Interior deals. The strategy has Interior taking a leadership role in transition to metric use in areas where the Department can make a meaningful difference, such as construction, mineral leasing and reporting, mapping, regulations, and publications.

With respect to procurements and grants, Interior's position is that where metric units have not been the accepted industry standard, dual dimensions may be used during the transition. Also, the strategy recognizes that the completion of many transition tasks will require a phased-in approach that may take several years. The following are the transition tasks:

a) Transition Management. The goal is to provide Department-wide direction and coordination of the Interior metric transition effort.

Provide management support to the Interior Metric Work Group (IMWG). Issue revised Departmental policy (758 DM) on the use of the metric system by January 6, 1992. 
Monitor progress of the actions required within each task of the Metric Transition Plan and provide guidance to OPRs on all tasks.

Prepare the annual report to Congress by January 15 each year.

Establish a reference library of metric publications by January 1, 1991.

b) Procurements. The goal is to acquire all commodities, supplies, and other items in metric units, as appropriate.

The Office of Acquisition and Property Management (PAM) is to issue Departmental Policy requiring the use of the metric system in procuring all commodities, supplies, and other items (e.g., engineering and scientific data) consistent with the metric provisions of the Federal Acquisition Regulation.

c) Grants. The goal is that all grant requirements that are measurement-sensitive will be fulfilled using the metric system when appropriate.

The Office of Acquisition and Property Management (PAM) is to issue Departmental Policy requiring that the metric system be used when appropriate for all measurement-sensitive items in grant application instructions, in applications in fulfilling grant requirements, and in submitting grant reports, consistent with government-wide policies developed by $\mathrm{OMB}$.

d) Regulations, Policies, and Manuals. The goal is to ensure that measurementsensitive matters in all regulations, policies, and manuals are expressed in exclusively metric units or in dual dimensions (metric/inch-pound). If dual dimensions are used, all dimensions are to be expressed with metric units first, inch-pound units second. The Office of Management Improvement (PMI) will monitor new and revised regulations, policies, and manuals for compliance.

PMI is to revise the Departmental Manual to require either exclusively metric units or dual dimensions (metric/inch-pound) for measurement-sensitive matters in all new and revised regulations, policies, and manuals.

Federal Standard 376A, "Preferred Metric Units for General Use by the Federal Government," dated May 5, 1983, is to be the official standard used when applying or converting to metric units.

By May 31, 1992, bureaus and offices are to review all regulations, policies, and manuals to identify those that contain measurementsensitive matters, highlighting those that are particularly important for early revision.

All bureaus and offices are to prepare a schedule by June 30,1992 , for revising regulations, policies, and manuals to include dual dimensions for measurement-sensitive matters. The schedule may reflect a phased approach. Those measurement-sensitive matters that are directly related to international competitiveness are to be scheduled for early revision. 
e) Training and Education. The goal is to train all Interior employees in the use of the metric system as necessary. Curricula in Native American schools incorporate metric training.

The Division of Development and Training Management will identify metric training materials for use in Interior and will offer a pilot metric training program on April 27 and June 1, 1992.

The Bureau of Indian Affairs (BIA) will continue to encourage and support the instruction of the metric system in all bureau-funded schools; wherever possible, BIA will influence non-funded Indian schools to incorporate the teaching of the metric system in appropriate program areas.

In accordance with Personnel Management Notice DTM-26 dated January 25, 1991, bureau/office Employee Development Officers will establish a schedule for incorporating dual dimensions in all inhouse training courses that contain measurement sensitive material by June 30, 1992.

f) Engineering and Construction. The goal is the use of the metric system in construction projects of the Department while minimizing disruption to small construction firms; ultimately, all engineering and construction drawings and reports are to be produced with metric units.

An Interior construction subgroup was formed on October 22, 1991, with construction representatives from the Bureau of Reclamation, Office of Construction Management, Bureau of Land Management, Bureau of Indian Affairs, Fish and Wildlife Service, and National Park Service to resolve metric conversion issues impacting Interior construction activities and to develop and propose any required Departmental metric construction policy.

In conjunction with review of task number 4 on regulations and policies, all bureaus are to identify any barriers to the use of metric in construction that can be removed without negative impact on small construction firms by May 31, 1992.

g) Reports and Publications. The goal is to express measurements in metric units exclusively or dual dimensions (metric/inch-pound), as appropriate, in all reports and publications. Interior publishes hundreds of scientific, technical, and other reports ranging from earthquake studies to water conservation. Many of these reports and official publications are already published in metric units, and it is the policy of several bureaus now to use the metric system in all scientific reports. The Bureau of Mines will transition reports on minerals and materials to metric units by the end of Fiscal Year 1992. The Office of Management Improvement (PMI) has responsibility for internal and interagency reports policy and the Office of Public Affairs (OPA) has responsibility for publications policy. Policies are to be revised to require the use of the metric system in all reports and publications and to develop a schedule for making the transition to metric units.

PMI and OPA will revise their policies in the Departmental Manual by April 30,1992 , to require either exclusive metric units or dual 
dimensions to express measurements in all new and revised reports and publications.

Bureau reports and publications offices will develop schedules for making the transition to the metric system or dual dimensions in reports and publications by May 31, 1992.

h) Mapping and Related Data. The goal is to develop the capability to produce maps and map products with metric dimensions and units. The U.S. geological Survey (USGS) is the official mapper of the United States. All intermediate scale maps: $1: 50,000,1: 100,000$, and $1: 250,000$ are now produced in metric units. The USGS is undertaking a complete modernization of its map production processes and has plans to convert all base maps to digital form by the year 2000. At that time, all digitized maps will be available in metric units when requested.

Important to the use of maps in analysis of land and resource management problems are data about the mineral, water, wildlife, and vegetative resources and other data that can be related to the geography of land, for example, population, transportation networks, industrial, and pollution data. These data, usually referred to as thematic data, also are to be expressed in metric units where appropriate. The Interior Geographic Data Committee (IGDC) is an inter-bureau committee chaired by the USGS and has responsibility for developing policies and standards for thematic data.

The USGS will complete its plan to have the capability to produce maps in metric units by the year 2000 .

At the request of the Departmental Metric Coordinator, the IGDC will review requirements for converting thematic data to metric units.

i) Minerals Leasing and Production. The goal is to conduct leasing of Federal and Native American lands and account for production of minerals using metric units. The Federal Government leases tracts of the outer continental shelf, federally owned lands, and Native American lands to companies and individuals for private use including mineral extraction. Interior bureaus involved in this activity are the Bureau of Indian Affairs, Bureau of Land Management, and the Minerals Management Service. Inchpound units are used to express land areas and amounts of minerals removed. Some of the minerals ultimately go into international markets. The use of metric units should be examined.

There is an Interior/industry task force currently studying the need for data standards for oil and gas leasing and production. The Interior Metric Work Group should keep the task force informed of metric developments and requirements.

The metric conversion of oil and gas leasing and production could be costly and timeconsuming. U.S. industry is in support of conversion to the metric system but has not yet begun to implement any transition efforts. The American Petroleum Institute (API) is made up of representatives from the oil and gas industry. API has formed a Petroleum Measurement Committee to study the costs and benefits of converting to the metric system. At this time, the Department will play a supportive/advisory role in industry's study of this issue. 
The Federal Government is the largest single lessor of coal in the United States. Federally-owned and managed coal resources are leased to companies and individuals for production.

The Minerals Management Service (MMS) is the bureau charged with collecting and accounting for the royalties received for Federal and Native American coal. The Bureau of Indian Affairs (B|A) is the leasing agent/authority for Native American coal. The Bureau of Land Management (BLM) is the leasing agent and is responsible for regulating exploration and development of the coal on Federal lands as well as environmental protection of affected resources on both Federal and Native American lands. The Office of Surface Mining (OSM) is responsible for approving mining permits and reclamation of mining sites.

Any effort involving Federal and Native American coal production needs the involvement of all four bureaus. Furthermore, since coal production data must be obtained from the lessees, the coal industry must be directly involved.

Conduct oil and gas leasing and production using metric units.

Conduct coal leasing and production using metric units; all bureaus are to identify coal reports and documents with potential to be presented in metric or dual dimensions.

BLM is to use dual dimensions for coal production data in the FY' 92 Annual Coal Report submitted to Congress.

\section{Significant Developments}

a) U.S. Geoiogical Survey (USGS). USCG continues to use metric units extensively in program activities. Maps and digital map products in the 1:100,000 scale are produced in metric units; $1: 250,000$ products are being converted to metric. Progress continues on developing a capability to produce other digital map products in metric. Aerial photography activities use dual dimensions. It is the policy of the USGS to use metric units in scientific publications. The FY 1993 budget justification submitted to Congress will use dual dimensions.

b) Bureau of Reclamation. Metric units are now used in some Bureau of Reclamation construction projects. In 1991, for example, construction specifications for the Yuma Desalting Plant and the Minidoka Replacement Powerplant were given in dual dimensions. In 1992, the bureau will develop plans to use metric units in all reports. From earlier metric conversion efforts in the late 1970s, the bureau has a comprehensive manual to guide staff on the use of metric units.

c) Bureau of Mines. Starting in FY 1991, the bureau's Helium Field Operations has presented prices for helium products in dual dimensions. The bureau continues to convert its commodity reports to metric units; 82 percent of the reports are now published in metric units. Five more reports are to be converted to metric units in 1992.

d) Bureau of Land Management. The bureau published a joint Federal Register notice with the Minerals Management Service seeking information from industry on the use of metric units in future oil and gas leasing and production reporting activities. The 
input will be used in developing plans for converting to metric in the bureau's future relations with industry.

e) Minerais Management Service. The Service is coordinating with the American Petroleum Institute on the metric transition in the oil industry. The bureau has developed the capability to produce digitized maps in metric units. Offshore protraction diagrams (OPDs) are being converted to metric. The conversion of OPDs is a longterm effort and will continue into FY'92 and beyond.

f) Fish and Wildilfe Service. All revisions to the Service's Manual will present measurement-sensitive material in dual dimensions with metric units given first.

Bureau scientific reports use metric units. Many other reports also use metric (e.g., the bureau's Federal Aid Annual Report and wildife and fisheries reports from the States. Environmental Contaminant Program reports are to be completely converted to dual dimensions by the end of FY '92. Also in FY'92, digitized wetland map data will be in metric units.

\section{DEPARTMENT OF LABOR (DOL)}

The Department of Labor has chosen to have no overall Metric Transition Plan. This strategy is based upon the position that the Department's agencies represent a disparate range of functions with little relationship to each other. The Department assists and encourages the individual agencies to develop metric plans that reflect their unique situations and needs. For example, the Employment and Training

Administration and the Bureau of Labor Statistics have completed transition plans, and the Department of Labor Academy is planning to offer metric classes.

\section{Directive}

The Department of Labor issued Secretary's Order 5-92 on July 16, 1992.

\section{Responsibilities}

a) Metric Executive. The Assistant Secretary for Administration and Management is designated as DOL's Metric Executive and is responsible for issuing guidelines as required to assure consistency among $\mathrm{DOL}$ organizations in the process of converting to metric units of measurement.

b) Metric Coordinator. The Metric Coordinator, appointed by the Metric Executive, is primarily responsible for coordinating and monitoring DOL agency metric conversion progress.

c) Agency Heads. DOL agency heads designate a senior official as Agency Metric Manager, direct the use of metric units in the acquisition of new equipment and supplies and in the modernization of existing equipment, where feasible and compatible with development of metric supply sources in the procurement base. Agency heads also direct the use of metric units for in-house design of equipment, in the development of regulations, standards, and specifications, in grant programs, and in the preparation of documents and data, consonant with the evolution of the capability of grantees and other users of data and reports to use metric units effectively. In addition, agency 
heads direct agency organizations to develop metric guidelines applicable to their specific mission responsibilities and make available metric training, where training will facilitate the Department's overall conversion to metric usage.

d) Agency Metric Managers. Agency Metric Managers are responsible for developing Agency Metric Transition Plans, which include specific milestones for implementation.

\section{Reporting}

The Secretary's Order assigns to agency heads the responsibility to report annually to the DOL Metric Executive on agency progress, problems, and plans related to conversion to usage of the metric system of measurement. The Metric Executive is required to oversee the preparation of DOL's Metric Transition Plan and progress reports, as well as the annual metric report to Congress.

\section{Exceptions to Metric Usage}

As appropriate, the agency heads request full or partial exemptions from or time extensions needed for compliance with the provisions of the Secretary's Order. Acceptable reasons are based upon the President's Executive Order. As Metric Executive, the Assistant Secretary for Administration and Management is responsible for reviewing agency requests for exemption and time extension requests.

\section{Transition Efforts}

It is the policy of DOL that its transition to the use of the metric system of measurement will encourage, assist, and facilitate the conversion to metric usage by public and private sector organizations, rather than exert pressure for change. Therefore, DOL agency conversion plans and schedules must take into account the impact on public and private sector usage organizations. DOL will effect its internal conversion to metric usage within budgetary allocations, and with minimum disruption of operations.

\section{DEPARTMENT OF STATE}

The Department of State has two concerns with metric measurement: the construction of diplomatic buildings abroad and the procurement of supplies for its establishments in all parts of the world. Supplies abroad are procured in local economies and are practically all in metric units, except, where procurement is from federal supply schedules.

\section{Directive}

The Department of State issued Procurement Policy Directive No. 10, Metric System Implementation Guidelines, on August 17, 1990. The policy was amended on December 10, 1991, to require written justifications when non-metric contracts that exceed $\$ 500,000$ are issued. 


\section{Responsibilities}

a) Metric Executive. The Metric Executive is the Assistant Secretary for Administration who represents the Department on the ICMP and ensures the implementation of P.L. 100-418. This oversight enables senior management with direct authority over the Department's contracting practices to coordinate metric usage effectively in contracts and business-related documents.

b) Metric Coordinator. The Metric Coordinator is responsible for developing guidelines consistent with ICMP policy.

c) Metric Steering Group. The Metric Steering Group is responsible for coordinating the dissemination of information within the Department to promote employee understanding and adoption of the metric system of measurement.

d) Foreign Service Institute. The Foreign Service Institute identifies, coordinates, and implements metrication training programs for Foreign Service and Civil Service employees.

e) Pubiic Affairs Office. The Public Affairs Office advises and assists, as necessary, in informing other Federal agencies and the public on issues concerning the Department of State metric conversion.

f) Office of Smail and Disadvantaged Business Utiilzatlon. The Office of Small and Disadvantaged Business Utilization is responsible for identifying any effect the Department's metric policy has on small business concerns.

\section{Reporting}

The policy directive stipulates that all heads of domestic contracting activities and regional bureau executive directors prepare annual metrication progress reports that quantify the extent of metric usage in all contracts, modifications, purchase orders, and other business-related documents. The regional bureau reports shall consist of consolidated metric information from at least ten randomly selected posts per bureau. Subsequent to the issuance of the amended metric policy, the Metric Executive implemented a quarterly reporting requirement for Fiscal Year 1992. Thirteen domestic contracting offices submit quarterly progress reports.

The Department's Metric Coordinator consolidates the reports and prepares the Department's annual metric report for the Assistant Secretary for Administration. The Assistant Secretary presents the final report to the Chief Financial Officer for submission to Congress as part of the annual budget.

\section{Exceptions to Metric Usage}

According to the policy directive, Contracting Officers are required to ensure that metric units are used in all contracts, modifications, purchase orders, and other businessrelated documents, to the extent practical. Furthermore, if the contract is expected to exceed $\$ 500,000$, the Contracting Officer is required to return statements of work/specifications that are not expressed in some form of metric terms to the program or requesting office that prepared the documents. An exception is made when 
the program or requesting office has forwarded to the contracting activity for approval, in a waiver format prescribed by the head of the contracting activity, a justification for the use of non-metric specifications/statement of work.

\section{Transition Efforts}

The policy directive contains the Department of State's Metric System Implementation Guidelines which serve as the planning instrument for its metric conversion. A synopsis of the guidelines' highlights follows:

a) Management Oversight. Effective October 1991, all contracts, modifications, purchase orders and other business-related documents are required to use metric units to the extent practicable. All State Department contracts that exceed $\$ 500,000$ must use metric units or a justification in the form of a waiver must be signed by the Contracting Officer. The extent to which waiver authority is invoked will be monitored by the chair of the Department's Metric Steering Group.

The policy directive requires metric usage considerations to be part of all acquisition planning so as to identify barriers to the use of the metric system in contract specifications. The extent to which the metric system is used in the preparation of specifications is considered an integral part of acquisition planning and early identification of metric usage is promoted during the planning phase of an acquisition. Announcements in the Commerce Business Daily are required to use metric units of measure.

b) Employee Training. The Department of State Metric Training Plan was developed to provide for training all appropriate employees no later than May 1992. Metric training has also been incorporated as part of the curriculum for all General Services Officers before assignment to overseas posts.

c) Construction. All new diplomatic construction is currently designed in metric units of measurement.

\section{Significant Developments}

a) Management Oversight. To date, no waivers to metric usage have been granted.

b) Empioyee Training. Approximately 100 specially selected employees have been trained under the Department's "Train the Trainers" program.

c) Construction. The Department of State is working closely with construction-related standards groups, as well as other federal agencies, to identify problems and processes necessary to adopt metric units in all Federal construction activities. The Office of Foreign Buildings has established a technical metric reference library and their master specifications are being revised to include metric considerations.

d) Industry Cooperation. Since August, 1990, it has been the Department's policy to recognize metric costs by private industry under negotiated contracting procedures. In addition, the Department's Small and Disadvantaged Business Utilization Office has 
been tasked to identify any effect metric conversion has on small business and to coordinate problems in this area with the Small Business Administration.

e) Embassy Property Acquisitions. The bulk of the purchases made at diplomatic missions are made from foreign vendors and manufacturers whose business practices require the use of metric measurements.

\section{DEPARTMENT OF TRANSPORTATION (DOT)}

Transportation programs in the Department of Transportation perform three functions: provide grants (mostly construction) to State and local governments, regulate the safety of all types of transportation, and perform direct services to the transportation sector, such as air traffic control and waterway navigation assistance. Nine separate agencies administer these activities covering land, sea, and air transportation.

The programs in the Department are measurement sensitive, including engineering specifications for construction, material standards and practices for safety regulations, and operating material and procedures for Department-operated systems. There are two major activities that may not be converted in the immediate future: (1) air traffic control and aircraft standards, in which worldwide usage is based upon U.S. standards and practices, and (2) material standards in railroad safety regulation, which are an established and well understood system of standards that are isolated in large part from world commerce and interchange, at least for now. All other programs are covered in the Department's plan.

Generally, transportation programs involve well-established technical systems and technical staff who are familiar with measurement standards and their conversion to metric units. These factors can facilitate metric planning and conversion. A difficulty arises from the co-existence of many diverse systems of standards and specifications governing all modes of transportation. Also, the Department's programs impact the large number of State and local governments and transportation-related private-sector organizations.

The metric plan of the Department consists of the nine operating agency plans. These plans were guided by a metric order that states a detailed policy and administrative framework and a set of guidelines. The Department as a whole is now in the process of implementing its conversion plans.

\section{Directive}

The Department of Transportation issued internal directive as Order DOT 1020.1D, "Department of Transportation Transition to the Metric System." The Order was supplemented by Departmental "Metric Conversion Planning Guidelines."

\section{Responsibilities}

a) Metric Executive. The Assistant Secretary for Policy and International Affairs is designated as the DOT Metric Executive and is charged with reviewing all actions associated with DOT's transition to the metric system. 
b) Heads of Operating Administrations. Heads of operating administrations prepare and recommend to the Secretary metric conversion plans for the administration, and upon approval are responsible for implementation.

c) Metric Coordinating Committee. The DOT Metric Coordinating Committee consists of a representative of each operating administration and Secretarial office. It coordinates metric activities in DOT and provides technical advice concerning metric plans and their revision.

d) Technicai Review Subcommittee. The Technical Review Subcommittee assists in the review and iteration of the metric conversion plans and advises the Metric Coordinating Committee on the plans.

\section{Reporting}

DOT Order 1020.1D specifies that metric conversion plans will be approved by the cognizant administration or office director. In addition, each administration metric coordinator forwards to the Assistant Secretary for Policy and International Affairs written summaries of progress on the completion of the plans and discussion of problems encountered.

\section{Exceptions to Metric Usage}

DOT Order 1010.1D, Attachment 1, "Guidelines for Metric Usage," calls for plans to identify excluded programs and provide a special analysis justifying those exclusions. The analysis is to be based on quantitative information and contain suitable analytical procedures for determining practicality, significant inefficiencies or loss of markets to U.S. firms.

\section{Metric Transition Plans}

DOT has delegated the development of specific metric transition plans to its operating administrations. Highlights of the individual plans follow:

a) Federai Aviation Administration (FAA). The FAA regulates U.S. aviation safety, certifies the airworthiness and safety of aircraft flying in the United States, operates the air traffic control system, and provides grants in aid to state and local airports. The metric conversion plan recognizes that international air traffic control is guided by the policies of the International Civil Aviation Authority (ICAO) which specifies the use of inch-pound units for altitude, distance, speed, and weight. This world-standard use of non-metric units is specifically exempted from the Metric Conversion Act in the Conference Committee report on the P.L. 100-418, section 5164 amendments to the Act. Metric issues are a concern in the following elements of the FAA program:

Transition Management. The goal is to establish the management framework for carrying out a program by which U.S. airports and airport equipment will be planned, designed, constructed, and installed utilizing the metric system of measurement.

Airport Standards and Advisory Standards. FAA intends to revise its advisory circulars (150 series) to provide metric units as the primary unit of measure. These circulars contain FAA airport planning, design, 
construction, and equipment standards, specifications, and technical information.

Airport Layout Plans. FAA plans to have all dimensions on layout plans for existing and planned runways and facilities within airport property boundaries in metric units.

Contract Drawings and Specifications. This will require all airport sponsors and their consultants to construct airport facilities and procure equipment with specifications that utilize metric units.

Education and Training. The development and implementation of a comprehensive metric education program that meets the needs of all FAA employees is required.

b) Federal Highway Administration (FHWA). The FHWA plan is an aggregation of the individual Metric Work Plans developed by the various FHWA headquarters offices for their program elements. Plan implementation is expected to be completed by Fiscal Year 1997.

In carrying out most of its metric responsibilities, the FHWA will be affected by its administrative and consultative arrangements with state highway organizations through the American Association of State Highway and Transportation Officials (AASHTO). In other cases, the FHWA will consult with other federal agencies such as the Departments of Agriculture and Interior on construction specifications for national forest, public land, and national park highways. The regulation of motor carrier safety will follow standard administrative procedures of notice, hearings, fact finding, and public announcement. The metrication effort is divided among the following program elements:

Engineering. Geotechnical design guidelines; hydraulic design guidelines; bridge specifications; national bridge inventory; bridge replacement and rehabilitation program; standard bridge plans; bridge inspector's training manual; highway geometric design standards; construction reports, cost estimates and data; pavement design standards; material sampling and testing standards; construction specifications; construction and maintenance.

Environment and Planning. Highway noise manuals; directives and manuals; environmental impact statement manual; seminar material and reports; computer programs for the highway performance monitoring system; computer programs for the national bridge inventory.

Rights-of-Way. States' right-of-way manuals; right-of-way plans; appraisal, acquisition, and relocation standards; highway beautification program standards and guidelines.

Highway Safety and Traffic Operations. Traffic signals and communications equipment; high capacity manual; highway safety program manuals and statistical reports; American Association of State Highway and Transportation Officials (AASHTO) roadway lighting standards; national maximum speed limit; traffic control devices; highway sign standards.

Technology Applications. Projects studies, programs, papers, and articles; procurement of equipment; manuals, reports, and computer programs; public awareness activities. 
Federal Lands Highway. Construction specifications; defense access roads; manuals, guides, and standards; computer programs; procurement of equipment and supplies; procurement of construction projects.

Motor Carrier. Commercial motor vehicle regulations; reports; motor carrier management information system; motor carrier safety assistance program; size and weight.

Offices of Policy. Highway statistics data collection and compilation; manual for highway statistics; computer program updates; seminar material; legislative change development; research and development; staff studies and contract studies; requests for proposals for contracts; testing apparatus; trust fund studies; publications; offices of administration; personnel and training; management systems; contracts and procurement; fiscal services.

c) Federal Railroad Administration (FRA). Highlights of the FRA metric transition plan include:

National Magnetic Levitation (Maglev) Initiative. FRA requires metric units as the primary units of measurement in solicitations for this initiative. In addition, language requiring metric units will be inserted into Maglev contract deliverables.

Research and Development. FRA will require metric units as the primary method of measurement in all new solicitations for analytical studies and for hardware development. This will include the Transportation Test Center (TTC) and the Transportation System Center (TSC).

Safety Program. FRA is determining the feasibility of requiring metric-only in its regulations for the safe operation of freight and passenger trains. If determined to be impractical, FRA would make recommendations for exclusion from the purview of the metric legislation.

Local Rail Freight Assistance Program (LRFA). The LRFA program deals with federal grants to fund the operation of local freight assistance. It establishes procedural requirements that must be adhered to by state agencies seeking grants for the acquisition of rail lines, track rehabilitation, and rail facility construction. The FRA will be analyzing the regulations to determine if exclusion from metric usage is warranted.

Title V Loan Guarantee Program. FRA will analyze the feasibility of requiring the use of the metric system in its regulations for guaranteeing loans to the freight railroads. The loan guarantees are for supporting freight car and locomotive rehabilitation programs and track upgrading projects.

National Railroad Passenger Corporation (Amtrak). The objective of this task is to determine if the metric system should be used in Amtrak's procurements that are funded by FRA grants.

d) Maritime Administration (MARAD). The MARAD plan consists of a combination of the program element plans prepared by the individual MARAD offices. The plan element descriptions and objectives are:

NATO Mobilization Planning. This element involves the preparation of civil plans for NATO merchant shipping during war periods. The NATO Sealift Ship List and DSA Vessel Standby Inventory will be maintained in the metric system. 
Maritime Aids--Ship Subsidy Programs. This goal is to perform metric conversion of measurement characteristics in Ship Financing, Construction Reserve Fund, Capital Construction Fund, Construction Differential Fund, and Operating Differential Fund applications and related publications. It also includes the conversion of all other Maritime Aids publications such as the Financial Report Form MA-172, and vessel and trade publications.

Shipbuilding. This element involves the conversion to the metric system in four sub-areas: Data collection and dissemination; development of published guidelines; assistance for building ships; procurement of new ships and conversion work.

Ship Operations. This program area involves metric conversion for the following sub-areas: ship repair; ship activation and deactivation; ship operations; ship-related services; ship acquisition.

Market Development. Two statistical databases under the Office of Market Development use the metric System: National Cargo Shipping Analysis System (NCSAS) and Ocean Freight Differential System (OFD).

Port Development. All contractual studies on improved port planning, productivity enhancement, and facilitation of commerce will be published using only metric units; the Maritime Statistical Information System will be reviewed for metric usage.

Research and Development. Beginning in 1992, all research reports will be published using both inch-pound and SI units; by 1997, all research reports will be published in only metric units.

U.S. Merchant Marine Academy. In the areas of math and sciences, and especially in physics and chemistry, all students will have instruction in and be familiar with the metric system standards to the extent necessary for success in those areas. Because at this time the Accreditation Board for Engineering and Technology ( $A B E T)$ requires that all instruction in the engineering area be conducted using the dual measurement system, textbooks discuss issues and contain problem sets involving both inchpound and metric dimensions. Since an increasing number of metric vessels are being introduced into the fleet, shipboard training and preparation for the "sea year" involves continuing metric indoctrination. Similarly, as the navigational charts are converted to the metric system, additional training will be conducted. The Academy intends to purchase its military uniforms according to metric sizes.
e) Nationai Highway Traffic Safety Administration (NHTSA). NHTSA's primary mission is to reduce the number of fatalities and injuries resulting from motor vehicle crashes. To accomplish this, NHTSA promulgates Federal Motor Vehicle Safety Standards (FMVSS). NHTSA works with the state governments to improve traffic safety at the state and local levels through grants and demonstration programs. It also enforces the FMVSS and conducts research to support the agency's programs.

Due to the complexity of addressing the highway safety problems, NHTSA has adopted a multi-faceted approach for implementing its metric transition. Each facet affects a different constituency and considers the requirements for these groups.

For the groups already acquainted with the metric system, hard conversion will occur in a relatively short time frame. For the remainder, a dual system will be used with complete conversion occurring after an extended time period. 
The following are brief descriptions of the NHTSA programs and transition plan highlights:

Rulemaking. Federal Motor Vehicle Safety Standards (FMVSS) issued after May 8, 1992 will be based on the metric system whenever possible. All regulatory actions, in order to prevent degradation of safety, will utilize administrative procedures.

Research and Development. All research contracts are to be issued using metric units. As of May 8, 1992, metric units will be used in all reports, papers, and other documents except for issues concerning highway speed limits. The Office of Crashworthiness Research. The signal analysis software was modified, tested, and operational on March 1, 1992. This includes a pre-processing program to convert time history files to metric units and a new subroutine to ensure that correct units and scales are used. On-line database resources are to be converted by March 1, 1992. These include: Safety Performance Databases, Vehicle Database, Component Database, Biomechanics Database, and Crashworthiness State Database. The Vehicle Research and Test Center (VRTC) is able to generate data in the whatever measurement units are used by the respective databases (metric and/or inch-pound). The National Center for Statistics and Analysis, Math Analysis Division, is to use metric units in its work beginning May 1991; the Accident Investigation Division, responsible for collecting crash data, will convert to metric standards over a 3-year period beginning in FY '92; the Office of Driver and Pedestrian Research's research and development efforts in support of traffic safety programs will be converted according to the overall R\&D schedule; and the Office of Crash Avoidance Research used metric units since May, 1991.

Enforcement. Metric conversion will require the revision of all investigative and contract reports, test notes and reports, briefings and presentations, and test procedures. Test procedures will be converted to metric units within a 3 to 4 year period after conversion of the corresponding standard(s).

Traffic Safety Programs (TSP). TSP's transition will primarily involve the occasional reference to weights and measures contained in TSP publication material. TSP's implementation will be in three phases: Phase I - From May 8, 1992 through May 7, 1994, new documents will include inch-pound units as the primary value, followed by the metric equivalent appearing in parenthesis. Phase II - From May 8, 1994 through May 7, 1997, new documents which contain weights and measures will include the metric measurement as the primary unit, followed by the inch-pound equivalent appearing in parenthesis. Phase III - After May 8, 1997, all documents prepared by TSP which contain weights and measures will include only the metric value. All reprinted documents will be revised to reflect the metric measurements even if other substantive modifications are not required.

Regional, State, and Local Offices. The metric transition for the Regional Offices will follow TSP's schedule. The 402 grant program which is managed through the Regional Offices will involve additional demands placed directly on the States and local governments. These requirements apply to their grant applications and Annual Highway Safety Program which will be contained in the 402,408 , or 410 grant agreements and guidance that is provided to the grantees. 
Excluded Programs. Fuel Economy Standards: Title $V$ of the Motor Vehicle Information and Cost Savings Act (Improving Fuel Economy), 15 U.S.C., Section 2001, et seq., requires motor vehicle manufacturers to meet corporate average fuel economy (CAFE) standards, as set forth in the statute, or as determined by the Secretary of Transportation. The statute specifically defines fuel economy in inch-pound units; accordingly, CAFE standards will be inch-pound units. Odometer Disclosure Requirements: Title IV of the Motor Vehicle Information and Cost Savings Act (Odometer Requirements), 15 U.S.C., et seq., prohibits the tampering of odometers and establishes safeguards for the protection of motor vehicle purchasers by requiring written disclosures of the mileage in connection with the transfer of ownership of the vehicles. The statute governs the actions of individuals possessing the vehicle, not the vehicle itself. A change to kilometers would require that every odometer in every vehicle would have to be converted.

International Standards. Changing to the metric system is expected to enhance the agency's harmonization program.

Private Sector Considerations and Impacts. NHTSA's primary impact on the private sector is through regulations that affect the manufacturing of motor vehicles. This is now largely accomplished using metric units. Additional impact provided through its programs that communicate safety messages to the general public. These instruments will use the dual system during the seven year transition period. Accordingly, this should be a reasonable time for the general public to be accustomed to the metric units.

f) Research and Special Programs Administration (RSPA). Highlights of RSPA'S transition plan are organized according to the following subunits:

Office of Hazardous Materials Safety. This Office carries on a national safety program and oversees the regulations and regulatory actions governing the safe transportation of hazardous materials. Much of the metric conversion of Hazardous Materials Regulations has been completed. Research contracts are to be written to request the use of SI measurements for study findings and reports. Training needs include conversion tables and brief staff training with minimal budgetary impact. The republication of some RSPA informational material will also be necessary.

Office of Pipeline Safety (OPS). The OPS carries out a national regulatory program for the safe transport of hazardous materials by pipeline. It also issues grants to State pipeline organizations. The OPS will be making metric changes in the following areas: Pipeline safety regulations, reporting and record keeping, forms and checklists, and publications.

Office of Emergency Transportation. This office, which overseas the transportation civil emergency preparedness and response policy and plans, recommends a dual measurement system until all locations and dimensions of assets and facilities are converted.

Office of Airline Statistics (OAS). The OAS collects, disseminates, and retains air carrier financial and operating statistics in support of major DOT programs. To determine the extent and impact of conversion, OAF intends to perform surveys of airline data users (OAS, FAA, RSPA, other Government agencies, and the private sector) and the providers (airlines). Regulations are to be revised, as well as OAF manuals, documents, 
publications, and computer systems. Historical databases will also require revision to accommodate trend analysis. Also, training will have to be provided to users of airline data. Furthermore, careful attention will be necessary with the coordination of FAA safety monitoring systems and the revised RSPA data collection system.

Office of Research Policy and Technology Transfer. This Office conducts a program of research and development and disseminates the technical information to the transportation community. As part of the effort, the radionavigation and communications programs are already using SI measurements.

Transportation Safety Institute (TSI). TSI serves as the primary source for DOT safety and security training and technical assistance. Since the sponsoring DOT agencies are responsive to the respective industries that it serves, the training criteria is defined by their needs. TSI's metric transition will be driven by the FAA conversion plan.

Office of Automated Tariffs. The Office of Automated Tariffs is responsible for air carrier tariff filings which are subject to various inch-pound standards contained in CFR 221, Tariffs. These regulations are followed by the airlines when requesting approval for tariffs. Consultation with the Airline Publishers Company and the International Air Transport Association will be required concerning the conversion. The automated computer program for filing international airline tariffs that is used by the Airline Publishers Company is excluded. RSPA will apply for an exception in accordance with the Executive Order. Furthermore, the term "Maximum Permitted Mileage" (MPM) is recognized worldwide to construct fares between any two points in the world.

Office of University Research and Education. The Office of University Research and Education acts as the point of contact with the academic community for RSPA and DOT. It administers and monitors the University Transportation Centers Program and awards grants under the Surface Transportation Act. Currently, there are no grant requirements for the use of the metric system; however, new guidelines are being drafted for the next generation of grants. The performance requirements for metric conversion of units set forth in DOT Order $1700.18 \mathrm{~B}$ will apply for the publication of scientific and technical reports.

g) Saint Lawrence Seaway Development Corporation. Since 1975, water flows, water levels, water temperatures, and ice thickness in the Saint Lawrence Seaway have been recorded in metric units as requested by the International Joint Commission. In addition, water usage and regulated data have been in metric since that date. In 1977, the Corporation converted its operational activities to the metric system. Accordingly the Seaway Regulations and notices to mariners have been published using metric units. The affected measurements are: cargo volumes, vessel dimensions, vessel drafts, lock dimensions, mileage markers, bridge signs, and lock wall markings. In addition, the navigation charts for the seaway have been converted to metric units by the National Ocean Service of NOAA and Canadian Hydrographic Services and are in the process of being printed.

h) Federal Transit Administration (FTA). Due to the nature of the major activities in which FTA is involved, it plays a major role in providing guidance for metrication rather than requiring conversion through rule making. Due to its multi-national markets, much 
of the industry that supports FTA has been actively converting to the metric system. Elements of the FTA plan are as follows:

Office of Grants Management (UGM). UGM collects data and apportions funds largely based on various size and distance measurement parameters. Currently, grant applications indicate vehicle, passenger, and fixed guideway route distances in miles. FTA's computers process and store this data in that form. To accommodate conversion, revised letters of intent to potential grant applicants will be issued, Circulars describing the new metric requirements will be required, and training in the use of the new system will be necessary.

Office of Technical Assistance and Safety (UTS). UTS is responsible for coordinating FTA's implementation. Since its information systems are principally maintained using the Section 15 reports, the converted data will appear as the using offices update their reports.

i) U.S. Coast Guard. The Coast Guard's metric conversion plan is based on 13 defined operating tasks, each with organizational provisions, definitions of actions required, statements of scheduled completion and goals, and responsibility for implementation and reporting. The following is a summary of the Coast Guard's task completion dates:

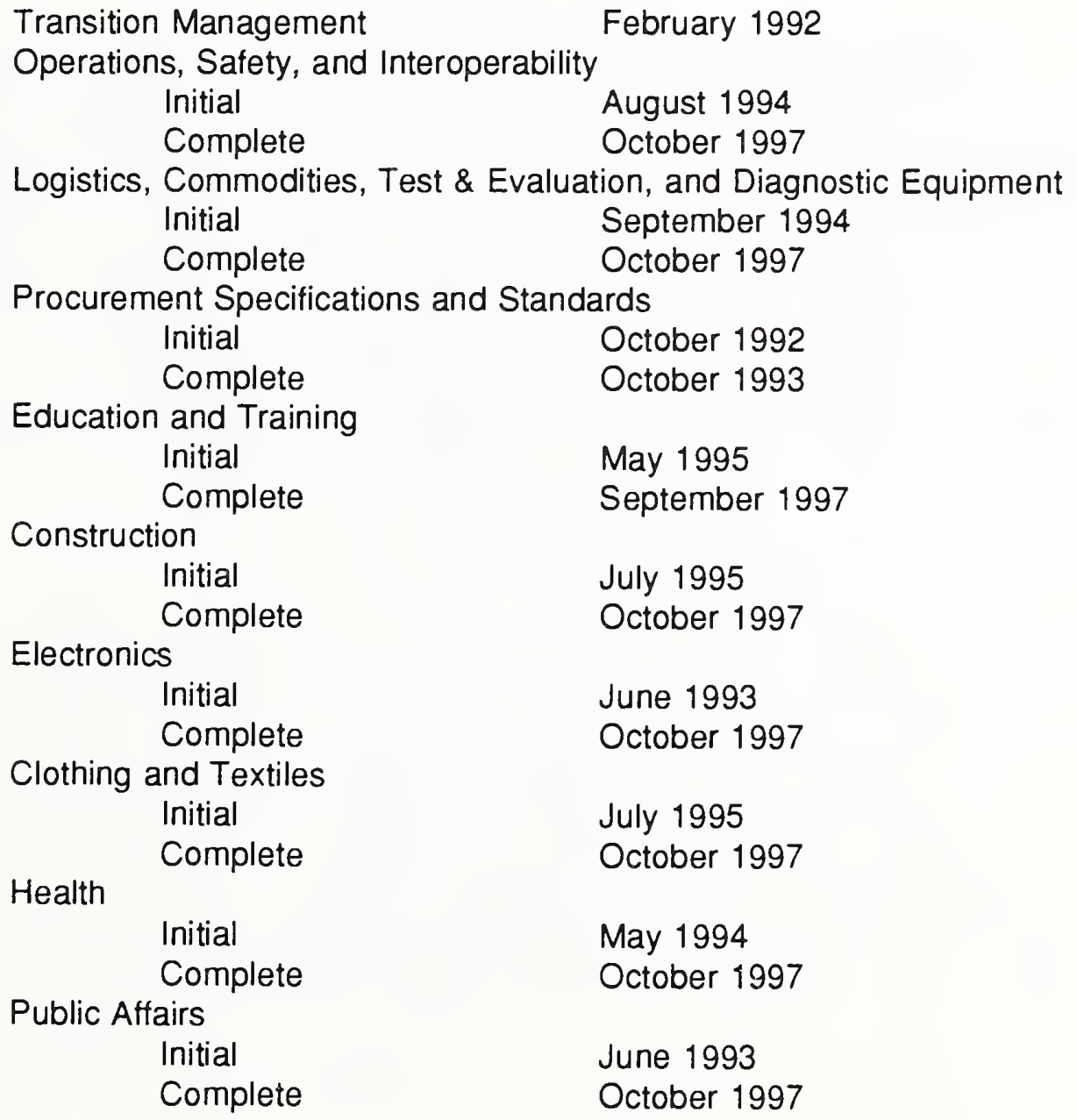


Metrication Handbook

Initial

Complete

Food

Initial

Complete
October 1992

October 1993

October 1993

October 1994

\section{Significant Developments}

a) The Federal Avlation Administration (FAA) will revise its procurement process in fiscal year 1992 to ensure that metric measurements are used as required, unless appropriate justification is provided. A Quality Action Team will be considered to deal with problems in this area. The FAA will periodically meet with industry associations to discuss problems in implementing metric policy. Program and contracting officials will be educated through the use of training sessions, teleconferences, and updates on progress in awarding metric contracts.

A primary area of activity in the FAA is the provision of grants for airport development. Action has already been taken to begin voluntary conversion to the metric system. This has been achieved during preparation of advisory circulars used by airports to design and construct airport projects with grant assistance.

The primary business-related activity of the FAA is the operation of the air traffic system and regulation of the aviation community. The international community has recognized U.S. customary standards and the U.S. has maintained the position that any proposed procedural change should be in response to a clearly defined problem. To date, the use of the non-international system of units (the foot and the nautical mile) has not been perceived to be a safety problem. To the contrary, safety problems could arise during the transition phase to the metric system, especially in the cockpit when converting measurements of height, altitude, and elevation. Consequently, the FAA has no plans at this time to support metric conversion, domestically or internationally through ICAO. Nevertheless, the Research and Development Service plans to conduct a safety impact study on metric conversion in cooperation with the Office of Safety Oversight. As the manufacturing sector of the aviation industry undergoes transition to the metric system, the FAA will accommodate metric measures in aircraft specifications as new aircraft are certified.

b) For the Federal Highway Administration (FHWA), two significant developments have occurred that are favorable to metric conversion of the highway program. First, Congress, in the Intermodal Transportation Authorization Act removed all restrictions on the use of metric measures on highway signs on Federal aid highways. FHWA is considering the complex factors involved in highway signing, including dual metric and inch-pound signing, the rounding off of speed limits in highway signs, amendments to the Manual on Uniform Traffic Control Devices and other traffic standards, public education, and traffic laws. The second development is the formation of a task force with AASHTO to review engineering specifications and federal aid regulations with respect to the use of the metric system in state highway construction where federal aid is authorized. 
c) The Federal Raliroad Administration (FRA) is already requiring the metric system as the primary measurement system for its research and development contract solicitations. The FRA, as the lead agency in the National Maglev Initiative, is requiring metric units of measurement. In solicitations for contracts, SI has been identified as the preferred measurement system. Responsive bidders are required to submit proposals in metric units, but are allowed to include the inch-pound equivalent in parentheses. Contract language will require metric units in all deliverables.

To determine whether FRA safety regulations should be excluded from a metric-only standard, it has requested data from the American Association of Railroads (AAR), the American Short Line Railroad Association (ASLRA), and the Regional Railroads of America (RRA), on the costs and benefits to the railroads of complying with FRA regulations published in both metric and inch-pound. The Railway Progress Institute (RPI), which is a trade association of railroad equipment suppliers, has been asked to provide similar information with respect to the equipment supply industry. RPI has been specifically asked to respond to the issue of metric impact on international competitiveness of railroad suppliers. The Local Rail Freight Assistance Program (LFRA) will be analyzed to determine if its regulations warrant exclusion from conversion to metric. The FRA has requested information from the ASLRA, RRA, and the National Conference of State Railway Officials (NCSRO) on the impact of the conversion. Also, FRA has requested assistance from Amtrak in evaluating the use of metric standards in Amtrak procurements funded by FRA grants.

d) To accommodate any future ship construction in the U.S., the Maritime Administration (MARAD) will complete a metric version of the Standard Specifications for Merchant Ship Construction by July 1994, develop a list that will differentiate metricbuilt ships from inch-pound-built ships to facilitate replacement part tracking, compile an inventory of ships whose fathometers are inch-pound only and will be targeted for replacement; convert cargo weight data in all database systems (pending a determination by MARAD's Associate Administrator for Maritime Aids and Office of Information Resources Management); include in all in-house, contractual, and cooperative study solicitations a provision for utilizing metric units in the final report; make program modifications to the Maritime Statistical Information System (MSIS) to permit the capture and display of metric data as it relates to port development.

e) The Nationai Highway Traffic Safety Administration (NHTSA) will base Federal Motor Vehicle Safety Standards (FMVSS), whenever possible, on the metric system. During the period before May 7, 1997, an orderly review will be performed on all FMVSS's currently in force. This review will be the basis for scheduling revisions to Standards in the upcoming years. For those cases where the conversion to an equivalent metric unit results in slight changes to the performance levels of the FMVSS, a composite rulemaking will be undertaken in the subsequent year if feasible. Odometer disclosure and fuel economy standards are not scheduled for conversion at this time. All new investigative reports, test and survey reports, contracts, and other documentation will be issued using metric equivalents. Traffic safety programs, including grants to state safety agencies, will undergo a less aggressive conversion than motor vehicle programs. The traffic safety programs to be converted are the workshop material, training course curricula, and public information material, etc. A dual system will be in place during the 5-year, May 8, 1992 through May 7, 1997 transition period and will use equivalent rather than exact metric units. After 1997, all new material will exclusively use metric units. All research reports, contracts, papers, 
etc. will contain metric equivalents. All research and development efforts are to be in metric by May 7, 1997. Originators of the Statements of Work (SOWs) will issue contract provisions using metric units. On April 21, 1992, NHTSA published a Federal Register Notice requesting public comment on its metric conversion proposals.

\section{f) In June 1992, the Research and Speclal Programs Administration (RSPA),}

published a notice in the Federal Register inviting public comments on all aspects of its metric conversion plan. On January 1, 1991, RSPA announced that all U.S. regulations on the transportation of hazardous materials were aligned with international rules based upon United Nations recommendations. A five-year phase-in period is allowed.

g) The Saint Lawrence Seaway Development Corporation (SLSDC) will expand the use of the metric system in its Lock Operations and Marine Services area. A listing of metric units to be implemented will be developed in cooperation with the Saint Lawrence Seaway Authority and mariners is scheduled for September 30, 1992. SLSDC will determine which supplies and materials are available in metric units and could be accepted for lock structures, aids to navigation, building and grounds, etc. SLSDC projects that by September 30,1992, it will establish acceptable metric design requirements for SLSDC structures. Starting in FY '92, procurement specifications will be written using a dual system with inch-pound taking the primary position. In FY '93, metric will take the primary position. Starting in FY' 94 , and if no major problems are encountered, metric-only measurements will be used. A similar policy will be in effect for the preparation of reports, letters, mernoranda, etc.

h) The Federal Transportation Administration (FTA) has inaugurated consultation with public transit organizations concerning transition to the metric system in the use of federal transit aid. On March 19, 1992, FTA published a Notice of Proposed Policy in the Federal Register. Comments on likely costs, service life of transit rolling stock, and the use of metric measures in the evaluation of land purchases are being assessed.

j) The U.S. Coast Guard has constructed 37 fully metric Island-Class patrol boats. Among other equipment, rigid-hull inflatable boats carried on the Island-Class and similar boats are designed to metric specifications, as is the Mk 75, Oto Melara $76 \mathrm{~mm}$ high speed cannon, a $25 \mathrm{~mm}$ machine gun installed on Island-Class boats, HH-65 helicopters, and Falcon jets (which are designed in metric units, but may include inchpound equipment and engines).

\section{DEPARTMENT OF THE TREASURY}

Although the Department of the Treasury has a limited range of measurement-sensitive activities, some of its bureaus are concerned with specific measurement-sensitive activities. For example, the Mint and the Bureau of Engraving and Printing are concerned with the technical dimensions of materials. The Customs Service is concerned with the weights, measures, and values of goods and services in international trade, thereby encountering regularly packages and documents that are stated in metric units. Other bureaus, such as the Internal Revenue Service, Bureau of the Public Debt, and Savings Bond Division are financial bureaus concerned with dimensions of documents and statistical presentations. (The IRS is probably the second largest document-printing organization after the Government Printing Office.) 
The Bureau of Alcohol, Tobacco, and Firearms is concerned with the measurement sensitivity of firearms and other products through its legal status and excise tax collection activities. The Secret Service deals with crime, fraud, and violence, which have complex measurement and evidentiary aspects.

\section{Directive}

Treasury issued its Directive 75-05 on July 31, 1991, "Department of the Treasury Metrication Program." In addition, Treasury's Office of Procurement published Procurement Instruction Memorandum No. 92-01 which stipulates the Department's metrication requirements as they relate to the Procurement function. Furthermore, the following Treasury bureaus have issued individualized directives to supplement the Treasury Directive:

Comptroller of the Currency (Policy and Procedures Manual, PPM-3120-36, Metrication, October 1, 1991);

Bureau of Engraving and Printing (BEP Circular 92-00-7, August 1, 1990); Internal Revenue Service (Internal Revenue Manual, 12(11)7, Metrication Program, December 13, 1991);

U.S. Mint (Mint Directive Memorandum-13, Metrication in the U.S. Mint, January 6, 1992);

U.S. Savings Bonds Division (Directive No. 70-06.17, Initial Metric Transition Plan, October 1, 1991);

\section{Responsibilities}

a) Metric Executive. Treasury Directive 75-05 designates the Assistant Secretary (Management) as the Metric Executive who is responsible for providing policy and direction for the Treasury Metrication Program.

b) Heads of Bureaus. The head of each Treasury bureau is responsible for implementing the provisions of Treasury Directive 75-05; designating a senior management official to have continuing staff responsibility for the bureau's metrication program; developing supplemental transition plans, if appropriate; and establishing bureau metrication coordinating committees.

c) Departmental Metrication Coordinating Committee. The Coordinating Committee consists of the Departmental bureau metrication officers and is responsible for the development and implementation of the overall Departmental Metric Conversion Plan. It also oversees the developments of the Treasury functional subcommittees; reviews policy issues for the Metric Executive; and recommends approval or disapproval of exceptions to metric usage.

d) Treasury Functionai Subcommittees. The Departmental Metrication Coordinating Committee has established six functional subcommittees to develop and implement transition goals that apply to specific functional areas common to all of the bureaus. The subcommittees are Transition, Procurement, Logistics, Publishing, Training, and Public Affairs.

\section{Reporting,}


The Deputy Assistant Secretary (Administration), bureau heads, and the Inspector General shall submit:

An annual report by November 1, of each year that includes significant metric accomplishments, milestones, or other information for the previous fiscal year; significant problems encountered; and actions planned for the current fiscal year; and

An initial metric transition plan for the bureau or office that incorporates the requirements of the law, to be approved by the Assistant Secretary (Management).

\section{4) Exceptions to Metric Usage}

The Treasury Metric Conversion plan stipulates that exclusions to the Department's metric policy must be authorized by the Assistant Secretary (Management).

\section{5) Transition Pian}

On November 27, 1991, Treasury submitted its Metric Conversion Plan which provided the Department's overall strategy, requirements, milestones, and tentative accomplishment dates. For the most part, the bureaus have prepared individualized conversion plans to supplement the Departmental plan and accommodate actions that are specific to the bureaus.

Since Treasury is primarily a finance-driven agency, its output is minimally measurement-sensitive. However, due to the scope of its mission, Treasury's supporting elements could have a significant impact on metrication in the electronics and publishing industries. Furthermore, Treasury is a participant in trade and competitiveness issues. Accordingly, it has recognized the important relationship of metrication to the other factors in the global economic equation.

a) The overall Treasury Metric Conversion Pian is categorized into six functions, each of which, is representative of the actions planned by the Departmental Metrication Coordinating Committee's functional subcommittees. The plan's milestones (and accomplishment dates) are:

Transition

(Completed)

Establish Departmental and bureau metrication programs

Establish functional subcommittees (Completed)

Determine Departmental record-keeping and reporting requirements $(9 / 30 / 92)$

Training

Assess bureaus' functional training needs (9/30/92)

Design the metric training methodology (9/30/92)

Develop the training materials (10/30/92)

Conduct metrication training (To be determined)

Evaluate training tracking system (To be determined) 
Logistics

Coordinate plan elements with Federal oversight agencies

(Completed)

Revise bureau directives, guidelines, regulations, and publications to include metric policy, procedures, and dimensions (9/30/94)

Advise the private sector of planned metrication policy and

Procurement procedural changes $(9 / 30 / 92)$

Advise bureau procurement personnel of metric policy (Completed)

Adopt procedures to foster the use of metric standards in the procurement function (9/30/92)

Establish communication with the private sector concerning procurement metrication initiatives of the bureaus (Ongoing)

Publishing

Assess the status of metrication in the printing and paper

Public Affairs manufacturing industries $(9 / 30 / 92)$

Inform the public of metrication developments (Ongoing)

b) In the bureau transition pians, the bureaus have supplemented the Departmental plan by incorporating the milestones and accomplishment dates into their individual plans. However, several have expanded or refined the tasks to accommodate metric initiatives that are unique to the particular bureau. The Treasury bureaus with mission-specific plans are include Alcohol, Tobacco, and Firearms, Customs Service, Comptroller of the Currency, Engraving and Printing, Internal Revenue Service,

\section{6) Significant Deveiopments}

a) The Director of Printing and Graphics is Chairman of the interagency Ad Hoc Committee on Metric Usage in Federal Publications. This committee is charged with surveying the Government agencies and printing and paper manufacturing industries to determine the best approach for the Governments' printing and publishing transition to metric standards.

b) Aicohoi, Tobacco, and Firearms (ATF) has been actively involved with the metric conversion of the industries for which it has regulatory oversight. The distilled spirits industry has been using metric measurements for quite some time. In addition, law enforcement officers are increasingly being equipped with weapons and ammunition designed to metric specifications. Also, more tobacco products are being sold in metric measures.

c) The Office of the Comptrolier of the Currency (OCC) distributed metric information advising vendors that the U.S. Government has begun converting to the metric system. Included is a statement that beginning in June, 1992, all OCC procurement specifications will be expressed in dual measurement values.

d) The U.S. Customs Service already mandates hard metric measurement input into its database for classifying goods moving in international trade. Since 1988, the 
Custom's Harmonized Commodity Description and Coding System and the United States Tariff System, better known as the "Harmonized System," requires all exporters and carriers to classify and report all products and commodities coming into this country using metric measurements only. The automated data base supporting the Harmonized System, called the Automated Commercial System or ACS, processes all of its customs and tariff calculations in metric units with the exception of its manifest or "bills of lading" information. Customs still allows the reporting of manifest data in inchpound and metric measurements.

e) The Bureau of Engraving and Printing (BEP) is actively engaged in the process of converting its manufacturing equipment to metric specifications. Currently, the majority of the presses that print BEP's principal products, currency and postage stamps, are manufactured to metric specifications. As replacement by attrition of auxiliary equipment dictates, conversion to metric standards will be given top priority.

f) The Internal Revenue Service (IRS) has assigned a full-time Project Manager to implement its metrication transition plan. In its procurement efforts, metric standards and specifications are to be included in the IRS information systems acquisitions related to the "Tax Systems Modernization" program. Accordingly, IRS will be revising its acquisition procedures to require a metric conversion analysis in its Source Selection Plans for major Federal Information Processing (FIP) acquisitions over $\$ 20$ million and in its advanced procurement planning phases for anticipated procurements exceeding $\$ 50,000$. Based on an IRS request, Treasury will include metric information as part of its fiscal year 1993 Forecast of Contract Opportunities. IRS is compiling a list of anticipated contract awards over $\$ 25,000$ to identify measurement-sensitive procurements. Also, IRS has revised its requisition form to accommodate metric products and specifications.

In the publishing area, IRS intends to issue one of its tax form instruction publications using metric-sized (A4) paper instead of 8-1/2 inch by 11 inch paper. This should provide a preliminary assessment of the printing and publishing industries' capability to convert to metric standards. IRS is assisting in the Government Printing Office assessment of the impact of converting to standard metric paper sizes. If the commercial paper and printing industries can economically supply the needed products, IRS intends to make a conversion to metric sizes in all its paper-based products.

In logistics functions, IRS has inventoried its measurement-sensitive directives relating to space, property, security, and records management and has identified items for conversion in the next document revision cycle. Measurement-sensitive items in its administrative manual will be converted to dual measurements as the portions are revised, except for certain key items that are being immediately revised.

IRS has developed an orientation program to train all contracting officers. A metric training profile will be used to identify staff requiring metric training. In addition, the agency purchased a metric conversion software package for its technical program and contracting personnel.

IRS published its detailed Metric Conversion Plan as a notice in the Federal Register. 
g) The U.S. Mint already uses hard metric weights for its penny, nickel, and dollar coins. It will also be pursuing metric conversion initiatives in the areas of other coinage metals, strip and blank fabrication, tool steels, carbide collar fabrication, chemicals, and purchased equipment components (motors, shafts, gauges, bearings, fasteners, etc.).

h) The U. S. Secret Service procures weapons for its law enforcement personnel and ammunition for the entire Department designed to metric specifications. It is increasingly utilizing dual measurement values in other procurement specifications.

i) The Office of Thrift Supervision has incorporated a metric notice in all small purchases and contract awards. It has conducted a metric awareness program for its staff, including an electronic sign giving the temperature only in degrees Celsius for its courtyard. It has purchased and distributed Metric scales, weights, and measuring devices.

\section{DEPARTMENT OF VETERANS AFFAIRS (VA)}

The Department of Veterans Affairs has significant involvement with metric measurements through three of its principal activities: hospital construction and management, provision of medical care and drugs, and management of the national cemetery system. These activities involve measurement-sensitive standards and criteria in construction, drugs and medical devices, and real estate management. Although another major activity, payment of veterans' benefits, consists primarily of financial transactions, veterans' housing loan guarantees involve the Department in housing standards in a manner similar to the way the Department of Housing and Urban Development is involved through its mortgage guarantee programs. This may also involve the Department in some issues of the residential construction industry.

\section{Directive}

The Department of Veterans Affairs (VA) Circular 00-92-11, "Metric Transition Plan and Policy," is dated May 18, 1992. The VA's intentions were published in the Federal Register on June 25, 1992.

\section{Responsibilities}

a) Metric Executive. The Circular designates the Deputy Assistant Secretary for Acquisition and Material Management as the Metric Executive who ensures the implementation of P.L. 100-418.

b) Metric Task Group. The Circular establishes the Metric Task Group to formulate metric policy for approval of the Metric Executive. This Group will develop the Department's guidelines and interpretations and assist in achieving a uniform and coordinated approach for implementing the requirements of the law.

c) Metric Coordinators. Metric Coordinators will be designated by affected Administration Heads, Assistant Secretaries, and other key officials. 


\section{Reporting}

The Circular stipulates that Field Facility Directors shall submit their reports to appropriate Administration Heads who will forward them to the Metric Executive. The Department-level Metric Coordinator consolidates the reports and prepares the annual Veterans Affairs Metric Report for concurrence by the Metric Executive. The Report is then forwarded to the Assistant Secretary for Acquisition and Facilities who presents it to the Secretary for submission to Congress as part of the annual budget.

\section{Exceptions to Metric Usage}

The Deputy Assistant Secretary for Acquisition and Material Management (Metric Executive) is responsible for approving exemptions for all categories of items (except for new construction and renovation projects) and services that require conversion to the metric system of measurement. The Deputy Assistant Secretary for Facilities will be responsible for approving exemptions for new construction and renovation projects, in part or total, from the conversion.

\section{Transition Efforts}

The Department's Metric Transition Plan appears as an Attachment to the Circular. The basic strategy is to require maximum practical use of SI units for those medical devices and supplies where the Department is the federal procurement manager, and to work with their suppliers of other products and services to strongly encourage their transition to predominately metric usage.

The plan is organized into seven major tasks. The responsibility for implementing the tasks is delegated to the various Department offices. The planned tasks involve:

Transition Management, which coordinates the conversion efforts and monitors progress towards the metrication goals;

Education and Training, which develops and implements a comprehensive metric education program, including briefing materials for VA personnel;

Specifications, Standards, and Grants, which identifies and converts measurement-sensitive documents to SI units and examines grants for research, development, and education for potential metric usage;

Construction, which reviews new construction or major renovation projects to determine the feasibility of using metric dimensions for installation of materials and repair parts;

Small Businesses, which develops procedures and techniques to assist industry, especially small businesses, as they voluntarily convert to the metric system;

Internal, Congressional, and Public Affairs, which assists with the internal and external communication of metric information, including evaluating appropriate modes of presentation and reviewing the proposed production of print or visual items and their targeted distribution; and 
Veterans Affairs Metrication Handbook, which provides guidance to Department acquisition offices based on experiences of organizations currently acquiring metric supplies and services.

\section{Signlficant Developments}

a) Contract Speclfications. VA has included either metric units or a clause indicating acceptable metric measurements in all new or revised $X$-series (Department of Veterans Affairs) specifications and Department-prepared commercial item descriptions.

b) Metric Acceptability Clause. VA developed a metric acceptability clause to comply with requirements contained in the Code of Federal Regulation, 50 C.F.R. 27578. The clause permits the acceptance of metric products when their dimensions are contained within the tolerances specified in the specification document. The metric acceptability clause has been adopted for use in Federal Supply Group 65 (Medical, Dental, and Veterinary Equipment and Supplies) standardization documents that are jointly managed by the Department and the Defense Personnel Support Center. The clause is also included in standardization documents under the shared procurement program with the Department of Defense and the Public Health Service.

c) Federal Item Identlficatlon Guldes (FIIG). When submitting new items to the Defense Integrated Data System, the Department includes metric units as required by the FllG. The majority of the FllGs used by VA have been changed to include SI units in reply tables.

d) Computerized Supply System. In the Department's automated supply system, metric units are added to the expanded product descriptions when industry provides metric units in its supplies literature.

e) Decentrallzed Hospltal Computer Program. The incorporation of metric functionality has already been achieved in some of the hospital computer program modules (e.g., vital signs in the nursing package and the clinical portion of the dietetics package). Efforts are now underway to determine the feasibility of converting the production portion of the dietetics module.

\section{CENTRAL INTELLIGENCE AGENCY}

The Central Intelligence Agency (CIA) is involved with the metric system mainly through procurement of supplies and construction. The task is straightforward, and fully controlled of the Agency. There does not appear to be any measurement sensitivity in its classified intelligence work.

\section{Directive}

The CIA issued its Metrication Transition Plan to provide guidelines for the Agency's conversion to use of metric measurements. The plan details the organizational structure that will oversee the conversion, describes the tasks necessary to accomplish this goal, and charges tasks Agency component organizations to prepare metric implementation plans for their offices and staffs. 


\section{Responsibillities}

a) Metric Executive. CIA's Procurement Executive, Office of Logistics serves as the Metric Executive and assists the Deputy Director for Administration in implementing the Agency's metric transition.

b) Metric Coordinator. The Chief, Procurement Management Staff, Office of Logistics serves as coordinator of the Agency's metric transition efforts.

c) Deputy Directors are responsible for overseeing the transition to the metric system of their respective directorates. Their duties include:

Preparing and submitting Directorate-level implementation plans and progress reports to the Metric Executive;

Applying the necessary resources required to accomplish the goals of Executive Order 12770 and the Agency's plan;

Appointing Metric Advocates to assist in the oversight of metric implementation within their respective directorates.

d) Metric Advocates are responsible for ensuring implementation of metric usage in their respective components.

\section{Reporting}

Directorate-level reports on metric transition progress are to be submitted quarterly to the Metric Executive in the first year of implementation, semiannually thereafter.

Component-level reports on metric transition progress are to be submitted quarterly in the first year of implementation, semiannually thereafter, to that component's Deputy Director for inclusion into Directorate-wide reports.

\section{Exceptions to Metric Usage}

Exemptions to using the metric system for procurements, grants, and other businessrelated activities must be fully justified and approved by the Metric Advocate for the particular component requesting the exemption. Exemptions will be on a case-by-case basis. The reason an exemption is being requested must be fully explained.

Justifications for exemptions include cost, significant inefficiencies or loss of markets to U.S. firms, impracticality, unavailability, existence of internationally accepted non-metric standards, and cover considerations. When an exemption is granted, dual, soft, or hybrid metric units will be used whenever possible. The date when conversion is expected to the use of metric measurements for the exempted item must be included in the exemption request. Directorate- and component-level progress reports will include the nature of exemptions to metric usage and will identify the actions being taken to eliminate the exemptions.

\section{Transition Efforts}

The CIA's Metric Transition Plan is categorized into five major tasks. Directorate- and component-level implementation plans are to supplement the Agency Transition Plan. Highlights of the actions required for the tasks are as follows: 
a) Transition Management. The transition management structure that is established by the plan will be responsible for obtaining Directorate- and component-level implementation plans, maintaining a reference library of metric transition publications and related items, and creating and maintaining a management information system to monitor and report on all transition tasks.

b) Education and Training. All CIA personnel are to be made aware of the requirement to use metric and how and when this will be accomplished. Agency-wide notices, brochures, and other types of materials explaining the metric system of measurement and the need to use it will be distributed. The extent and type of training will vary by Agency component. Most personnel will require a working knowledge of the metric system, while others will need more specific, detailed training.

c) Specifications and Standards. Specifications for all measurement-sensitive items procured by CIA after September 30, 1992 will be in metric units, unless an exemption has been granted. This includes items purchased by, as well as those developed uniquely for, the Agency. Metric conversion applies to new systems procured or developed after September 30, 1992, unless exemptions are granted or the new system interfaces an existing system designed in non-metric measurement units.

d) Design and Construction. This portion of the plan covers the actions necessary to determine the feasibility and availability of using the metric system in the Agency's construction projects. Highlights of this part of the plan include:

Changing from inch-pound units to "soft" metric units or dual units to motivate personnel and contractors to use the SI system;

Monitoring (through the MOC Construction Subcommittee) the availability of U.S.-made metric parts and equipment; and

Changing to "hard" metric units when adequate availability of U.S.-made parts and equipment is confirmed.

e) Procurement and Industry Coordination. Metric units will be required for all procurements in accordance with the exemption procedures. The Agency will assess the ability of the contractors with whom it deals to provide their products in metric dimensions and will incorporate statements of preference for metric in all contracts and solicitations. This task also involves the development of specialized training and/or briefings for procurement and program personnel to ensure proper preparation of specifications and contract documents.

\section{SIgnificant Developments}

a) TransItion Management. The Agency form "Justification for Exemption to Hard Metric Usage," the Headquarters Notice that outlines the requirements of the metric legislation and the Executive Order, and the statement of responsibilities for the metric advocates have been sent to all Agency employees.

b) Education and Training. A survey of metric education and training materials is to be conducted. Existing Agency training courses will be modified to include relevant revisions. Metric policy implementation segments are to be included in several courses, in particular, Agency Contracts Process, Agency Contracts Familiarization, and Managing Agency Projects. 
c) Speclfications and Standards. A metric conversion software program is to be loaded onto the Agency's mainframe computer and a "Tech Note" is to be published to announce the availability of the package.

d) Procurement and Industry Coordination. Agency contract officers shall be attaching metric policy statements to their contractual documents with a request for contractors to respond with their capabilities for or impact of providing products in SI dimensions. Also, CIA is drafting solicitation and contract clauses that state its metric policy and request contractors to describe their capabilities to provide products or services in metric units.

\section{FEDERAL COMMUNICATIONS COMMISSION (FCC)}

The FCC plan indicates that the telecommunications industry has largely converted to the metric system. The FCC will issue public notices on its own metric conversion activities, mainly in the area of procurement, which will be completed in 1992.

\section{FEDERAL EMERGENCY MANAGEMENT AGENCY (FEMA) •}

FEMA expects that its metric transition policy will be in effect by September 30, 1992. The policy is to review publications prior to reprinting them to determine whether measurement citations in the document can be converted to metric units.

\section{FEDERAL MARITIME COMMISSION}

The main impact of the Federal Maritime Commission on the maritime industry is in the Commission's procurements and in tariff conversions. The plan notes the diversity of measurements used throughout the world and the need to computerize tariff filing and publication. The Commission will cooperate with the desires of the appropriate sectors of the international shipping enterprise.

\section{FEDERAL TRADE COMMISSION (FTC)}

The FTC plan notes the complexities of labeling of consumer goods and conversion of FTC regulations and advisories to metric units. The Commission plans to extend some of its consumer and business education material to incorporate the use of metric units. For those measurement-sensitive procurements not covered by GSA schedules, the FTC will seek to educate prospective small contractors about government metrication by distributing appropriate Small Business Administration or other brochures and materials. Where suitable, the FTC will encourage contractors to bid on measurementsensitive procurements using metric as well as inch-pound measurements.

\section{GENERAL SERVICES ADMINISTRATION (GSA)}

The mission of the General Services Administration, sometimes called the "housekeeper" of the government, is to provide services such as supply services for the entire Federal establishment, and to develop suitable policies for the administration 
and management of these services. Because it involves procurement and businessrelated activities, GSA's mission has the highest significance for carrying out the mandate of the amended Metric Conversion Act and the Executive Order. Most federal agencies rely on GSA for support in acquiring services and supplies.

\section{Directive}

The General Services Administration (GSA) administrative directive GSA Order ADM 8000.1A, "GSA Metric Program," dated February 12, 1990, establishes the policies and assigns the responsibilities for implementation. The GSA Metric Transition Plan, approved by the Administrator on March 27, 1990, and revised on November 29, 1991, defines general requirements and procedures for transition efforts, details general requirements and procedures for transition efforts, and details the tasks to be accomplished by designated GSA organizations. GSA also issued GSA Order APD 2800.12A, Change 20, Chapter 5, General Services Administration Acquisition Regulation, dated January 11, 1991.

\section{Responsibilities}

a) The Associate Administrator for Acquisition Poiicy is designated as the GSA Metric Executive and is tasked to ensure GSA's implementation of the metric transition, establish GSA policy for use of the metric system, and appoint the GSA Metric Coordinator to serve on the MOC and its Executive Committee and to chair the GSA Metric Steering Group.

b) The GSA Metric Steering Group is to formulate metric policy for the approval of the Associate Administrator for Acquisition Policy.

c) The Associate Administrator for Pubilc Affairs is to advise, clear, coordinate, and assist in the production of all publications and audiovisuals proposed by GSA services and staff offices to inform other Federal agencies or the public of uses of the metric system in GSA programs.

d) Central Office services and staff offices and regional offices are to:

Designate an organizational element to monitor metric conversion activities for which they are responsible;

Appoint an individual as their metric coordinator; and

Develop metric guidelines applicable to their specific mission and responsibility.

\section{Reporting}

a) The Central Office Services, staff offices, and regional offices are to submit to the Office of Acquisition Policy annual reports covering metrication progress, problems, and recommendations.

b) The GSA Metric Coordinator is to consolidate the reports into an annual GSA Metric Report for approval by the Associate Administrator for Acquisition Policy. 


\section{Exceptions to Metric Usage}

The Associate Administrator for Acquisition Policy approves or disapproves deviations from the GSA metric transition policy.

\section{Transition Efforts}

The GSA Metric Transition Plan was revised and approved on November 29, 1991. It contains nine major tasks. The following provides a brief description of the task milestones, and their scheduled completion dates.

a) Transition Coordination. This task involves the coordination necessary to effectively implement the metric transition. Actions include creating and operating a management information system to monitor and report on GSA metrication tasks, serving as the contact point for external organizations, and preparing the necessary reports.

Milestone and Date: Revise GSA Order ADM 8000.1A to incorporate changes mandated by Executive Order 12770. (6/30/92)

b) Training. This task involves the development, marketing, and maintenance of a comprehensive metric training program for individuals both internal and external to GSA.

Milestones and Dates:

Develop, market, and conduct two interagency metric training courses, orientation and correspondence. (Completed)

Research and locate resources with available metric orientation program for use in the GSA Self Learning Instructional Centers (SLIC's). (10/91)

c) Specifications and Standards. This task involves the review of specifications and standards currently used by GSA to determine which are already in metric, which are measurement-sensitive but can be converted to metric units, and those which are not metric sensitive. It also requires the initiation of dialogue with industry and trade groups to increase awareness of GSA's interest in obtaining metric products, ascertain the ability of industry to provide products specified using metric measurements, and establish time frames for conversion and to encourage industry in their transition efforts.

Milestones and Dates:

Review all Federal Supply Schedule (FSS) prepared technical documents for potential metric conversion. (12/31/91)

Survey 56 industry associations to determine their metric conversion plan, and to promote the metric transition. (9/30/92)

Establish schedule of conversion dates for technical documents. (9/30/92)

Revise Federal Property Management Regulation (FPMR) Part 101-29 to place more emphasis on the use of the metric system. (9/30/92)

d) Construction and Related Building Functions. The conversion to the metric system in the fields of building design and construction will require a multi-faceted approach. The ability of industry to respond to metric requirements requires thorough 
research. The availability of metric building materials is another concern. In addition, appropriate codes and standards must be changed to foster the conversion.

Furthermore, design and construction guidance that is available both internal and external to GSA will require revision to reflect metric measurements.

Milestones and Dates:

Identification and implementation of four metric pilot projects. (1/94)

Report on industry response to pilot projects. (12/94)

Develop metric guide for project managers involved in metric construction projects. (1/93)

Develop metric guide specification supplement for the Masterspec System. $(1 / 93)$

Convert GSA Design and Construction Handbooks; add metric dimensions to facility standards. (1/93)

Convert Real Property Management and Safety handbooks and guidelines in repair and alteration and in contracting for applicable building or support services. (1/93)

Develop all new contracts in metric units; convert to soft metric where necessary and using hard metric modules where feasible. (9/93)

Convert procurement handbooks, guides, or other directional materials to metric units. (1/92)

Implement metric training (1/97)

e) Eiectronics. This task involves surveying the electronics industry to determine the extent of use of the metric system. Based on the survey results, GSA will identify and implement recommendations to foster the transition. To foster and promote the use of metric standards in Federal information processing resources acquisitions, GSA will develop metric guidance for inclusion in standard solicitation documents for those acquisitions.

Milestones and Dates:

Develop and include guidance on the use of metric measurements in standard solicitation documents for Federal information processing resources procurements. (9/30/91)

Issue a Federal Information Resource Management Regulation (FIRMR) Bulletin to provide guidance on the use of metric standards in procurements dealing with federal information processing resources. (Completed)

Survey the electronics industry to determine the extent of metric use; develop questionnaire, analyze results, and make recommendations to NIST. (9/30/92)

Convert GSA's Standard and Optional Forms Program to metric units. (6/1/94)

f) Small Business GSA will work with industry, especially small businesses, to encourage their transition to the metric system.

Milestones and Dates:

Revise publication, "Doing Business with the General Services Administration." (3/1/92)

Include Federal and GSA metric policy in Office of Small and Disadvantaged Business Utilization (OSDBU) and Business Service Center counselling to small and disadvantaged businesses. (Ongoing) 
Provide updated conversion information to Federal agencies (OSDBU), state governments, trade associations, and the Small Business Administration for dissemination to small and small disadvantaged businesses. (Ongoing)

Ensure that small and small disadvantaged firms capable of responding to metric requirements are identified to appropriate offices for addition to source lists. (Ongoing)

g) Internal Education and Public Affairs GSA will develop and implement an agency-wide educational awareness program on the metric system. Also, service and staff offices' will continue to publicize new metric uses and initiatives.

Milestone and Date: Develop and implement employee information/education campaign on metric. (10/92)

h) Metrication Handbook GSA will develop and issue a metrication handbook for acquisition offices based on experiences of organizations currently acquiring metric supplies and service.

Milestone and Date: Publish Handbook. (7/1/92)

i) Real Property Disposais. GSA will identify all areas involving real property disposal where dual measurements can appropriately be used and implement the new system with GSA regions and client agencies.

Milestones and Dates:

Review and revise service directives to reflect metric measurements. (4/92)

Change all materials requiring metric units (marketing, reports, etc.) (2/92)

\section{Significant Developments}

a) GSA Interagency Training. The GSA Interagency Training Center developed two metric training courses. Both the orientation course and the more extensive correspondence course are available for other agencies and organizations. Over 500 persons, both internal and external to GSA, have been trained.

b) GSA News Releases. GSA news releases now utilize metric as well as inchpound units of measurement.

c) Regulatory Provislons. Regulatory language on metric usage in federal procurements was published in the Federal Acquisition Regulation (FAR).

d) Review of Specifications and Standards. A review of 2,857 specifications and standards in the GSA index and under Federal Supply Service (FSS) has been completed. One hundred twenty-five specifications, standards, and commercial item descriptions have been or are being converted to metric units. The FSS has contacted about 70 industry associations, companies, and other groups to advise them of GSA's metrication plans and to promote the development of metric products and standards. In addition, the FSS has proceeded with industry conferences to determine the availability of metric products and to ascertain industries' ability to provide products designed to metric specifications. 
e) Federal Standardization Handbook. The FSS revised the Federal Standardization Handbook to incorporate guidance on the use of the metric system of measurement in the development of Federal product descriptions. The revised handbook, scheduled for issue by the end of fiscal year 1992, specifies the metric system as the preferred units of weights and measures in specifications.

f) Metric Communlcations Plan. GSA's Office of Public Affairs has implemented their communications plan promoting the use of the metric system throughout GSA. The purpose of the plan is to increase employee understanding and acceptance of the metric system.

g) Information Resources Management. GSA's Information Resources Management Service issued Federal Information Resources Management Regulation (FIRMR) Bulletin C-31 to provide guidance on the use of metric standards in federal information processing acquisitions. In addition, revised Standard Solicitation Documents (SSD's) have been issued.

h) Public Bulldings Service (PBS). PBS has identified four pilot construction and/or repair and alteration projects to be designed in "hard" metric units during FY' 92 . As part of this effort, architecture and engineering firms selected for design will report to PBS on areas not suitable for the use of "hard" metric units. These initiatives will provide the necessary education and experience to determine the feasibility of future metric projects.

i) Federal Property Resources Services (FPRS). FPRS has taken a proactive approach to metric transition. Approximately $85 \%$ of FPRS staff have had metric training. Metric units are being used in a number of real property sales brochures including the $\$ 6.5$ million Federal Supply Depot auction.

\section{GOVERNMENT PRINTING OFFICE (GPO)}

The Government Printing Office (GPO) is pledged to adopt metric sizes in its printing and binding specifications and to use metric conversion as a basis for reducing the number of sizes of paper for efficiency and economy.

\section{Directive}

Although the GPO is part of the legislative branch and not under the purview of the Trade Act and Executive Order, it has elected to comply with the statutory provisions. Accordingly, GPO issued Instruction 725.1B, entitled GPO Metric Program, dated May 13, 1991.

\section{Respons|bllities}

a) Metric Executive. The Assistant Public Printer (Operations and Procurement) is designated as the GPO Metric Executive and is to establish policy for the use of the metric system within GPO. 
b) Metrlc Coordinator. The Metric Coordinator is responsible for chairing the GPO Metric Steering Committee and assisting office managers in developing metric conversion guidelines for their respective operations.

c) Metric Steering Committee (MSC). The Metric Steering Committee is responsible for formulating metric policy for the approval of the Metric Executive and developing and administering the GPO Metric Transition Plan.

d) Offices. Department, Services, and Staff Offices, including regional offices are responsible for developing metric guidelines applicable to their specific mission and responsibilities.

e) Offices of Primary Responsibility (OPR). Offices of Primary Responsibility are responsible for their assigned tasks and submitting a periodic progress report highlighting significant accomplishments during the planning and implementation phases of the transition.

\section{Reporting}

GPO Departments, Services, and Staff Offices designated in the GPO Metric Transition Plan as an OPR or an Office of Collateral Responsibility (OCS) are to submit an annual metrication report to the GPO Metric Executive. The Metric Executive is to present the final report to the Public Printer for submission to Congress.

\section{Exceptions to Metric Usage}

The Metric Executive approves or disapproves deviations from GPO policy regarding the use of the metric system.

\section{Transition Efforts}

The GPO Metric Transition Plan is organized into 7 major tasks which are supplemented by individual task plans(that were to be completed by August 1991) and actions. The major tasks are:

Transition Management

Education and Training

Internal and External Communications

Printing and Binding Specifications

Material and Supplies Specifications

Equipment Specifications and Conversion

Automated Data Processing (ADP) Conversion

All measurement-sensitive correspondence, paper and printing contract specifications, and other business-related activities will contain statements in both metric and inchpound dimensions.

\section{Significant Developments}

a) Standard Metric Paper Sizes. The Joint Congressional Committee on Printing (JCP) has indicated that it desires to establish a policy for converting the current inch- 
pound paper standards to metric standards ( $A$ and $B$ series). The U.S. printing industry is based upon a standard size of $216 \mathrm{~mm}$ by $279 \mathrm{~mm}$ ( 8.5 by 11 inches), the common business correspondence size. Metric conversion implies the adoption of internationally standard metric sizes. Initially, a segment of the U.S. printing industry, specifically web-offset and forms printing, which both use a continuous roll of paper, will be affected should the metric A-4 size $(210 \mathrm{~mm}$ by $297 \mathrm{~mm})$ replace the current " $81 / 2$ by 11 inch" size. The issue is the cut-off dimension, where the roll is cut into page sizes, inherent in roll-fed presses. The standard metric correspondence size, A4 , requires a $629 \mathrm{~mm}$ ( 24.75 inch) cutoff while the " $81 / 2$ by 11 inch" size requires a $578 \mathrm{~mm}$ (22.75 inch) cutoff. The transition to metric sizes will require a period of time for the printing industry to retool.

b) Survey of Federai Agency Printing and Publishing Functions. GPO has issued a survey to the Metric Executives of the Departments and Independent Agencies to ascertain the impact of a transition to standard metric paper sizes. Results of the survey are to assist in the formulation of the JCP paper-size standard policy.

c) Survey of Metrication Activities in the Printing and Paper Industries. GPO is presently soliciting comments from its commercial contractors in the printing and paper industries to determine current and planned capabilities for responding to the Federal government's metric printing and paper requirements.

d) Public Awareness and Metric Promotion. GPO has presented talks on metric conversion to trade associations in the printing industry. In addition, GPO participated in the development of public awareness and promotional material on the metric system in poster and videotape formats. Employees at the GPO are being trained in the metric system using a two-hour orientation course. GPO will soon begin using metric units in all of its customer-related activities.

\section{INTERSTATE COMMERCE COMMISSION (ICC)}

In August 1991, in an Advance Notice of Proposed Rulemaking, the ICC requested comments from carriers, shippers, and other interested parties on its metric conversion proposal. As a result of the comments, the Commission discontinued a rulemaking proceeding proposing conversion to use of the metric system of measurement for tariff, contract, reporting, data collection, and evidence submission activities. The

Commission policy is that a voluntary rather than mandated approach is preferable and that, in any case, the Department of Transportation metric transition makes ICC actions redundant. The Commission will consider specific metric conversion proposals filed by carriers and shippers on a case-by-case basis.

\section{NATIONAL AERONAUTICS AND SPACE ADMINISTRATION (NASA)}

The National Aeronautics and Space Administration (NASA) developed its inch-pound standards and specifications in conjunction with aerospace industry and military space programs. As a result, it built all its space flight systems to inch-pound standards. At the same time, two factors provide a basis for NASA's metric transition. These are the current use of metric units in scientific research and development and the increasingly international nature of space development. 


\section{Directive}

NASA issued its metrication program directive as Management Instruction NMI $8010.2 A$, entitled Use of the Metric System of Measurement in NASA Programs, on June 11, 1991.

\section{Responslbilities}

a) Administrator. The Administrator or designated alternate is responsible for approving the NASA Metric Transition Plan, waivers to the use of metric measurements that are otherwise required for major programs, and NASA's Annual Metric Transition Report.

b) Metric Executive. The Associate Administrator for Safety and Mission Quality (S\&MQ) is responsible for serving as the NASA Metric Executive. The Associate Administrator also establishes procedures to implement the NASA metric policy; Establishes and directs supporting activities; Develops the NASA Metric Transition Plan; advises the Administrator on metric transition requirements and waivers for major systems; and prepares NASA's Annual Metric Transition Report.

c) Officials-in-Charge of Headquarters Offices are responsible for establishing program plans for transition to use of the metric system, reporting on transition progress and barriers, and forwarding to the Associate Administrator for Safety and Mission Quality requests for waivers to the use of metric units.

d) Directors of Field Installations are responsible for establishing plans for transition to use of the metric system at their installations.

e) The NASA Metrication Planning Group (NMPG) is responsible for providing assistance in preparing NASA's metric policy and transition plan, oversight, and reporting for the support activities.

\section{Reporting}

a) Quarterly Progress Reports. Technical progress reports are to be compiled quarterly covering all program office and functional support activities. These reports are to contain material provided by organizations participating in transition tasks and are to be submitted to the Associate Administrator for Safety and Mission Quality and the NASA Metrication Planning Group.

b) Annual Reports to Congress. NASA will submit annual reports to Congress that contain a list of NASA's metric programs and projects, accomplishments in the past year, and plans for the current year. They are based on information supplied by each NASA Program Office and NASA Center.

c) Review Process. Metric transition plans, reports, and evaluations are to be reviewed by the NASA Metrication Planning Group which is the NASA Headquarters working group responsible for planning and coordinating the transition. Results are given to the Engineering Management Council, whose members are the principal management officials for engineering and safety and mission quality at each NASA 
Center. The Council reports to the Deputy Administrator and advises NASA management on engineering issues for NASA flight and ground programs.

\section{Exceptions to Metric Usage}

NASA Management Instruction NMI 8010.2A establishes the metric system of units as NASA's preferred measurement system. 'If a new program plans to use inch-pound units, the NMI requires approval for a waiver. The waiver process applies to NASA Headquarters and Field Installations, and to all new NASA programs and projects initiated after July 1, 1991. Existing programs may continue to use the inch-pound system of measurement without a waiver or exception.

A waiver of the required use of metric units are to be considered only when one of the following conditions applies:

Hardware would be built to an existing inch-pound design;

Recognized international standards for the intended application use inchpound units;

Commercial practice beyond NASA's control dictates inch-pound use; or Metrication would be impractical or have a significant adverse effect on program costs, schedule, or performance.

The use of the metric system must be considered from the program onset, beginning with the conceptual phase (Phase A). Prior to or during the definition phase (Phase B), requirements for metric use and barriers to its use must be identified. A Request for Waiver must be supported by an assessment of the entire program that demonstrates metric system use has significant adverse impact. For existing non-metric design and adverse affect waivers, the assessment must address the following:

$$
\begin{aligned}
& \text { Cost/budget--specifically incremental costs for developing and operating } \\
& \text { metric versus inch-pound hardware. } \\
& \text { Schedule--particularly delays in meeting requirements for developing or } \\
& \text { operating metric hardware. } \\
& \text { Safety--where unavoidable risks would result from changing or mixing } \\
& \text { measurement units. }
\end{aligned}
$$

The assessment must also identify activities that can be initiated to address and remove barriers to future metric system use and must show that the Request for Waiver, if approved, would not impede metric system use for other programs.

Programs entering the detailed design phase (Phase $C$ ) or the hardware development phase (Phase D) must meet at least one of the justification conditions and have a completed assessment. There are four categories for programs that determine the process that must be used for approval a waiver or exception. Exceptions for major programs require approval by the Administrator, while other programs waivers can be approved by the Associate Administrator, the next lower level. Exceptions within a program can be approved by the program management, but must be reported to the Metric Executive. Where lack of industry readiness may make use of metric specifications impractical, multi-program waivers may be approved for groups of projects. In detail, the following are the procedures. 
Major Programs. For major programs or systems, the cognizant Associate Administrator reviews the Request for Waiver and the supporting assessment and sends both to the Associate Administrator for $S M Q$ for evaluation. After consulting with the Associate Administrator, the cognizant Program Associate Administrator may forward the Request to the NASA Administrator. The Administrator (or Deputy Administrator) must decide to approve or disapprove the Waiver before granting Authority to Proceed (ATP).

Other-than-Major Programs. For programs not classified as major programs, the Request for Waiver and supporting assessment is submitted to the cognizant Program Associate Administrator who sends both to the Associate Administrator for SMQ for evaluation. After consultation with the Associate Administrator for SMQ, the cognizant Associate Administrator (or Deputy Associate Administrator) approves or disapproves the Request for Waiver for such programs and notifies the Associate Administrator for SMQ of the decision. The Waiver decision must be made before granting ATP.

Program Element Exception. For discrete elements within approved programs, the cognizant Program Associate Administrator designates the official authorized to approve exceptions. (This official may be the Project Manager or more senior official.) This official evaluates exceptions, makes the decision, and sends copies of approved exceptions to the cognizant Program Associate Administrator and the Associate Administrator for SMQ. An element that is "inherited" or "off-the-shelf" hardware and has an inch-pound design is a suitable candidate for an exception. Exceptions should not impede future use of metric units. The element should have a metric interface when the program uses metric units.

Multi-project Waiver. A Multi-project Waiver covers a group of projects for which the recognized international standards use inch-pound units or commercial practice beyond NASA's control dictates use of inch-pound units. The group may be a list of specific projects, or a well-defined class of related projects or applications. In the latter case, the period of the waiver is to be no more than 3 years. When removal of barriers cannot be completed during the initial waiver period and the need for a waiver continues, an extension may be granted under this procedure. The cognizant Program Associate Administrator reviews Multi-project Waivers and the supporting assessments, and sends both to the Associate Administrator for SMQ for evaluation. After consulting with the Associate Administrator for SMQ, the cognizant Program Associate Administrator may forward the Request to the NASA Administrator for a final decision.

\section{Transition Efforts}

NASA science publications have used the metric system of measurement since 1970. Although NASA has maintained a metric use policy since 1979, practical constraints 
have restricted actual use of metric units. NASA's goal is to use the metric system for program development and functional support activities to the greatest practical extent by the end of 1995. This is consistent with NASA's primary responsibilities for preserving U.S. leadership in aeronautics, space science, and technology and conducting activities in space that expand human knowledge.

NASA has required consideration of the metric system in the development of major programs since 1979. Insufficient experience and support capabilities, and perceived costs in building those capabilities, made program managers reluctant to design and build hardware using metric units. Cost, schedule, and safety factors generally account for continued use of inch-pound units for flight hardware.

Because existing hardware programs will not change measurement systems due to cost and safety considerations, the introduction of the metric system into new flight programs will determine the pace of the metric transition. Transition of institutional capabilities and support functions are to be phased to enable use of the metric system in flight program development and operations.

Externally oriented elements of the NASA plan will introduce and actively support use of the metric system in education, public information, and small business programs. Coordination with other Federal agencies and departments (through the Interagency Council on Metric Policy) and industry (directly and through professional societies and interest groups) will identify sources of external support and minimize duplication of effort. The NASA metric transition outlook is discussed for each major program office. Descriptions of support tasks address objectives, rationale, required actions, milestones, and responsibilities. The plan is to be updated as needed to reflect major changes in NASA's program plans or metric transition efforts.

a) Transition Goais. The NASA plan will enable NASA to use the metric system for all activities not restricted by practical limitations. The scope of this transition includes new hardware development and technical support operations as well as administrative functions and externally oriented activities that affect U.S. industry and the public.

Some existing ground facilities and space systems will require modifications to support metric interfaces.

In concert with other Federal transition programs, NASA's transition should encourage and support U.S. industry in adopting the metric system to ensure its future competitiveness in world markets. NASA will maximize use of commercial capabilities to accomplish its transition. The fraction of NASA development programs that use the metric system will increase steadily. However, existing complex technical programs built using the inch-pound system may continue operating with that measurement system into the next century due to safety and cost considerations.

The end of 1995 is the target date by which NASA should complete all internal metric initiatives and establish the widest possible use of the metric system consistent with the availability of external support capabilities.

b) Transition Strategy. NASA's strategy integrates metric transition with the established planning and approval process for hardware development programs that are a large part of NASA's activity and budget. Because new programs must adopt the 
metric system measurement before obtaining Authority to Proceed, the rate of new program approvals determines the pace of NASA's metric transition.

Functional support activities such as standards, training, supply and equipment management, and other institutional capabilities are shared resources for all flight programs. To avoid delays and/or unnecessary spending, the pace of the metric transition for these activities must be matched to the needs established by flight programs.

To minimize disruption and risk to ongoing activities, existing programs may continue to use the inch-pound system. Safety and cost considerations will limit use of soft metric descriptions of inch-pound quantities. An integral part of this plan is a carefully controlled procedure for processing requests for waivers and exceptions to the use of the metric system for new programs. This procedure balances the requirement that new programs use the metric system with program cost, schedule, safety, and performance.

Because industry provides hardware and support services for most NASA programs, the success of NASA's metric transition depends on industry acceptance and support of the metric system. Another major consideration is NASA's substantial investment in inch-pound hardware. The designs of most current NASA flight and ground systems use the inch-pound system, including the Space Transportation System, Space Station Freedom, launch facilities, and wind tunnels. Although policy requires using the metric system for new programs, NASA is likely to continue using the inch-pound system to operate and maintain elements of existing programs.

Following the example set by the Office of Space Science and Applications (OSSA) in 1990, other major NASA program offices developed metric transition plans during 1991. NASA integrated these individual program office plans into an overall NASA Metric Transition Plan approved by the Administrator on February 20, 1992. The NASA Plan provides the structure that NASA field installations and individual programs will use during 1992 to formulate more detailed metric implementation plans. The NASA Headquarters Program Offices have approved Metric Transition Plans. The plans of the Office of Space Flight (OSF), Office of Aeronautics and Space Technology (OAST), and OSSA reflect assessments of programs already underway and projected new starts through the year 2000. In 1991, the Office of Management Systems and Facilities developed a transition plan for training, supply and equipment management, and facilities engineering. Because these areas are common to all flight and ground programs, this Plan addresses them across individual program and institutional boundaries.

c) Ground and Flight Programs. NASA employs a systematic process of phased program development for initiating new ground and flight programs. The procedures used in this process have a major impact on NASA's ability to implement the metric transition. NASA uses a five-phase development process for all major procurements:

Phase A. Conceptual Phase

Phase B. Definition

Phase C. Detailed Design

Phase D. Hardware Development

Phase E. Full-Scale Operation. 
Use of the metric system from program onset is the ideal situation. For programs already in planning, introduction of the metric system can be considered at major program decision points such as the start of Phase $B$ or $C$. Once a program enters Phase $C$, changing the measurement system is impractical because revision of completed design work has significant adverse cost and schedule consequences. Although NASA's plan produces a gradual metric transition, it offers a practical metric transition procedure without incurring unnecessary program costs and delays.

The NASA Ground and Flight Program plan summaries are the following:

Offlce of Space Flight (OSF). The Space Shuttle Program (the Orbiter, External Tank, Solid Rocket Motor, and Main Engine) is NASA's only current capability for taking humans into space. The Space Shuttle uses the inch-pound system for all NASA-developed elements. The European Space Agency (ESA) developed the Spacelab module for the Shuttle Orbiter using the metric system. Although upgraded hardware is being developed to extend system life and capability (such as the Advanced Solid Rocket Motor and new computers), the Space Shuttle is in the operational phase.

OSF has developed a metric transition plan. Except for Spacelab, all Space Shuttle hardware in inventory or in production uses the inch-pound system. Drawings of Space Shuttle payload interfaces give dimensions in both inchpound and metric units, so metric payloads can be accommodated now. Any new or replacement hardware developed for the Space Shuttle will require either a metric interface description, a waiver, or an exception to use of the metric system. Because the Space Shuttle will be maintained and operated indefinitely, OSF will use the inch-pound system beyond the year 2000 .

Office of Space Systems Development (OSSD). The Office of Space Systems Development develops new systems that support humans in space and new launch vehicles for delivering automated spacecraft to space. The Space Station Freedom Program will establish a crew-tended laboratory, leading to permanent human presence in space. Space Station Freedom entered Phase $C$ before NASA policy required use of the metric system by new programs. In February 1987, NASA decided to use the inch-pound system for all elements developed in the U.S. Space Station Freedom does have elements designed by international partners (such as the modules from ESA and Japan) using the metric system. Space Station Freedom interfaces, especially for payloads, generally express dimensions in both inch-pound and metric units, so future hardware built with the metric system can be accommodated. All elements now in development should be launched by the year 2000. After that date, the metric system will be used for most hardware design and development. Maintenance and production of direct replacement hardware for Space Station Freedom may be an exception. For continuity, Space Station Freedom will continue using the inch-pound system for operational support beyond the year 2000.

Two major OSSD programs for the future are the National Launch System (NLS) and the Assured Crew Return Vehicle (ACRV). The NLS is a joint program with the Department of Defense (DoD) to develop a next-generation launch vehicle that accommodates payloads of varying size and is more 
economical to operate than the Space Shuttle. The NLS design can be upgraded to carry humans to space. The ACRV is a basic reentry vehicle that will provide an independent means of returning crew members stationed on Space Station Freedom. The NLS and ACRV programs are expected to use the metric system of measurement.

Office of Space Science and Applications (OSSA). The Office of Space Science and Applications (OSSA) plans, directs, executes, and evaluates NASA programs that use the space environment to conduct scientific studies of the universe, understand the Earth as an integrated system, develop a basis for solving some practical problems on the Earth, and provide a research base supporting human presence in space.

OSSA pursues an integrated approach encompassing ground-based laboratory research; suborbital flights on airplanes, balloons, and sounding rockets; experiments conducted on Shuttle/Spacelab and Space Station Freedom; and automated Earth-orbiting and interplanetary spacecraft. The core science program includes the Mission to Planet Earth as well as other missions that are not classified as major programs.

The Advanced X-ray Astrophysics Facility (AXAF), Cassini, and the Earth Observing System (EOS) are OSSA's current major development programs. AXAF will examine the universe at $x$-ray wavelengths. Cassini will inject a probe into Saturn's atmosphere and orbit Saturn to study the atmosphere, rings, and satellites. EOS, a series of well-instrumented spacecraft in polar orbit, will make concurrent observations of the atmosphere, oceans, land, and life on the Earth. All three development programs are using hybrid measurement systems. OSSA's ongoing development activities include Spacelab experiments that will fly in 1992 and beyond, as well as some Explorers and small satellites. OSSA plans to develop all satellites and instruments initiated after 1992 using the metric system.

The future major core science missions are the Orbiting Solar Laboratory (OSL) and the Space Infrared Telescope Facility (SIRTF). Other major initiatives are the Stratospheric Observatory for Infrared Astronomy (SOFIA) in the core science research base, the Geostationary Platforms in Mission to Planet Earth, and the Mars Environmental Survey in Mission from Planet Earth. OSSA expects these major programs will be approved for development by FY 1998.

OSSA plans to use metric units for a new class of "intermediate" missions proposed for initiation in FY 1994. An augmentation to the Explorer program would provide a series of small, university-developed satellites that also would be designed and built using the metric system. The initial Space Station Freedom experiments will be developed using the metric system.

OSSA scientific publications and procurements now use the metric system. Most hardware now in the inch-pound system should be launched by 1998 . Some use of the inch-pound system may continue as existing hardware is reflown (e.g., Spacelab instruments) or copied for new missions. OSSA also plans to use the inch-pound system for on-orbit maintenance of the Hubble Space Telescope. However, future programs will use the metric system unless 
a waiver is requested and approved. The same is true for future Spacelab and Space Station Freedom experiments. Therefore, by 1998, the metric system should be used for all new hardware design and development.

Office of Aeronautics and Space Technology (OAST). The Office of Aeronautics and Space Technology concentrates on technology advancement and validation, not development of major flight programs. It conducts an Aeronautics Research and Technology program for civil, commercial, and military aircraft. The program develops emerging technologies for subsonic transports, high-speed transports, high performance aircraft, and hypersonic/transatmospheric vehicles. The program develops, operates, and maintains unique national laboratories and facilities and addresses critical barriers to technology introduction.

OAST's Space Research and Technology program advances technologies for future space missions and strengthens U.S. industrial and academic engineering and research capabilities. This program supports technology development for new launch capabilities, scientific observations, human presence in space, and ground and space operations. It provides near- and long-term support for space and earth science missions, space transportation systems, utilization of Space Station Freedom, ground and space operations, and human solar system exploration missions. The Space Research and Technology program currently uses the inch-pound system. Because NASA's goal that future missions use the metric system, OAST's supporting projects in the Space Research and Technology program will use the metric system.

With DOD, OAST funds technology development for the National Aero-Space Plane (NASP). The stated goal for NASP is a single-stage-to-orbit vehicle. During its current technology phase, the program is advancing technology in key areas such as propulsion, materials, structures, and computational sciences. Application of these technologies is critical to future aerospace vehicles and extends beyond aerospace into other U.S. industries.

Currently, OAST hardware designs, research reports, and engineering publications use the inch-pound system. The Aeronautics Research and Technology program requires a Multi-project Waiver to metric system. This waiver is desired because the inch-pound system is the international standard for research, production, and operations in the aircraft industry.

Through advisory committees and other liaison with the aeronautics industry, OAST is monitoring industrial plans for conversion to metric. Because NASA is a source of information for this industry, not a major customer, NASA and industry must have parallel metric transitions. The National Aerospace Plane (NASP) also may require a waiver because the aeronautics industry uses the inch-pound system. The decision to proceed with Phase 3 of NASP, the design, construction, and flight test of a research vehicle, is scheduled for 1993. The decision on metric system use can be included in the DOD Phase 3 approval process.

Office of Space Communications (OSC). The Office of Space Communications is responsible for key communications, mission control, and data management 
systems. Communications involves sending signals between the Earth and spacecraft and also between critical NASA facilities. OSC's role in mission control focuses on routing commands from an operations center to the intended spacecraft. The data management function accomplishes data transport from an individual satellite to the appropriate mission operations facility.

OS has many ground facilities and operates the Tracking and Data Relay Satellite (TDRS) system. TDRS is the only major space hardware development program in OS. Four of the seven satellites are now operational; one was lost in the Challenger accident. The sixth TDRS will be launched in a late 1992; the seventh is in production. All spacecraft are nearly identical designs using the inch-pound system.

TDRS II is intended as a next-generation replacement for the current TDRS. NASA needs these advanced spacecraft to support increased demand from the Space Station Freedom and Earth Observing System programs. The Phase B study for TDRS II has been completed.

TDRS II is a hybrid design that may need a waiver or exception for u'se of inherited elements developed with the inch-pound system. The results of the Phase $B$ studies will be evaluated and decisions will be made regarding waivers and exceptions before TDRS II proceeds to Phases $C$ and D.

Office of Exploration. The Office of Exploration manages the Space Exploration Initiative (SEI). The long-term goal of SEI is a permanent presence on the Moon and human exploration of Mars. SEl focuses on developing the knowledge, experience, and cost estimate base needed to make the ultimate decision of how to proceed. The SEI activities include life sciences research, technology development, solar systems data gathering, and opportunity definition.

NASA is formulating an implementation approach for SEI. A detailed master plan for development programs will follow. SEI is establishing a basis for major programs.

SEI uses the metric system for many technical reports and publications. Future programs will use the metric system.

e) Transition Support Tasks. The overall pace of NASA's metric transition will be determined by the rate at which the metric system of measurement can be introduced into individual hardware development programs. Since these programs need timely functional support, the success of the metric transition depends on coordinating the support function transition with development program requirements.

The NASA Metric Transition Plan defines eight functional support tasks that NASA must perform to ensure a smooth transition to the metric system of measurement. The tasks involving direct hardware support address metric standards, specifications, and supply and equipment management. Other tasks deal with basic support functions at the NASA Field Installations such as facility construction, personnel training, and institutional capability development. A third set of tasks focuses on metric information and awareness, specifically public affairs, education, and small business. 
The following are the task descriptions. Each task description states the task objective, gives a brief rationale, lists specific required actions and near-term milestones.

Metric Standards, Specifications, and Practices. The objective is to ensure the availability of the standards, specifications, and processes required to support the design, fabrication, and operation of metric systems. The rationale is that cost-effective design, fabrication, and operation depends on timely availability of adequate metric standards, specifications, and processes.

NASA uses nationally developed standards, specifications, and procedures such as those prepared by DOD and professional societies. NASA also develops its own specifications, standards, and procedures to meet the specific needs of individual programs.

Because NASA hardware presently uses the inch-pound system, current NASA specifications, standards, and procedures use the inch-pound system almost exclusively. To use the metric system, NASA's new development programs require metric versions of these documents. New procedures may be required to ensure consistent use of metric units.

The tasks that must be accomplished to ensure the availability of the required standards, specifications, and practices include:
Establish a master list of all standards, specifications, and practices required by NASA organizations;
Identify the specifications and standards in the master list that require conversion to metric;
Establish priorities and need dates for development or conversion of specifications and standards required by NASA programs; and
Establish joint programs with industry, national standards organizations, and other federal agencies to expedite development and coordination of metric versions of standards and specifications.

The task milestones and the schedule are as follows:

Complete master list of specifications and standards by April 30, 1992. Identify priorities for metric standards, specifications, and procedures by July 31, 1992.

Establish plan and schedule for preparation of the required metric standards, specifications, and procedures by October 31, 1992.

Supply and Equipment Management. The objective is to ensure that NASA installations are able to use the metric system of measurement for supply and equipment management. The rationale is that to support the operations of NASA technical and administrative offices, supply and equipment management systems must be able to identify, describe, and maintain records of stocked metric items including spares, materials, and supplies.

In the metric transition process, supply and equipment management organizations are "providers," not "drivers," of supplies and services. Supply and equipment management "customers" (program and institutional) establish 
the requirements for spares, materials, and supplies, including descriptions, standards, and specifications. Consequently, customer requirements drive the rate of the metric transition for supply and equipment management.

Descriptions of cataloged items are primarily in the inch-pound system.

However, the capability to describe items in metric units is inherent to all supply and equipment records and systems. Similarly, many established units of order and issue are applicable to both systems of measurement, i.e., each, box, reel, etc.

The use of metric units of issue will be driven by customer needs and supply source availability. The following tasks must be completed to ensure availability of the required support:

Inform all installation supply and equipment management organizations that the metric system is the preferred system of measurement;

Establish a preference for material acquisition in metric measures when cost, schedule, safety, and performance requirements can be met;

Evaluate near- and long-term transition effects on all supply and equipment management elements; and

Ensure that automated information and functional operating systems have the capability to accommodate metric weights and measures.

The following milestones are scheduled

At the April 1992 Annual Supply and Equipment Management Conference, state that the metric system is the preferred system of measurement and that material should be acquired in metric measure when cost, schedule, performance, and safety requirements can be met;

Survey all NASA installation supply and equipment functional operating systems to ensure they can accommodate metric weights and measures by May 1992; and

Determine near- and long-term effects of metric transition on all supply and equipment management operational elements by June 1992.

Public Affairs. The objective is to inform NASA civil service and contractor personnel about the Agency's transition to the metric system and to incorporate metric units in NASA news materials. The rationale is that publicizing the Agency's planned metric transition to NASA employees is an essential part of gaining internal acceptance.

External public affairs materials currently use the inch-pound system.

Experience indicates that news media reporting on NASA activities will use the metric system only if the public widely accepts and understands this system.

Public Affairs employs a wide range of tools and activities to provide the "widest practical and appropriate dissemination of information" to the media and general public. Practical and efficient ways must be found for incorporating metric units so that the Public Affairs Office can support NASA programs. 
The plan has two phases: publicize NASA's metric transition activities to employees, then support metrication of NASA programs by incorporating metric units in NASA media materials. (NASA Public Affairs would use the inch-pound system when the program uses this measurement system.)

The following tasks will implement use of the metric system in public operations:

Provide training and metric conversion tools to NASA public affairs personnel.

Publicize NASA's metrication activities via NASA Select Television and internal newsletter publications.

In coordination with other Federal agencies, develop common metric information to prepare the media and public for the Federal Government's metric transition.

The public affairs milestones and schedule are as follows:

Begin submitting articles about the metric system to newsletters, bulletins, and the NASA Magazine by January 31, 1992;

Provide metrication information to Agency-wide public affairs personnel by June 30, 1992; and

Begin incorporating dual units in NASA media materials by September 30 , 1992.

Training. The training objective is to prepare NASA personnel for routine use of the metric system of measurement. The rationale is that although NASA personnel generally have some knowledge of the metric system, few use it regularly and comfortably. NASA personnel need a solid working knowledge of the metric system to use metric units routinely without constantly converting between systems. Administrative support personnel need a general familiarity, and engineering staff require an operational capability. Private sector experience indicates that general education takes 1 or 2 days. Common modules should be used wherever practical to avoid unnecessary duplication in course development.

NASA should assess training programs developed by other Federal agencies such as the General Services Administration (GSA). Information about the metric system should be incorporated into professional development, skills upgrade, and apprentice programs. In addition, brochures briefly explaining the metric system and its application within NASA should be distributed to all NASA personnel.

The following tasks must be accomplished to develop and implement a common metric education program for NASA personnel:

Determine the variety, scope, and timing of training in metric system use required for administrative, engineering, research, and fabrication personnel.

Adapt currently available training courses to meet established training requirements. 
Develop metric modules for existing training and professional development programs.

Conduct pilot training courses.

Implement a metric awareness program to prepare NASA personnel for use of the metric system.

The current milestones are to identify training requirements for NASA personnel and implementation approaches by March 31, 1992 and to initiate pilot orientation and training courses by July 31, 1992.

Education. The objective is to improve public awareness of the metric system through its use in the educational materials, publications, and video and computer products developed by NASA.

NASA supports mathematics, science, and technology education from grade school through graduate school. NASA has developed metric instructional materials such as "Space Mathematics" and "Metrics in Space" that schools frequently request. In writing new materials and revising existing materials, text and figures will be prepared using the metric system. These efforts will be coordinated with other Federal agencies through the Metrication Operating Committee.

The following tasks must be accomplished by NASA's Education Division to implement the metric system:

Adopt the metric system as the primary system of measurement for NASA educational materials and publications; and

Identify topics for publications that offer particularly good opportunities to expose students and teachers to practical use of the metric system of measurement.

The milestones and schedule for educational tasks are:

Use the metric system as the primary system of measurement for new educational materials and publications after October 1, 1991; and Select topics for educational materials that expose students and teachers to practical metric system use by March 31, 1992.

Construction of Facilities. The objective is to prepare for use of the metric system of measurement in NASA facilities and construction programs. The metric system of measurement has been used for constructing a few NASA facilities in foreign countries such as Space Shuttle support sites and tracking stations. NASA's conventional facility and construction needs totally depend on commercial practice.

Generally, the materials and equipment needed for metric construction are not available in the United States, although a growing number of U.S. manufacturers are exporting metric building materials.

The Construction Subcommittee of the Metrication Operating Committee (MOC) initiated an assessment of transition requirements for facility construction. The 
subcommittee, including NASA, is working closely with industry groups to develop product specifications and design standards for metric construction. The subcommittee has established January, 1994 as the date by which industry should be ready to submit bids for metric construction. However, to maintain its current facilities, NASA recognizes that a dual-system capability must be maintained even after the metric system becomes established.

Although NASA has coordinated its plan for converting to metric construction with the MOC Construction Subcommittee plan, it intends to ensure the following specific results:

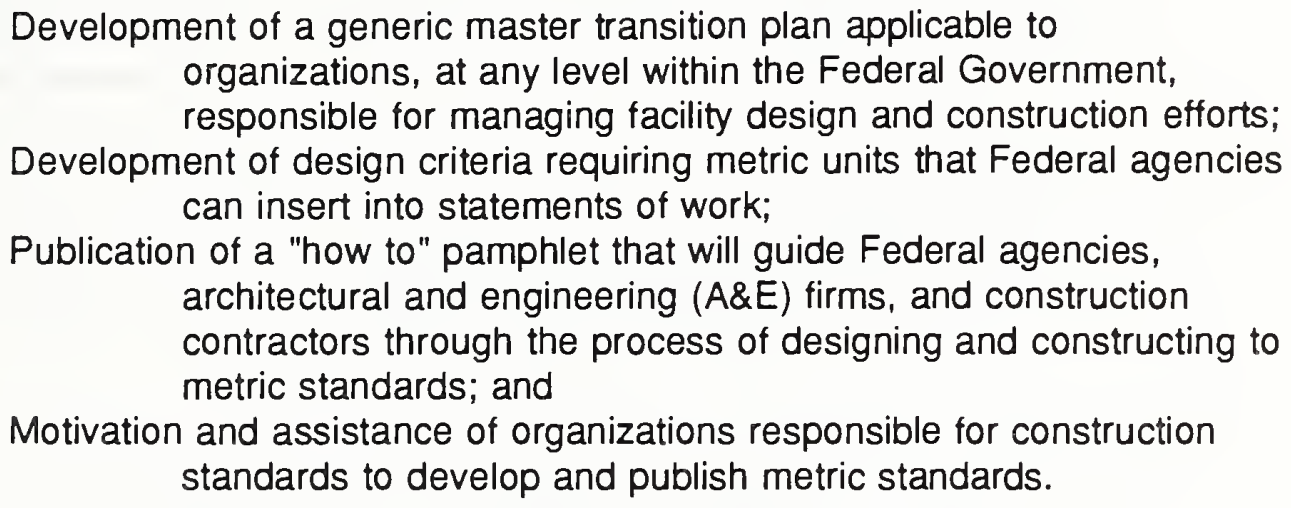

By November 1992, NASA's Facilities Engineering Division will solicit participation among Field Installations, A\&E firms, construction contractors, and material suppliers to estimate the growth rate of construction capability in metric units. The study should also identify methods to accelerate and ease NASA's ultimate transition to "hard metric."

The construction-related milestones and their schedule are:

Develop a generic metric transition plan for construction by December 1991;

Develop metric standards and specifications for construction by July 1992;

Develop a NASA metric implementation plan for construction by November 1992;

Coordinate metric standards and specifications for construction by July 1993;

Conduct training for use of metric standards and specifications for construction by December 1993; and

Implement design of NASA facilities per metric standards and specifications by January 1994.

Small Business. The objective is to assist small businesses in preparing to use the metric system and to support NASA's transition to metric hardware development and functional support. The rationale is that small businesses are key partners with NASA. NASA cultivates and maintains strong relationships with small businesses, particularly with disadvantaged firms.

Small businesses especially are responsive to NASA's needs. Once informed, they could make valuable contributions to NASA's metric transition and to the 
competitiveness of U.S. industry in international (metric) markets. A 1990 survey of small machine shops indicated most had metric experience.

The following tasks must be accomplished to assist small businesses supporting NASA in converting to the metric system:

Prepare materials that inform. small businesses about the NASA metric transition and opportunities for providing metric products and services;

Include information about the metric transition in NASA workshops for small businesses;

Insert questions concerning metric capabilities into the Small Supplier Quality Survey form to collect information from a broad sample of small businesses;

Conduct targeted surveys of metric experience and capability for key small businesses areas; and

Ensure that NASA personnel responsible for contacts with small business are aware of plans for the metric transition and of further information sources on metric system use.

The small business milestones include:

Prepare materials by February 28, 1992, that inform small businesses about the NASA metric transition; and

Incorporate metric capabilities into workshop activities directed at small businesses by March 31, 1992.

Institutional Capability Deveiopment. The objective is to establish support capabilities at each NASA Field Installation for conducting research and technology development using the metric system of measurement. The rationale is that in addition to the functional support and program points of view requirements for supporting the metric system also must be defined from an institutional point of view. Each NASA installation must conduct an internal survey that compares available metric capabilities with program requirements for metric system use, and estimates the resources needed for new capabilities.

NASA Headquarters Program Offices responsible for institutional support and oversight (OSF, OAST, and OSSA) must determine how to implement metric transition at their Field Installations. Metric capability development should be phased so that Field Installations can support metric programs as assigned. Wherever practical, development of metric capabilities should be incorporated into normal maintenance and replacement activities, thus avoiding additional transition costs.

The following tasks must be accomplished to implement a metric transition at each NASA Field Installation:

Establish groups to conduct assessments and coordinate the metric transition at each NASA Field Installation.

Involve the Field Installations in NASA Headquarters metric planning, information exchange, and reporting. 
Conduct surveys at each NASA Field Installation to assess current metric capabilities, define the rate of conversion that can be accomplished with available resources, and identify additional resources needed to meet program support requirements.

Establish a metric transition plan at each NASA Field Installation with concurrence of the responsible Program Office.

Ensure that each Field Installation knows the status of metric transition activities at other NASA, Government, and industrial facilities.

In addition to supporting Field Installation transition planning, the surveys will establish an overall baseline for assessing NASA's metric transition progress and will identify resources that can be shared among NASA programs.

The institutional milestones include:

Submit a metric transition plan for each NASA Field Installation to the cognizant Program Office and the NASA Metrication Planning Group by July 31, 1992; and

Establish baseline institutional plans by September 30, 1992.

\section{Significant Developments}

a) Research. NASA supports a wide range of research in astronautics and space science; the latter encompasses the disciplines of astronomy and astrophysics, earth and planetary sciences, life science, microgravity science, and space physics. Space science research and publications commonly use the metric system. A NASA policy established in 1971 requires the use of metric units in technical publications. Although results are published in metric units, they often are obtained with laboratory or flight instruments designed with inch-pound units.

b) Internatlonal partnershlps. NASA has acquired some engineering experience with metric units through joint flight programs with international partners. The most prominent example is Spacelab. The European Space Agency built Spacelab's pressurized modules and payload carriers using metric units. Key interface drawings have both metric and inch-pound dimensions so that Spacelab can be integrated into the Space Shuttle's inch-pound cargo bay and can accommodate both metric and inchpound experimental hardware. Another example of a joint program where international partners using metric units while NASA does not is the International Solar-Terrestrial Physics (ISTP) program. The spacecraft and instruments provided by NASA are inchpound where as those built by ESA and Japan are metric. Properly documenting the interfaces allow inch-pound spacecraft to carry metric experiments and metric spacecraft to support inch-pound instruments.

c) Space Shuttle Payloads. Half of NASA's Space Shuttle payloads for 1991, and almost all such payloads for 1992, have some metric-based elements. In 1992, NASA will begin assessing requirements for space-quality piece parts fabricated to metric standards, leading to part development and qualification.

Four of the six Space Shuttle launches in 1991 carried major NASA payloads. Two payloads were hybrid (used both metric and inch-pound units), and two were inchpound designs. The metric content of these payloads came from foreign sources. 
The Shuttle Pallet Satellite (SPAS), built in Germany using the metric system, has been used by the Department of Defense for one of their missions flown on the shuttle. The engineering analyses and physical integration needed to prepare this hardware for flight expands NASA's metric system experience and provides a strong basis for assessing metric support requirements for NASA programs.

During 1991, NASA began preparing the major payloads for six Space Shuttle launches in 1992. The first five payloads are hybrid because they involve NASA's inch-pound experiments and a Spacelab module or pallet built by the European Space Agency. The sixth mission carries two NASA payloads: LAGEOS, a cooperative program with Italy for an upper stage and satellite that use the metric system, and USMP designed with inch-pound units.

During 1992, NASA will begin integrating major payloads for 1993; half involve hybrid measurement systems. The payload elements using the metric system are the module for Spacelab-D2, the Spacelab pallet for ATLAS-2, and the SPAS payload carrier for ORFEUS.

d) Education Publications. In a significant decision, the NASA Education Program decreed that all future materials produced for primary through high school students and teachers will use the metric system of measurement. There are six such publications scheduled for 1992 that use the metric system.

e) NASA Staff Assigned to Metrication Activities. At least 100 NASA personnel are members of metric planning groups at Headquarters or field installations. Detailed assessments supporting the planning involve a growing number of personnel. Involvement will expand further where the metric system is chosen for future major programs. Participants currently come from many different disciplines including engineering, procurement, supply and equipment, and training.

g) Metric Parts Development and Quaiification. Threaded fasteners are widely used standard parts in all NASA flight and ground systems. Although U.S. metric standards exist, manufactured parts are available only by special order. NASA requires large quantities of fasteners encompassing a variety of materials, configurations, coatings. At the end of 1991, NASA started a fastener requirements and qualification project to procure and qualify selected metric fasteners.

The requirements of individual pilot projects designed using the metric system will be the starting point for defining a set of common piece parts in metric sizes. This project is coordinated with NASA-wide mechanical parts program newly initiated by NASA's Office of Safety and Mission Quality. Availability and cost comparisons will be made between equivalent metric and inch-pound parts. Design and assembly data (e.g., torque and lubrication requirements) will be developed and published to provide engineering reference data for future programs.

Spacecraft use fluids for propulsion, attitude control, thermal control, and life support functions. Availability of suitable metric fittings for ground processing and servicing of international payloads has been an issue for several years. NASA will begin a fluidcoupling requirements and qualification project in 1992 focusing on the needs of payloads launched by NASA. This project will survey the variety of current and projected space hardware, determine needs for metric fluid system parts, and work with 
national standards organizations such as the Society of Automotive Engineers to develop the required metric standards.

\section{NATIONAL ARCHIVES}

The National Archives Metric Transition Plan states that there is no effort to convert new archival facilities to metric dimensions because of the nature of the archival supplies industry.

\section{NATIONAL SCIENCE FOUNDATION (NSF)}

The National Science Foundation requires all research and education proposals to use the metric system. The Foundation has modified its publications to require conformance to metric specifications. It will respond to the concerns of small business in its Small Business Innovation Research program, but proposes no specific initiatives. The plan relies on the long acquaintance of the research community with the metric system.

\section{NUCLEAR REGULATORY COMMISSION (NRC)}

The proposed NRC metrication policy was published for comment in the Federal Register on February 10, 1992. Under the proposed policy, the NRC will: (1) encourage the use of the metric system of measurement by the licensed nuclear industry, (2) work with industry and national standards organizations to bring about use of metric units in standard-setting activities, (3) revise existing regulatory documents as needed to facilitate use of metric units by NRC licensees and license applicants, and (4) publish all future regulatory documents such as rules, regulatory guides, and standards in dual units. For the present, for continued assurance of protection of the public health and safety, the NRC will continue to use inch-pound units in communications with licensees and state and local authorities in event reporting and emergency response. Under the proposed policy, after three years, the Commission would review the status of conversion to metric usage by the licensed nuclear industry to determine whether changes to its policy are needed.

\section{OFFICE OF PERSONNEL MANAGEMENT (OPM)}

The Office of Personnel Management's Metric Transition Plan is a listing of activities and target dates. Policy statements and implementation reports are not included.

\section{OFFICE OF THE U.S. TRADE REPRESENTATIVE}

The Office of the Trade Representative, who has the responsibility for coordination of U.S. trade policy, supports the federal metric transition effort and appreciates its impact in helping to improving the U.S. competitive position in international markets. 


\section{OFFICE OF SCIENCE AND TECHNOLOGY POLICY (OSTP)}

OSTP believes it has completed reporting requirements under the Act and the Executive Order.

\section{SMALL BUSINESS ADMINISTRATION (SBA)}

The Small Business Administration's Metric Transition Plan was among the first in the Federal Government, dating from September, 1990.

\section{Directive}

The Small Business Administration (SBA) has developed an internal administrative Standard Operating Procedure (SOP), entitled SBA Metric Transition Program.

\section{Responsibilities}

a) Metric Executive. By SBA Administrator memorandum, the Associate Administrator for Procurement Assistance is designated as the Metric Executive who is responsible for managing the implementation of the SBA metric transition.

b) SBA Metric Committee. The SOP states that the SBA Metric Committee, based on its review of the task plans submitted by each office of primary task responsibility, is to propose measurable agency-wide objectives and target dates.

c) Office of Procurements and Grants Management (OPGM). The OPGM is to establish procedures for the preparation, coordination, and approval of metric specifications and standards for use by SBA in its procurements, grants, and businessrelated activities. OPGM is to establish and monitor a "Metric Review" process to determine necessary changes to appropriate documents.

d) Office of Procurement Assistance (OPA). OPA is to establish a metric component within their ongoing "Surveillance Review" process of monitoring the overall impacts of federal procurement activities on small businesses.

\section{Reporting}

Offices of primary task responsibility are to provide quarterly progress reports in memorandum format to the Metric Executive. The Annual Report to Congress is to be prepared by the Office of the Metric Executive based on input from the Metric Committee and the offices of primary task responsibility. The report is to be approved by the SBA Administrator.

\section{Exceptions to Metric Usage}

Based on the SOP, the Office of Procurements and Grants Management is to request exceptions to metric requirements. These exceptions are to be approved by the Metric Executive. 


\section{Transition Efforts}

To ensure that SBA complies fully with the requirements of Section 5164 and to help small business owners decide whether to go "metric" and how to go "metric," the SBA proposes to engage in an Agency-wide effort to reach the following goals:

Provide a program of entrepreneurial education and business training on growth and survival strategies that consider the current and future benefits of adding metric standards to their operating procedures;

Organize an internal system of operating procedures that will ensure SBA compliance with federal agency metric requirements as described in Section 5164 of P.L. 100-418; and

Assume an external presence in the public and private sectors where SBA will advocate and guide "metrication" issues and efforts that reduce any negative impacts of metric conversions on small business.

The SBA Metric Transition Plan is categorized into five major tasks:

Transition Management

Education and Training

Specifications and Standards

Procurement Assistance

Public Affairs

\section{SIgnificant Developments}

a) Metrication Booklet. SBA will publish a small business booklet that would serve as the core educational element around which other training structures and materials could be developed. Major topics might include: domestic and international importance of converting to metric; current law, emphasizing requirements and time frames; the cost of not converting (lost opportunities); the cost of the conversion process; the time and training required for the conversion process; and any available financial assistance.

b) Metrication Awareness Factsheet. SBA will prepare and disseminate a factsheet that will serve as a generalized, informational promotion designed for the widest possible dissemination.

c) Metrlc Awareness Presentation. SBA will produce a 20-minute video-tape presentation that would serve as a motivational and instructional aid designed for use in conferences and workshops. This video would be produced with an eye towards its eventual use as an informational service on access television. SBA is exploring is exploring the possibility of engaging a private sector sponsor to produce the video tape.

d) Training Package. SBA will develop a "Metrication Awareness" training package that will serve as a generalized introduction to the topic and would be designed for the widest possible delivery to three target audiences: SBA staff; SBA resource providers, e.g., SCORE, SBI, SBDC, etc.; and small business entrepreneurs. 
e) Small BusIness Metrlcatlon Assessment Materials. SBA will develop a "Metrication Evaluation" training package that will serve as a process and as an instrument to help small business owners determine their best possible metric solutions ("not to metricate" is an option). If "metrication" is suggested, then the package will offer recommendations on a possible plan of action.

f) Industry Metrication Factsheets. SBA will produce a series of "Metrication Factsheets" that will cover a variety of practical metrication topics, with some topics being covered on an industry-specific basis. These factsheets will be used as handouts for conferences and workshops as well as supplements in informational kits.

g) Promotional Campaign. SBA will develop and implement a series of promotional campaigns as motivation and support for other elements of the training program. These promotional elements should include: an awareness conference; public service announcements; workshop announcements; press releases; and program brochure mailings.

h) Loan Guarantees. SBA will authorize due consideration for metric conversion within existing SBA loan guarantee programs. Once input and guidelines are obtamed, press releases, fact sheets and other promotional vehicles would be engaged to advertise the availability of loan guarantees for the purpose of metric conversion (e.g., plant renovations, equipment re-tooling, convert mechanical drawings).

1) Metric Data on SBA PASS Database. SBA will use its PASS database as a major small business linkage tool for contracting agents In both the public and private sectors. The Agency can obtain data on the metric capabilities of its PASS businesses by modifying the PASS update questionnaire to include several questions on metrication. Once sufficient data is received, the Agency could then promote PASS as a metric small business resource.

J) MOC Small Business Assistance Subcommittee. SBA will continue to provide Federal leadership through the Small Business Assistance Subcommittee of the Metrication Operating Committee. The SBA is identified as the lead agency in the MOC's Small Business Assistance Committee. As such, the Agency is responsible for providing guidance that both supports federal efforts to convert to metric its procurement, grants and other business activities and assures that minimal hardships are imposed on small business during the transition.

k) Business Memorandums of Understanding (MOUs). SBA will engage in an energetic effort to negotiate MOUs with private sector entities that are interested in helping small business make the transition to metric standards. Such entities may include the American National Metric Council, the TRIAD industry group, individual firms and individual citizens.

\section{SMITHSONIAN INSTITUTION}

The Smithsonian's plan is to execute all its procurements using the metric system and to incorporate metric materials into its public programs and educational efforts. 


\section{TENNESSEE VALLEY AUTHORITY (TVA)}

The Tennessee Valley Authority (TVA) is a unique independent corporation owned by the Federal Government, created by an act of Congress in 1933. The agency is charged with developing the resources of the Tennessee River Valley and surrounding areas, covering all of Tennessee, plus parts of Kentucky, Virginia, North Carolina, Georgia, Alabama, and Mississippi. The agency is charged with flood control and navigation along the Tennessee River and its tributaries and production of electric power within the constraints of flood control and navigation. TVA operates 29 hydroelectric plants, 11 coal-fired plants, and 2 nuclear plants with a total generating capacity of 26,000 megawatts of power for 8 million people. The agency is a leader in agricultural and fertilizer development and related environmental issues for the Nation, and in economic and community development within the Tennessee Valley.

In the area of electrical power generation, the TVA Metric Transition Plan deals with TVA operations in terms of procurement of materials, supplies, equipment, and construction. Equipment replacement and modernization cycles, the opportunities to phase in metric usage as newer equipment is introduced, and the economics of replacement and possible limitations are discussed.

\section{U.S. CONSUMER PRODUCT SAFETY COMMISSION}

The Commission's draft Metric Transition Plan is concerned with metrication in two areas, mandatory requirements and voluntary industry standards. The first includes administrative processes and requirements for the design of specified products (where it acts as a regulatory agency); the second is based upon outreach and educational activities.

\section{U.S. INTERNATIONAL TRADE COMMISSION}

The Commission issued USITC Directive 1801, "Metric Conversion Policy for the Commission," dated December 6, 1990. The Directive outlines the Commission's metric policy and assigns responsibility for implementation. The Commission has installed software on its Local-Area Network that provides mathematical conversion factors among metric and other units. To assist Commission employees in attaining proficiency in the metric system of measurement, each office is supplied with a binder containing relevant metric documents and publications.

In 1989, the Commission issued the "Harmonized Tariff Schedule of the United States" (HTS), in which virtually all units of measurement are in "hard" metric units. As a result, most U.S. international trade is now conducted and reported in metric units. The Commission is continuing its metrication effort as it modifies and updates the HTS to accommodate new products or new reporting classes. The Commission encourages the metric conversion process as an integral part of U.S. trade policy. 


\section{U.S. POSTAL SERVICE}

The Postal Service will support the government's metric transition programs and will convert as it deems appropriate. Many of its automated mail handling systems are in metric format. 


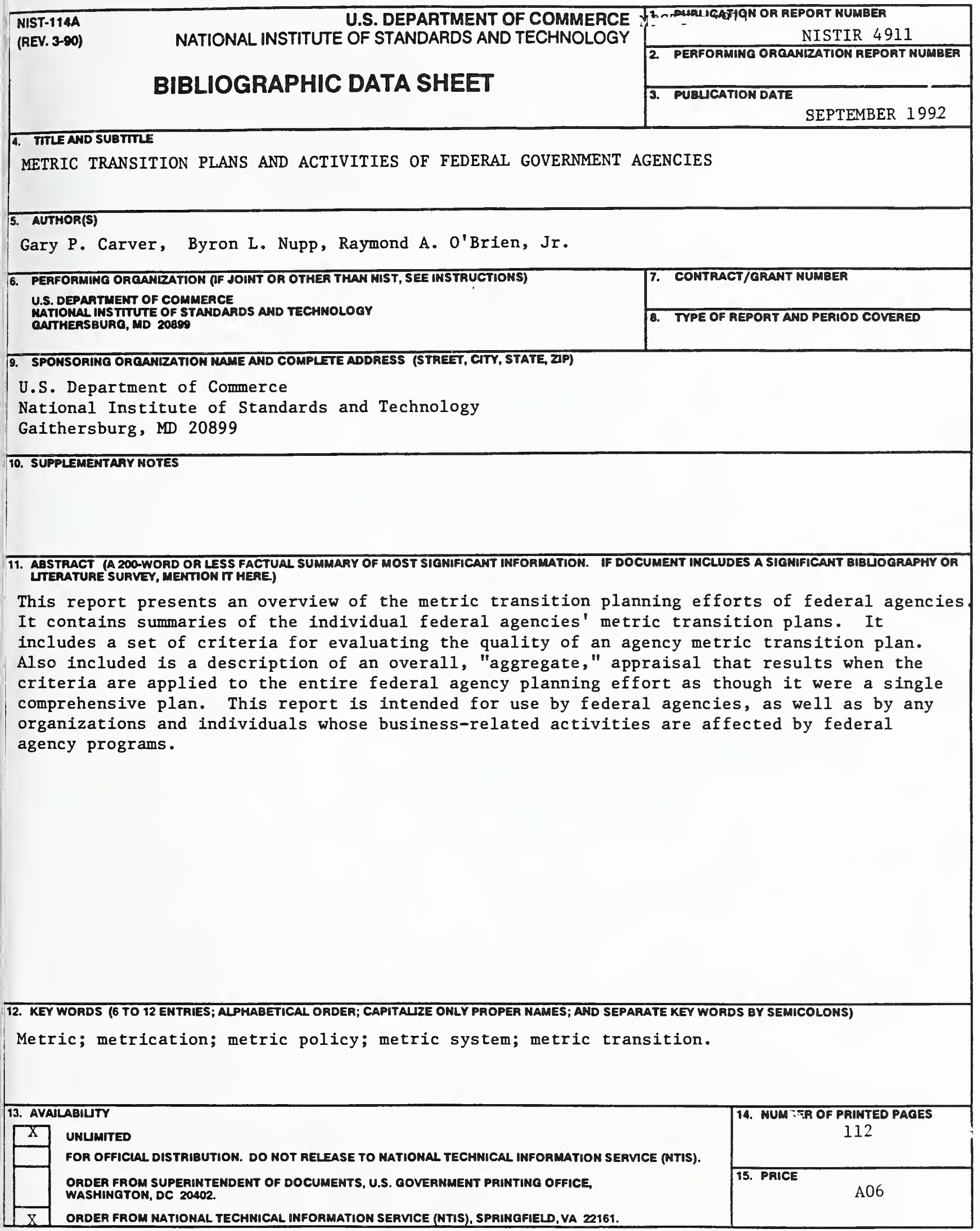




